San Jose State University

SJSU ScholarWorks

Master's Theses

Master's Theses and Graduate Research

1990

\title{
One-dimensional modeling study of carbonaceous haze effects on the springtime Arctic environment
}

Christopher A. Emery

San Jose State University

Follow this and additional works at: https://scholarworks.sjsu.edu/etd_theses

\section{Recommended Citation}

Emery, Christopher A., "One-dimensional modeling study of carbonaceous haze effects on the springtime Arctic environment" (1990). Master's Theses. 3256.

DOI: https://doi.org/10.31979/etd.752u-h869

https://scholarworks.sjsu.edu/etd_theses/3256

This Thesis is brought to you for free and open access by the Master's Theses and Graduate Research at SJSU ScholarWorks. It has been accepted for inclusion in Master's Theses by an authorized administrator of SJSU ScholarWorks. For more information, please contact scholarworks@sjsu.edu. 


\section{INFORMATION TO USERS}

The most advanced technology has been used to photograph and reproduce this manuscript from the microfilm master. UMI films the text directly from the original or copy submitted. Thus, some thesis and dissertation copies are in typewriter face, while others may be from any type of computer printer.

The quality of this reproduction is dependent upon the quality of the copy submitted. Broken or indistinct print, colored or poor quality illustrations and photographs, print bleedthrough, substandard margins, and improper alignment can adversely affect reproduction.

In the unlikely event that the author did not send UMI a complete manuscript and there are missing pages, these will be noted. Also, if unauthorized copyright material had to be removed, a note will indicate the deletion.

Oversize materials (e.g., maps, drawings, charts) are reproduced by sectioning the original, beginning at the upper left-hand corner and continuing from left to right in equal sections with small overlaps. Each original is also photographed in one exposure and is included in reduced form at the back of the book.

Photographs included in the original manuscript have been reproduced xerographically in this copy. Higher quality $6 "$ × 9 " black and white photographic prints are available for any photographs or illustrations appearing in this copy for an additional charge. Contact UMI directly to order.

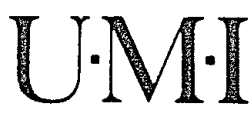

Universily Microfims Internalional

A Bell \& Howel! Informalion Company

300 North Zeeb Road. Ann Arbor. M1 48106-1346 USA

$313761.4700 \quad 800521.0600$ 

Order Number 1840509

One-dimensional modeling study of carbonaceous haze effects on the springtime Arctic environment

Emery, Christopher A., M.S.

San Jose State University, 1990 


\title{
ONE-DIMENSIONAL MODELING STUDY OF CARBONACEOUS HAZE EFFECTS ON THE SPRINGTIME ARCTIC ENVIRONMENT
}

\author{
A Thesis \\ Presented to \\ The Faculty of the Department of Meteorology \\ San Jose State University
}

In Partial Fulfillment

of the Requirements for the Degree

Master of Science

by

Christopher A. Emery

May 1990 
Approved for the Department of Meteorology
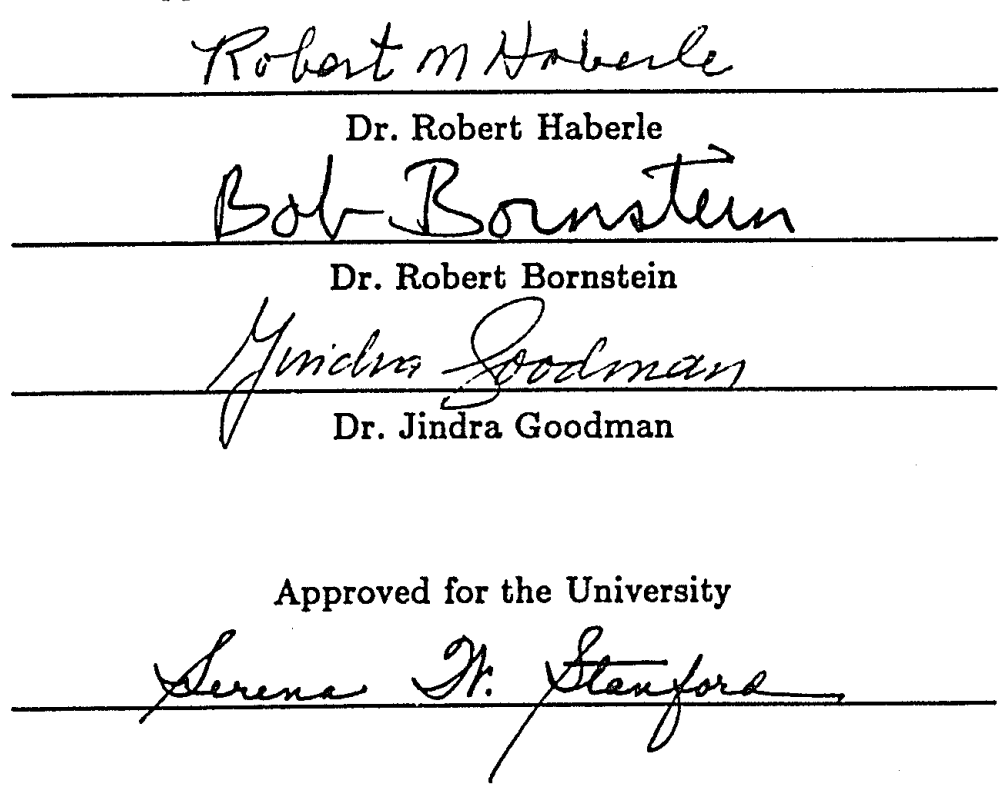


\section{Abstract \\ ONE DIMENSIONAL MODELING STUDY OF CARBONACEOUS HAZE EFFECTS ON THE SPRINGTIME ARCTIC ENVIRONMENT \\ by \\ Christopher A. Emery}

This project employs a high resolution one-dimensional model, which combines routines for radiative transfer, planetary boundary layer processes, and heat conduction through a snow/ice slab. A Mie scattering formulation calculates aerosol optical properties. The model is primarily used to understand haze impacts on the Arctic surface-atmosphere heat balance at late-spring equilibrium conditions. Parametric studies are performed to determine model sensitivity to surface albedo and humdity.

Results show haze induces a $\sim 15 \mathrm{~K}$ warming within $1-2 \mathrm{~km}$ above the surface. The surface is only slightly warmer ( 1-5 K), leading to increased stable stratification, which increases sensible heat flux to the surface in all experiments. Haze-induced reduction of surface solar absorption is about compensated by increased surface longwave absorption, but this effect is sensitive to the moisture treatment. In general, the model predicts a robust Arctic climate system where changes in one component are very nearly compensated by changes in others. 


\section{Acknowledgements}

I wish to extent thanks to my supervisor/coach, Dr. R. Haberle, for supplying the original boundary layer model, and for his assistance in all facets of this project, including funding, guidance, support, and review. Also deserving credit is Dr. T. Ackerman for his help in conceiving the project, for supplying the radiation and Mie codes, and for defining the original experimental approaches reported herein.

I also wish to thank Drs. R. Bornstein and J. Goodman for their timely review, suggestions, and comments. Other thanks are extended to J. Schaeffer of Sterling Software for his tireless assistance with various computer and coding problems; to J. Francis of the University of Washington for supplying Arctic sounding data and moral support; to J. Murphy of the University of Washington and Dr. D. Westphal of NASA Ames Research Center for thoughtful and enlightening discussions pertaining to this project and topics ranging from atmospheric sciences to athletics; and to the Dregs/White Dwarfs, for making my work at Ames enjoyable and for teaching me how to play big-league softball.

Most of all, I would like to express my gratitude to my wife, Jacqueline, whose unfaltering love, support, and devotion carried me through two years of hard work and long hours.

This project was funded through the San Jose State Universtiy Foundation via, in part, the NASA-Ames University Consortium (contract No. NCA2-220), and the NASA-Ames Research and Development Program (contract No. NCA2-295). 


\section{Table of Contents}

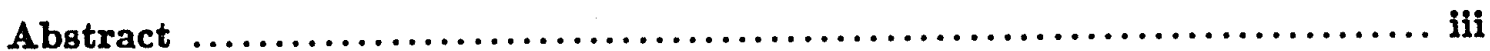

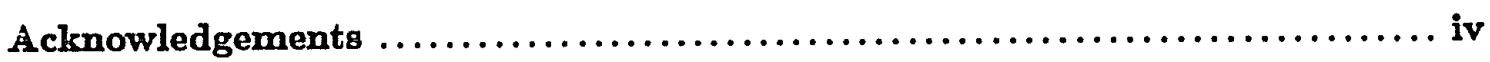

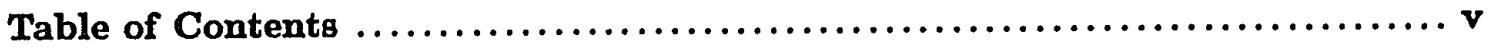

List of Tables $\ldots \ldots \ldots \ldots \ldots \ldots \ldots \ldots \ldots \ldots \ldots \ldots \ldots \ldots \ldots \ldots \ldots \ldots \ldots \ldots$, vii

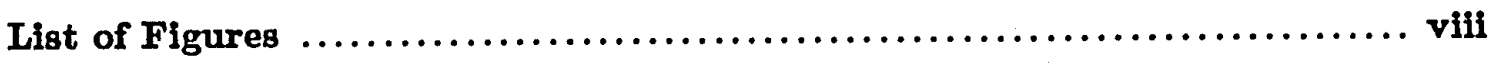

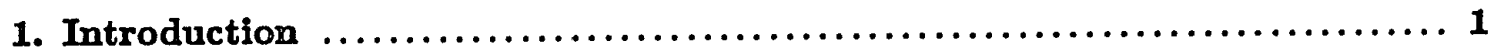

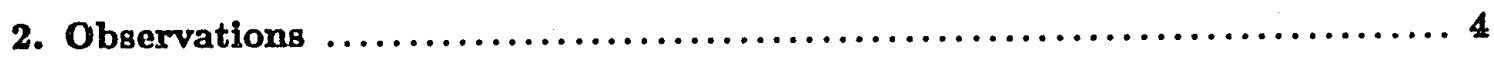

3. Previous Studies $\ldots \ldots \ldots \ldots \ldots \ldots \ldots \ldots \ldots \ldots \ldots \ldots \ldots \ldots \ldots \ldots \ldots \ldots \ldots \ldots, \ldots$

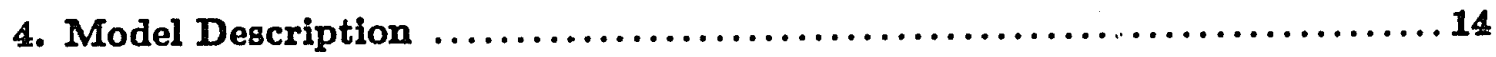

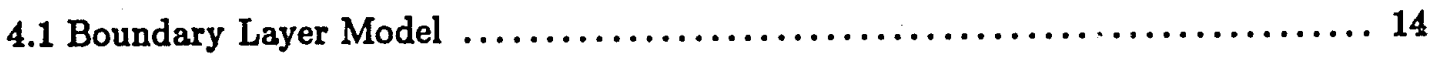

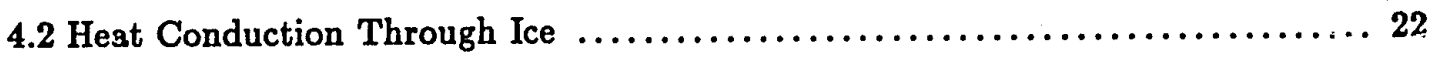

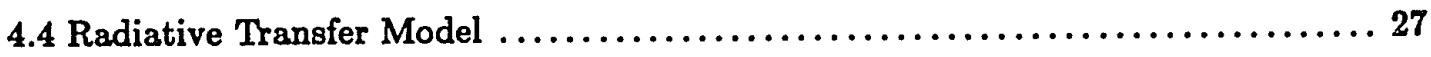

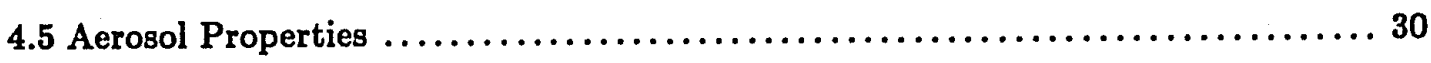

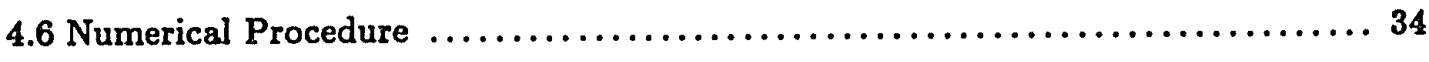

5. Results

5.1 Control Runs

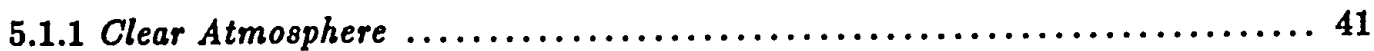

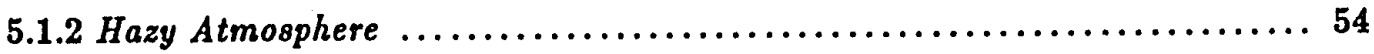

5.2 Constant Specific Humidity vs. Relative Humidity $\ldots \ldots \ldots \ldots \ldots \ldots \ldots \ldots \ldots 6$

5.3 Sensitivity Studies

5.3.1 Effect of Relative Humidity ..............................66 66

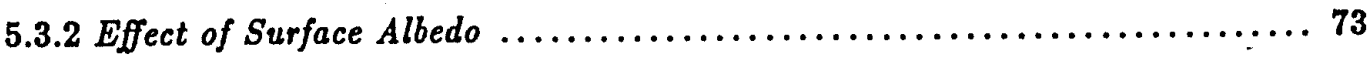

6. Conclusion

6.1 Summary

6.2 Uncertainties and Recommendations 


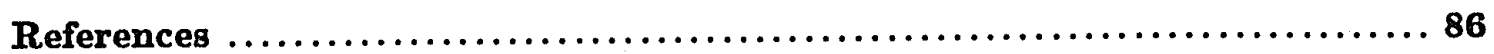

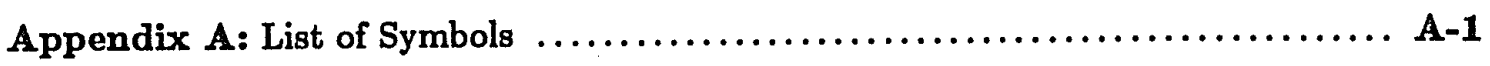

Appendix B: PBL Finite Difference Equations $\ldots \ldots \ldots \ldots \ldots \ldots \ldots \ldots \ldots \ldots \ldots \ldots \ldots \ldots \ldots \ldots$

Appendix C: The VIF and Surface Heat Balance $\ldots \ldots \ldots \ldots \ldots \ldots \ldots \ldots \ldots \ldots$, C-1 


\section{List of Tables}

2-1 A summary of values for Arctic haze physical and optical parameters from AGASP I (Geosphysical Research Letters, 1984). See Appendix A for description of symbols. . . . . . . . . . . . . . . . . 7

4-1 Initial profiles of pressure, temperature, dewpoint (and resulting specific humidity), and winds, where $d d$ represents wind direction. . . . . . . . 36

4-2 Values of constants for all experiments. See Appendix A for description of symbols. . . . . . . . . . . . . . . . . . . 39

5-1 Equilibrium daily averages of surface temperature $(K)$, planetary albedo, and heat fluxes $\left(\mathrm{W} \mathrm{m}^{-2}\right)$ for the surface, surface-atmosphere, and atmosphere. . . 42

5-2 Same as in Table 5-1, except for the case when constant (in time) specific humidity from the initial dewpoint profile is specified. . . . . . . . 65 


\section{List of Figures}

4-1 The PBL/radiation grid used for the finite difference algorithms. See text for explanation of symbols and indices. . . . . . . . . . . . 21

4-2 Schematic diagram of the VIF sea ice model of Neeman et al. (1988). See Appendix A for description of symbols. . . . . . . . . . . . . . 24

4-3 The analytic $\mathrm{Cg}$ mass concentration profile calculated from a log-normal height distribution of the extinction coefficient using $a=12 \mathrm{~m}^{2} \mathrm{~g}^{-1}$ and $\varpi_{0}=0.86 \ldots \ldots \ldots \ldots \ldots \ldots \ldots \ldots \ldots \ldots \ldots \ldots \ldots \ldots \ldots \ldots$

5-1 Clear-sky equilibrium temperature trend (K) over 24 hours at the surface (solid) and at $1 \mathrm{~m}$ above the surface (dashed). . . . . . . . . . . 43

5-2 Clear-sky surface flux trend $\left(\mathrm{W} \mathrm{m}^{-2}\right)$ for net solar (solid), net IR (line-dash), sensible heat (dotted), latent heat (dashed), and conductive heat (line-dot). A gain of heat is positive. . . . . . . . . . . . . . 43

5-3 24-hour time section of potential temperature $(K)$ within the PBL domain for clear-sky equilibrium. Contours plotted every $1 \mathrm{~K} . \ldots . . . \ldots 46$

5-4 Same as Fig. 5-3, but for total wind $\left(\mathrm{ms}^{-1}\right)$. Contours plotted every $2 \mathrm{~ms}^{-1} \cdot 47$

5-5 Same as Fig. 5-3, but for Richardson number. Dashed contours are negative, and the dotted contour is for $R i_{c}=0.2$. Contours plotted every $0.25 \ldots \ldots 48$

5-6 Same as Fig. 5-3, but for momentum diffusivity $\left(\mathrm{m}^{2} \mathrm{~s}^{-1}\right)$. Contours plotted every $5 \mathrm{~m}^{2} \mathrm{~s}^{-1} \ldots \ldots \ldots \ldots \ldots \ldots \ldots \ldots$

5-7 Same as Fig. 5-3, but for turbulent heat flux $\left(\mathrm{W} \mathrm{m}^{-2}\right)$. Positive contours are solid, negative contours are dashed, and they are plotted $\epsilon$ very $2 \mathrm{~W} \mathrm{~m}^{-2}$. . 50

5-8 Same as Fig. 5-3, but for specific humidity $\left(\mathrm{g} \mathrm{kg}^{-1}\right)$. Contours plotted every $0.2 \mathrm{~g} \mathrm{~kg}^{-1} \ldots \ldots \ldots \ldots \ldots \ldots \ldots \ldots \ldots \ldots \ldots \ldots \ldots \ldots \ldots \ldots \ldots$

5-9 Same as Fig. 5-3, but for radiative heating rate $\left(\mathrm{K} \mathrm{day}^{-1}\right)$. Contours plotted every $0.5 \mathrm{~K} \mathrm{day}^{-1} \ldots \ldots \ldots \ldots \ldots \ldots \ldots$

5-10 Daily averaged clear-sky equilibrium profiles of total (solid), radiative (dashed), turbulent (dotted), and imposed dynamic (line-dot) heating rates ( $\mathrm{K} \mathrm{day}^{-1}$ ) for the PBL domain. . . . . . . . . . . . . . . . 53 
5-11 The haze-induced change in equilibrium temperature trend $(K)$ at the surface (solid) and at $1 \mathrm{~m}$ above the surface (dashed). . . . . . . . . . 55

5-12 The haze-induced change in surface fluxes $\left(\mathrm{W} \mathrm{m}^{-2}\right)$ of net solar (solid), net IR (line-dash), sensible heat (dotted), latent heat (dashed), and conducted heat (line-dot). A gain of heat is postive. . . . . . . . . . . 56

5-13 24-hour time section of potential temperature (K) within the PBL domain for haze equilibrium. Contours plotted every $1 \mathrm{~K} . \ldots \ldots \ldots$

5-14 Same as Fig. 5-13, but for Richardson number. Dashed contours are negative, and the dotted contour is for $R i_{c}=0.2$. Contours plotted every $0.25 \ldots \ldots$. . 59

5-15 Same as Fig. 5-13, but for turbulent heat flux $\left(\mathrm{W} \mathrm{m}^{-2}\right)$. Positive contours are solid, negative contours are dashed, and they are plotted every $2 \mathrm{~W} \mathrm{~m}^{-2}$. 60

5-16 Same as Fig. 5-13, but for specific humidity $\left(\mathrm{g} \mathrm{kg}^{-1}\right)$. Contours plotted every $0.2 \mathrm{~g} \mathrm{~kg}^{-1} \ldots \ldots \ldots \ldots \ldots \ldots \ldots \ldots \ldots \ldots \ldots \ldots \ldots \ldots \ldots \ldots \ldots \ldots \ldots . \ldots \ldots \ldots$

5-17 Same as Fig. 5-13, but for radiative heating rate $\left(\mathrm{K} \mathrm{day}^{-1}\right)$. Contours plotted every $0.5 \mathrm{~K} \mathrm{day}^{-1} \ldots \ldots \ldots \ldots \ldots \ldots$

5-18 Daily averaged haze equilibrium profiles of total (solid), radiative (dashed), turbulent (dotted), and imposed dynamic (line-dot) heating rates (K day ${ }^{-1}$ ) for the PBL domain. . . . . . . . . . . . . . . . . . . 63

5-19 Clear (solid) and haze (dashed) daily-averaged equilibrium surface temperature $(K)$ as a function of relative humidity. . . . . . . . . . . 67

5-20 Clear equilibrium surface fluxes $\left(\mathrm{W} \mathrm{m}^{-2}\right.$ ) of net solar (solid), net IR (dashed) and net radiation (dotted) as a function of relative humidity. Positive indicates surface absorption. . . . . . . . . . . . . . . . 68

5-21 Same as Fig. 5-19, but for planetary albedo as a function of relative humidity. 68

5-22 Same as Fig. 5-20, but for non-radiative surface fluxes of sensible (solid), latent (dashed), and conducted (dotted) heat. . . . . . . . . . 69

5-23 The haze-induced change to the non-radiative surface fluxes $\left(\mathrm{W} \mathrm{m}^{-2}\right)$ as a function of relative humidity. Positive changes indicate more absorption (or less emission). . . . . . . . . . . . . . . . . . 70 
5-24 Same as Fig. 5-23, but for the surface fluxes of net solar (solid), net IR (dashed), and net radition (dotted). . . . . . . . . . . 71

5-25 Same as Fig. 5-24, but for the atmosphere as a whole. . . . . . . . . . 72

5-26 Clear (solid) and haze (dashed) daily-averaged equilibrium surface temperature (K) as a function of surface albedo. . . . . . . . . . . . 73

5-27 Same as Fig. 5-26, but for planetary albedo as a function of surface albedo. 74

5-28 Clear equilibrium surface fluxes $\left(\mathrm{W} \mathrm{m}^{-2}\right.$ ) of net solar (solid), net IR (dashed) and net radiation (dotted) as a function of surface albedo. Positive indicates surface absorption. . . . . . . . . . . . . . . . . . 74

5-29 Same as Fig. 5-28, but for non-radiative surface fluxes of sensible (solid), latent (dashed), and conducted (dotted) heat. . . . . . . . . . 75

5-30 The haze-induced change to the non-radiative surface fluxes $\left(\mathrm{W} \mathrm{m}^{-2}\right)$ as a function of surface albedo. Positive changes indicate more absorption (or less emission). ............................. 76

5-31 Same as Fig. 5-30, but for the surface fluxes of net solar (solid), net IR (dashed), and net radiation (dotted) . . . . . . . . . . 77

5-32 Same as Fig. 5-31, but for the atmosphere as a whole. . . . . . . . . 78 


\section{Introduction}

The Arctic is usually considered to be a pristine environment. Within the last few decades, however, extensive observations have revealed large, persistent concentrations of optically thick aerosols in the lower Arctic troposphere. Mitchell (1957) first documented this "Arctic haze ${ }^{»}$ in detail, noting that it extended over a $1000 \mathrm{~km}$ range from the surface to $500 \mathrm{mb}$. Physical and optical evidence at that time suggested the haze was composed of particles smaller than $2 \mu \mathrm{m}$ diameter.

Data concerning aerosol physical and optical properties have been collected only since the mid 1970's, particularly from continuous ground-level monitoring by the National Oceanic and Atmospheric Administration's (NOAA) Geophysical Monitoring for Climatic Change (GMCC) station at Barrow, Alaska. Concurrently, research on Arctic haze has accelerated in the 1980's. One particular issue of Atmospheric Environment (1981) is dedicated to this topic. Consensus from these reports indicates (Schnell, 1984) that haze events are widespread throughout the Arctic; are most frequent and intense in March and April; consist of well-aged aerosols, as shown by a dominant submicron concentration peak (the accumulation mode); and contain a large combustion-derived component, which originates in Eurasia. These hygroscopic anthropogenic aerosols are found to be mainly composed of up to $2 \mu \mathrm{g} \mathrm{m} \mathrm{m}^{-3}$ of sulfate, $1 \mu \mathrm{g} \mathrm{m}^{-3}$ of organics, and $0.3-0.5 \mu \mathrm{g} \mathrm{m}^{-3}$ of graphitic carbon (Cg) or soot. In contrast to the springtime, the summer Arctic troposphere is observed to be much cleaner because weak summertime transport mechanisms decouple the Arctic from the sources, and because widespread summer Arctic stratus efficiently removes haze via washout processes.

A demand for more complete aerosol data for use in detailed modeling efforts spawned two Arctic-wide surface and upper air sampling programs; the NOAA Arctic Gas and Aerosol Sampling Programs of 1983 and 1986 (AGASP I and II). By extending aerosol sampling to three dimensions, and increasing the type of data gathered, researchers were presented with spatial- and time-dependent data on aerosol size distributions, compositions, scattering, and absorbtion properties. A general discussion of the observed physical and optical properties of Arctic haze will be presented in Section 2.

Studies utilizing the information gained by the monitoring programs have primarily 
focused on the haze's ability to absorb solar radiation, since it has been commonly assumed the particles are too small to have any serious impact in the infwared (IR) spectrum (Shaw and Stamnes, 1980; Coakley et al., 1983). Indeed, use of both high and low resolution solar radiation schemes, run with a number of vertical profiles of simple and complex aerosols, show such particles are quite active in absorbing solar radiation. This is particularly true over the typically high albedo snow/ice surface, which dominates the Arctic basin during the spring season. From the absorption calculations, haze-induced instantaneous heating rates of up to $1 \mathrm{~K} \mathrm{day}^{-1}$ have been reported. Large-scale energy balance modeling efforts run for low resolution and with gross parameterizations have also reported a net warming of the Arctic surface-atmosphere system. A detailed description of several modelling studies and their results will be discussed in Section 3.

It is now accepted that the Arctic surface-atmosphere system gains energy through a process by which an optically thick haze layer over a highly reflective snow/ice surface lowers the planetary albedo. This is generally shown by calculations of instantaneous solar heating rates. Still, it is not yet clear how the energy is distributed thereafter. It appears to be related to how the surface and atmosphere are coupled (MacCracken et al., 1986); inferring the haze-induced impacts on surface temperature is not so easy because compensations are taken up by other forms of heat transfer, particularly by turbulent transport, snow/ice melt, or oceanic-icepack storage. Thorough investigation into this area requires much more detail than has been done in the past.

Whereas such recent studies have focused on anthropogenic aerosol influences either to the instantaneous solar stream or to the Arctic seasonal energy balance in only the simplest fashion, this project develops a high resolution, one-dimensional, three-component numerical model combining tropospheric radiative transfer, sea-ice conduction, and planetary boundary layer routines. Optical and size properties of haze required by the radiation routine will be calculated from a Mie scattering program, based on data reviewed in Section 2. By taking into account the important forms of hest transfer, we may better resolve how the haze impacts the surface energy balance, which could lead to changes in surface temperature. Also, the extent of haze-induced atmospheric heating and stabilization will be verified, rather than reporting only instantaneous heating rates. 
The model will be initialized with data representative of the Arctic in late spring to evaluate the difference between springtime equilibrium conditions for a clear and hazy Arctic atmosphere. Although haze events are less frequent toward the summer, at which time the integrated haze profiles yeild substantially less mass loading, significant background amounts still exist in late spring. When coupled with the stronger 24-hour solar insolation near the summer solstice, a darker snowpack from melting and aerosol deposition, and large solar atmospheric path lengths at Arctic latitudes, late springtime haze optical depths may have an even stronger impact on the Arctic than the more intense haze episodes recorded in late winter and early spring. A complete discussion about the development of the model, and an outline of the numerical procedure for each experiment will be given in Section 4.

In Section 5 the results of three sets of experiments will be discussed. The preliminary experiments will be performed with and without a representative arctic haze tropospheric optical depth profile to test model performance and to try to explain how the haze disturbs the surface-atmosphere system. We wish to determine how the clear case differs from the haze case; if the surface is warmer or cooler; which variables change to offset or compensate for changes in other variables; and how these results compare to previous literature. Second, similar to the first experiment, a clear and haze environment will be produced, but with a representative temporally constant specific humidity (rather than relative humidity) profile. Such an approach isolates the relative importance of how the amount of water vapor and its variation with height may lead to significant changes to the heat budget of the model environment. Finally, sensitivity studies will examine model reaction to a range of surface albedos and humidity profiles. These experiments will determine how the system, given the same representative haze profile, reacts to various choices of albedo; what critical albedo causes the system to flip from cooling to warming (or if such an albedo even exists for the model); if the humidity specification is a stronger forcing than albedo; and what critical constant relative humidity profile will allow the surface system to cool as opposed to warm. 


\section{Observations}

Since such a large variety and quantity of data were obtained and published from AGASP I and II, it is necessary to summarize the ranges, and determine mean values, of various aerosol properties. These bulk numbers can then be used to confine both input and output aerosol parameters required for this project, and to compare these parameters with those used among previous modeling studies.

Results of Spring 1983 NOAA AGASP I were printed in one special volume of Geophysical Research Letters (1984). The primary experimetal zones included the Alaskan and Norwegian Arctic (mostly within $70-80^{\circ} \mathrm{N}$ ), based respectively in Barrow, Alaska, and $\mathrm{Ny}$ Alesund, Spitzbergen. Some objectives of the AGASPs were (Schnell, 1984): (1) to determine aerosol spatial and size distributions, composition, optical properties, and trajectories; (2) determine distributions and concentrations of trace gases; and (3) to measure in situ and surface radiative effects.

Graphitic and sulfuric aerosols were found throughout the Arctic troposphere during AGASP I, but their spatial and temporal extents were extremely variable (Schnell and Raatz, 1984; Raatz and Schnell, 1984; Joranger and Ottar, 1984). For example, a low concentration background haze existed when airmass trajectories circled the Arctic. In Arctic haze episodes, however, multiple layers of haze over the Beaufort and Chukchi Seas existed in airmasses that originated in eastern Europe, eastern North America, and Asia. These airmasses were rapidly transported into the Arctic within distinct organized transport zones (Bodhaine et al. 1984; Radke et al. 1984; Harris, 1984; Raatz, 1984). Iversen (1984) concluded if motions in the atmosphere are assumed to be adiabatic, source areas of Arctic haze detected at ground level must be in areas with almost the same potential temperature as observed in the Arctic, i.e., areas north of the polar front. Sources south of the polar front can only contribute to low values of upper tropospheric pollution (the summertime situation). Therefore, the amplitude and phase of winter and springtime baroclinic planetary waves are important as they determine the position of the polar front and provide conditions for meridional transport of air from lower latitudes.

In the vertical, the haze was sometimes uniformly distributed, and sometimes confined within layers 10's-100's of meters thick (regardless of the moisture profile), which were 
separated by layers of extremely clean air. Maximum concentrations usually existed between 800 and $600 \mathrm{mb}$ while the bulk of the haze occupied the lowest $3 \mathrm{~km}$ of the troposphere (Valero and Ackerman, 1985; Tsay et al., 1989). Concentrations measured aloft were in many cases significantly greater than ground-based measurements (Schnell and Raatz, 1984; Hansen and Rosen, 1984). In fact, Rosen and Hansen (1984) discovered Cg concentrations in some elevated layers were as high as $2 \mu \mathrm{g} \mathrm{m}^{-3}$; higher than some U.S. urban centers. The large vertical gradients near the surface suggested the icepack acts as a strong sink. In the horizontal, Radke et al. (1984) reported haze could appear patchy on a typical scale of 2-20 km. Hansen and Rosen (1985) found that horizontal inhomogeneities in $\mathrm{Cg}_{\mathrm{g}}$ measurements were typified by a five-fold change in concentration between dirty and clean areas. These layered, patchy regions were often associated with, and maintained by, distinct meteorological boundaries such as fronts and inversions.

During AGASP I Arctic haze consisted of sulfur, mainly in the forra of sulphate and sulfuric acid, and $\mathrm{Cg}$ from fossil fuel and wood combustion (Cahill and Eldred, 1984; Shaw, 1984). Other components included vanadium, from oil-fired industrial plants in Western Europe; arsenic and selenium, from nonferrous smelting and coal burning in the Soviet Union; and silicon, antimony, oxides of nitrogen, various metals, and sea salts containing sodium, chlorine, and bromine (Carey, 1988; Radke et al., 1984; Hansen and Rosen; 1984; Li and Winchester, 1990). Cahill and Eldred (1984) found large differences in elemental ratios of hydrogen, carbon, nitrogen, and oxygen to exist between the aerosols of the Alaskan and the Norwegian Arctic, supporting the hypothesis of a source dependency.

Hansen and Novakov (1988) state many reasons why $\mathrm{Cg}$ is the most environmentally significant component of the Arctic haze. Produced only during incomplete combustion, it has few natural sources; therefore its presence in haze aerosols is proof of anthropogenic sources and long-distance transport. Since it is not produced by chemical interactions with atmospheric precursors and is inert to transformation, $\mathrm{Cg}$ exhibits long residence times. Thus $\mathrm{Cg}$ aerosols act as carriers of adsorbed organics, and when wet, act as sites for $\mathrm{SO}_{2}$ oxidation to sulphate or sulfuric acid (Brodzinsky et al., 1980; Shaw, 1984; Radke et al., 1984; $\mathrm{Li}$ and Winchester, 1990), which in turn can acidify precipitation. Acting as condensation nuclei, $\mathrm{Cg}$ alters cloud droplet size spectra and optical properties (Forkel 
and Wendling, 1986), and if mixed into the stratosphere, may catalytically destroy ozone. Finally, and possibly most importantly, no other submicron aerosol component has such a large optical absorption cross section. This causes the aerosols containing small quantities of $\mathrm{Cg}$ to be considerably active in absorbing solar radiation in the troposphere and in the snowpack.

Haze particle size distributions exhibited long-term uniformity in vertical and horizontal extent throughout the Arctic during AGASP I (Hoff and Trivett, 1984; Joranger and Ottar, 1984). Table 2-1 is a compilation of value ranges for some physical and optical parameters reported by 11 AGASP I invesigators. The secondary concentration peak in the $0.15-0.30$ $\mu \mathrm{m}$ diameter range and the quick drop-off above $0.3 \mu \mathrm{m}$ is indicative of the typical peak and steep slope for aged urban haze aerosols. Most investigators found the peak at 0.2 $\mu \mathrm{m}$. For example, Radke et al. (1984) found Alaskan samples yielded multi-modal volume distributions with a distinct accumulation mode at $0.25 \mu \mathrm{m}$ diameter, primarily consisting of the principal aerosol component, sulfate. Shaw (1984) found a bimodal pattern, with an accumulation mode at $0.2 \mu \mathrm{m}$ and a nucleation mode of less than $0.015 \mu \mathrm{m}$, which suggested in situ sulphate gas-to-particle conversion. Shaw noted aged aerosol at $0.2 \mu \mathrm{m}$ represented a third to a half of all mass, and $80 \%$ of the total number concentration. Concentrations were nearly constant in time for this size, so residence times were largest for particles in the accumulation mode and less for larger or smaller particles. This further suggested long distance transport (Shaw, 1984; Bodhaine et al., 1984, Schnell and Raatz, 1984).

The important aerosol optical properties are the extinction coefficint $\sigma_{e}$, which determines the amount of incident radiation attenuated (absorbed + scattered) per meter of aerosol-laden medium; the asymmetry factor $g$, a measure of the azimuthal distribution of scattered radiation from a particle; and the single scattering albedo $\varpi_{0}$, a ratio of the amount of radiation a particle scatters from the direct incident beam to the amount of total extinction by the particle. Since $\sigma_{e}=\sigma_{a}+\sigma_{a}$, where subscripts $s$ and $a$ are for scattering and absorption, respectively, then $\varpi_{0}$ can be given by $\sigma_{\iota} / \sigma_{\iota}$. These parameters are functions of aerosol composition, size distribution, and concentration. $\varpi_{0}$ is highly sensitive to particle composition, particularly for its aqueous component, and size distribution. Size distribution can be constrained due to its spatial and temporal uniformity, but composition 
Table 2-1: A summary of values for Arctic haze physical and optical parameters from AGASP I (Geosphysical Research Letters, 1984). See Appendix A for description of symbols.

\begin{tabular}{|c|c|c|}
\hline Parameter & Value range & Remarks \\
\hline $\mathrm{CN}$ number $(<0.2 \mu \mathrm{m})$ & $50-2000 \mathrm{~cm}^{-3}$ & mean: $200 \mathrm{~cm}^{-3}$, low in moist layers \\
\hline $0.09-0.20 \mu \mathrm{m}$ & $60-240 \mathrm{~cm}^{-3}$ & mean: $100 \mathrm{~cm}^{-3}$ \\
\hline $0.15-0.30 \mu \mathrm{m}$ & $80-240 \mathrm{~cm}^{-3}$ & mean: $110 \mathrm{~cm}^{-3}$ \\
\hline $0.24-0.84 \mu \mathrm{m}$ & $40-100 \mathrm{~cm}^{-3}$ & mean: $60 \mathrm{~cm}^{-3}$ \\
\hline $0.28-0.32 \mu \mathrm{m}$ & $5-80 \mathrm{crn}^{-3}$ & mean: $20 \mathrm{~cm}^{-3}$ \\
\hline $0.37-0.50 \mu \mathrm{m}$ & $0.02-8.0 \mathrm{~cm}^{-3}$ & mean: $0.3 \mathrm{~cm}^{-3}$ \\
\hline$>2.5 \mu \mathrm{m}$ & $4 \times 10^{-3} \mathrm{~cm}^{-3}$ & \\
\hline$\frac{\partial N}{\partial \log D}$ peak & $0.1-0.3 \mu \mathrm{m}$ & the accumulation mode \\
\hline $\mathrm{SO}_{4}^{=}$mass & $0.1-5 \mu \mathrm{g} \mathrm{m}^{-3}$ & primary accumulation mode component \\
\hline Cg mass & $0.1-2.0 \mu \mathrm{g} \mathrm{m}^{-3}$ & highly variable \\
\hline $\mathrm{SO}_{2}$ mass & $0.1-1.2 \mu \mathrm{g} \mathrm{m}^{-3}$ & \\
\hline$\sigma_{s}$ & $1.0-7.3 \times 10^{-5} \mathrm{~m}^{-1}$ & often highest aloft \\
\hline$\sigma_{a}$ & $0.4-7.0 \times 10^{-6} \mathrm{~m}^{-1}$ & \\
\hline$\varpi_{0}(\lambda)$ & $0.77-0.88$ & mean: 0.86 \\
\hline$g$ & $0.6-0.7$ & \\
\hline$r_{a}$ & $0.010-0.068$ & internal and external mixes \\
\hline$\tau_{e}$ & $0.18-0.5$ & internal and external mixes \\
\hline$a$ & $8.3-18.1 \mathrm{~m}^{2} \mathrm{~g}^{-1}$ & \\
\hline
\end{tabular}


is shown to be quite variable. The scattering and absorption coefficients are in turn dependent on $\varpi_{0}$ and aerosol concentration, both of which are also quite variable over many spatial and temporal scales. Finally, extinction optical depth $\tau_{e}-$ the amount of incident radiation attenuated by an serosol-laden atmospheric layer of depth $z$ - can be obtained from $\tau_{e}=\tau_{s}+\tau_{a}=\sigma_{e} z=\left(\sigma_{a}+\sigma_{b}\right) z$.

The $\sigma_{\varepsilon}$ and $\sigma_{a}$ values in Table 2-1 were measured by many investigators (Patterson et al., 1982; Bodhaine et al., 1984; Schnell and Raatz, 1984; Joranger and Ottar, 1984; Clarke et al., 1984; Radke et al., 1984; Rosen and Hansen, 1984). The large values of $\sigma_{a}$ suggested the presence of a highly absorbing aerosol component, which may in the concentrations recorded cause significant radiative perturbation. The values of $\sigma_{s}$ were usually much higher aloft than measured at the surface and were sensitive to spatial variations in both concentration and humidity. Temporal changes in $\sigma_{\theta}$ were clearly linked to changes in accumulation mode concentration, so it was aerosols in that size range that accounted for a majority of extinction. The relative magnitudes of $\sigma_{s}$ and $\sigma_{a}$ led to $\varpi_{0}$ values of $0.77-$ 0.88 , with a mean at 0.86 . This range indicated no dominance of crustal $(0.99)$ or natural background $\left(\varpi_{0}>0.99\right)$ materials such as continental dust or maritime salts (Clarke et al., 1984; Patterson et al., 1982; Valero and Ackerman, 1985). Measurements at Barrow during 1977-78, however, have shown $\varpi_{0}$ can vary much more substantially, from 0.70 to 0.98 over daily and interannual time scales (Patterson et al., 1982; Cess, 1983). Total integrated $\tau_{0}$ magnitudes for AGASP I were 0.18-0.5 (Dutton et al., 1984; Valero and Ackerman, 1985), and calculations have lead to $\tau_{a}$ magnitudes of $0.020-0.068$ (Rosen and Hansen, 1984; Valero et al., 1983).

The variablility in optical properties were illustrated by measurements during Spring 1986 AGASP II. Valero et al. (1987) found $\tau_{a}=0.01-0.02$ and $\tau_{e}=0.3-0.5$. The higher $\tau_{e}$ combined with lower $\tau_{a}$ indicated a higher value of $\varpi_{0}(0.90-0.98)$, which suggested a larger quantity of non-absorbing material in 1986 than in 1983. This must be true since Hansen and Novakov (1988) stated mean Cg concentrations were also generally higher in AGASP II, which should at first approximation increase $\tau_{a}$ and decrease $\varpi_{0}$. Aerosol physical properties from AGASP II closely paralleled those of AGASP I, however, showing the aerosol characteristics quoted here to be indeed grossly representative of Arctic haze. 


\section{Previous Studies}

One of the first studies on the radiative impacts of Arctic haze was performed by Porch and MacCracken (1982). They employed a complete detailed 35-layer (0-70 km) 83-band (0.28-2.45 $\mu \mathrm{m})$ solar radiative transfer model, which included, along with aerosol extinction, Rayleigh scattering and absorption due to ozone, oxygen, water vapor, and carbon dioxide. Estimated absorption coefficients from limited NOAA GMCC data were used to calculate aerosol optical properties for two very simple dry sulphate-carbon models; a large aerosol with a mean radius of $0.3 \mu \mathrm{m}$, and a small aersol with mean radius $0.05 \mu \mathrm{m}$ (which is favored in the Arctic). The single scattering albedos differed between the two distributions from $\varpi_{0}=0.45$ for the small mode, to $\varpi_{0}=0.62$ for the large mode - both too low for the generally accepted range, even before AGASP I, of 0.7-0.98. In the vertical, they assumed the number concentrations remained constant with height from the surface to 1 and $5 \mathrm{~km}$, based on surface concentration data from Barrow.

Instantaneous cloud-free integrations for the $5 \mathrm{~km}$ haze layer over a range of zenith angles and surface albedos yielded a reduction in surface solar absorption by 5-15\%. The biggest reductions were related to high surface albedo (0.9) and large zenith angle $\left(80^{\circ}\right)$ for both aerosol models. Net solar absorption for the entire troposphere $(0-8 \mathrm{~km})$ increased 14-30 $\mathrm{W} \mathrm{m}^{-2}$ while the respective haze-induced instantaneous heating rates were $0.16-0.57$ $\mathrm{K} \mathrm{day}^{-1}$. Changes to the solar fluxes were more sensitive to aerosol absorbing capabilities and vertical ditribution (1 vs. $5 \mathrm{~km}$ haze layers), rather than the size distribution effect. It was recognized that the optical constants of the aerosols represented a gross estimation and that the small scattering abilities of these aerosols were caused by the lack of a significant quantity of scattering material.

When the model was integrated over a diurnal period, daily averaged heating rates induced by the haze were $0.01-0.06 \mathrm{~K} \mathrm{day}^{-1}$. Porch and MacCracken suggested that without IR compensation, atmospheric solar heating should intensify stabilization. They concluded the effects of carbonaceous haze are likely to be counterbalanced by changes in other components of the local energy balance, both in the atmosphere and at the surface.

Using surface aerosol scattering data taken from the NOAA GCMM station in Barror: Alaska, during the late 1970's, Patterson et al. (1982) employed a complex Mie scatter- 
ing model to better estimate Arctic haze optical properties. Besides considering two giant modes (with radii between $0.5-5 \mu \mathrm{m}$ each) to account for marine and crustal materials, they constructed a hygroscopic large mode (0.05-0.5 $\mu \mathrm{m})$, which contained uniformly mixed sulphate, water, organics, and $\mathrm{Cg}$. It was assumed sulphate was the only soluble component, so the aqueous mass was allowed to change with relative humidity. They found particles in the large mode grew significantly in response to increased relative humidity. The larger particles became better scatterers; increases in $\varpi_{0}$ were extremely sensitive to particle growth in this way. They concluded that particle growth with humidity is sufficient to account for differences between optical properties measured at the surface and those measured aloft, and that such differences do not neccessarily require an increase in aerosol concentration with height.

Cess (1983) ran a number of sensitivity studies to ascertain the relative importance of selected aerosol model, haze vertical distribution, surface albedo, and zenith angle. Two important differences existed between this study and the Porch and MacCracken study. First, a simple 2-stream 7-band (0.3-1 $\mu \mathrm{m})$ solar radiation model was used; the model occupied only one atmospheric layer, but it was expanded to two layers for the cases that concerned vertical variations in humidity or concentration. The model accounted for Rayleigh scattering, absorption from only ozone and water vapor, and aerosol extinction. Second, the aerosols were incorporated using the full aerosol model of Shettle and Fenn (1979), which included an anthropogenic urban component along with natural continental and maritime components. At $70 \%$ relative humidity, the urban component had $\varpi_{0}=0.7$.

Radiation calculations using both the simple aerosol model of Porch and MacCracken, and more complete Shettle-Fenn model, were compared. Absorption was specified at $\tau_{a}=0.02$ for both, so only the values of $\tau_{\theta}$ differed between the two models via $\varpi_{0}$. In comparison, the one-layer radiation model run with the two aerosol models calculated both surface and atmospheric solar absorption within just a few percent of results from Porch and MacCracken. This supported Porch and MacCracken's conclusion that size distribution was fairly unimportant. The choice of radiation treatment and its low resolution also appeared insignificant. Using the full aerosol model, solar forcing on the surface-atmosphere system was sensitive only to a few extreme aerosol vertical distributions, and nearly insensitive to 
the vertical distribution of humidity. Results were strongly sensitive, however, to the underlying surface albedo since its value determined the amount of solar radiation sent back through the haze.

The later studies of Valero and Ackerman (1985) and Valero et al. (1987) used in situ atmospheric solar flux data from AGASP I and II, respectively, to calculate aerosol optical depths and heating rates. Both studies incorporated very simple aerosol models; Valero and Ackerman (1985) assumed aerosols existed in an external mixture of sulphate and $\mathrm{Cg}_{\mathrm{g}}$ (meaning each particle was composed of just one material), and Valero et al. (1987) utilized an aerosol that contained only water and $\mathrm{Cg}$ in both external and internal mixtures. Both studies employed a complete $\delta 4$-stream 26-band $(0.25-4.3 \mu \mathrm{m})$ solar radiation model. It was also assumed aerosols were uniformily mixed within each of the lowest three model layers (each of which were 1-3 km thick). The resulting optical depth profiles from AGASP I resulted in instantaneous solar radiative heating rates of $0.1-0.2 \mathrm{~K} \mathrm{day}^{-1}$. For the AGASP II data, haze-induced instantaneous solar heating rate profiles of up to $0.6 \mathrm{~K} \mathrm{day}^{-1}$ were found. Valero et al. (1987) stated that besides increased atmospheric absorption (30-40\%) and scattering, surface absorption of solar radiation was reduced $6-10 \%$ while the planetary albedo was reduced by $3-6 \%$.

Direct effects of Arctic haze may, however, go beyond purely atmospheric perturbations. Clarke and Noone (1985) focused on soot in Arctic snowpack and concluded that reductions in snow albedo of one to several percent were probable. Impacts on the radiation budget from lowering surface albedo were found to about equal that of Arctic haze itself. From this, it was suggested that absorption of solar energy by a springtime snowpack was about 5-10\% higher than a soot-free snowpack, increasing ice temperatures and thus melt rates. There has also been concern that haze may inflict change on the nearly ubiquitous summertime Arctic stratus, causing further perturbations in radiative forcing. Forkel and Wendling (1986) found only very high pollution modifies the life cycle of Arctic stratus by radiative processes.

MacCracken et al. (1986) were the first to address the possible impacts of Arctic haze on the large scale. To examine certain climate forcing and response processes, their study utilized a one-dimensional 2-layer tropospheric radiative-convective model. The model in- 
corporated a delta-Eddington solar and longwave radiation routine, a boundary layer parameterization based on a constant specified heat exchange coefficient multiplied by the atmosphere-surface temperature difference, and vertical eddy diffusion procedure to keep the lapse rate at least $6.5 \mathrm{~K} \mathrm{~km}^{-1}$. Arctic haze was represented by Shettle-Fenn urban aerosol model $\left(\varpi_{0}=0.7\right)$ with an assumed optical depth of 0.1 and uniform atmospheric mixing ratio.

Their results suggested that if haze is concentrated in the lower troposphere, and if the surface and atmosphere are convectively coupled (a low surface albedo, high surface temperature condition), the Arctic climate should warm; the surface-atmosphere forcing governs the climate. But in Spring (a high albedo, low surface temperature condition), strong static stability suppresses total (sensible + latent heat) turbulent energy losses by the surface. In this case the surface and atmosphere are decoupled; direct surface forcing governs the climate. The previous studies suggested the surface should cool because reduced surface solar absorption is the direct surface forcing. But under strong static stability, it is the net radiative forcing that controls surface climate. The hazy atmosphere was shown to warm - the warmer atmosphere increased longwave emissions to the surface, which compensated for the loss of solar absorption and warmed the surface. Since relative humidity was held constant, this effect was amplified since warming of near-surface atmospheric layers increases the amount of water vapor, hence increasing IR emmisivity. As shown by Cess et al. (1985), however, the direction of increased longwave propagation, i.e. whether to the surface or to space, is dependent on the height of the aerosol layer.

On an even larger scale, results from Blanchet (1987), who used a General Circulation model (GCM), suggest the main consequence of induced long-term aerosol diabatic warming is a weakening of the polar and Ferrel cells due to reduction of the radiation deficit in the Arctic. Increasing aerosol concentration warms the atmosphere, increases overall humidity, cloud cover, cloud opacity, and precipitation. Blanchet also concluded the variations in clouds and atmospheric moisture are as important as the variation in aerosol concentration in influencing the regional heat balance.

In retrospect, these results have shown haze definitely alters the radiation balance in the surface-atmosphere system. Two important parameters continuously appear; humidity 
and surface albedo. Humidity affects radiative fluxes and aerosol optical properties. Surface albedo is very important for surface radiative forcing and determines the strength of radiative forcing in a haze-laden atmosphere. Most investigators have found solar radiation results are more sensitive to assumed scatter/absorption efficiencies rather than the form of the size distribution or the height of the aerosol layer. But while optical properties are certainly the most sensitive component of the modelling problem, their spatial and temporal variations remain the most difficult to constrain.

Most of these conclusions were based on models of very low resolution and/or gross parameterizations. In. the current study, a high resolution model is developed with the hope of better resolving the impacts that Arctic haze has on the local environment. The model will improve on previous work in several important ways. It allows for a fully interactive surface heat budget, results from which may verify previous solar and radiative-convective studies. It will also allow determination of which components change to offset direct surface and atmospheric forcing. By increasing resolution, we may incorporate a more representative haze distribution, localize atmospheric heating, and isolate surface from atmospheric forcing. The PBL model allows a better turbulence parameterization, which when applied to the high resolution grid, allows turbulent fluxes to play a more interactive role in the heat budget. Inclusion of a conduction scheme adds another important factor into the surface heat balance by accounting for ocean-ice-atmosphere interactions. 


\section{Model Description}

The numerical model is designed to be integrated forward in time from initial profiles of temperature, moisture, and winds until equilibrium conditions are satisfied (the initial conditions and numerical procedures are outlined in Section 4.5). The PBL model solves a set of time-marching finite-difference equations. Hence, it is used as the driving routine and passes necessary data to the radiation and ice routines to obtain radiative and conductive flux values at selected timesteps. Two of the components have already been developed at NASA Ames Research Center. The PBL model was developed for use in a number of current projects, and the $\delta 2$-stream radiation code, along with the Mie scattering routine, were first developed and used in studies by Ackerman and Toon (1981). The turbulent parameterization in the PBL model is upgraded, as discussed below; the ice model, developed for this study, is simply substituted for the ground temperature routine that the PBL model originally contained.

\subsection{Boundary Layer Model}

At scales of this particular study, boundary layer physics cannot be bulk parameterizations as they are in large scale energy balance modeling. The Arctic PBL over smooth pack ice is quite thin, having low values of turbulence generally confined to the surface layer where surface winds turn as much as $25^{\circ}$ from equilibrium (Katz, 1980). In the winter, surface heat and moisture fluxes are near zero. During this time, the lower troposphere exhibits strong stability where elevated inversions, and in cases of light winds, surface inversions cover more than $10^{6} \mathrm{~km}^{2}$ of the Arctic with high persistence (Overland, 1988). In spring and summer, while stability remains strong and sensible heat flux remains low, latent heat flux increases to $10-30 \mathrm{~W} \mathrm{~m}^{-2}$, approximately $10 \%$ of the net surface radiation (Andreas, 1988; Kellner et al., 1987). Overland (1985) has shown leads, polynas, and areas of thin ice, which are strongly season-dependent, are sources of buoyancy during strong winds and temperatures below $-5^{\circ} \mathrm{C}$. The high degree of stability and horizontally inhomogeneous coupling of surface and atmosphere, therefore, make the Arctic PBL difficult to model accurately.

Nevertheless since surface fluxes significantly increase in spring, a reasonably accurate representation of turbulence within the $\mathrm{PBL}$ over a homogeneous snow/ice surface is in- 
cluded in this model system. Also, the difference between solar gains and longwave losses is small, so the radiative residual is on the same order of magnitude as the turbulent heat fluxes.

Development of the PBL model follows that of Mellor and Yamada (1974, 1982). Mellor and Yamada (1974) start with a complete hydrostatic second-order turbulence closure model based on turbulence hypotheses from Kolmogoroff (1942) and Rotta (1951). This complex model (Level 4) contains ten prognostic equations for turbulent moments besides the momentum, thermodynamic, and continuity equations. By systematically eliminating various terms in the second-moment turbulence equations according to their degree of anistropy, two simpler useful models are achieved (Levels 3 and 2). The simpler "compromise" first order closure model (Level 2) is attained by: (1) disregarding advective and diffusive terms in the second moment equations, which leads to the specification that production of isotropic turbulent kinetic energy (TKE) equals its dissipation; and (2) closing the momentum and thermodynamic equations by $K$-theory, where $K$, a diffusion coefficient, is a function of TKE. This results in a model containing eight simple, independent, wholly algebraic turbulence equations.

A simple one-dimensional Level 2 PBL model was aquired for the current project for use as the primary driving routine for all three model components. This model contained three Eulerian prediction equations for two velocity components and potential temperature applied to a horizontally homogeneous hydrostatic lower Arctic troposphere. Following Mellor and Yamada (1974), the diffusion coefficients were calculated from $K=l q S$, where $l$ is the turbulence-weighted mixing length from Blackadar (1978), $S$ is a stability function based on local Richardson number $R i$, and $q$ (TKE $\left.\equiv q^{2} / 2\right)$ is calculated diagnostically. During its development, the PBL model was initialized with Mellor and Yamada's mid-latitude conditions and tested against their integrations; surface temperature forcing was contained in a simple sinusoidal pattern, while values for surface roughness, coriolis parameter, geostrophic wind speed, and the initial potential temperature profile were specified. In comparison, the model predicted all fields identically to their results.

The major weaknesses of Level 2, especially for the stable Arctic regime, are that it requires the specification of a mixing length, and that turbulence vanishes when $R i$ be- 
comes larger than the critical Richardson number $R i_{c}=0.21$. To partially remedy these deficiencies, predictive equations for TKE and mixing length were added to the system of equations. This raises the model to what Mellor and Yamada (1982) call Level 2.5 since it is not fully second-order, i.e. Level 3, turbulence closure (this is also commonly called TKE closure, $1 \frac{1}{2}$ order turbulence closure, or $q^{2} l$ closure (Holt and Raman, 1988]). Mellor and Yamada (1982) state Level 2.5 "has a greater predictive range than the Level 2 model, and the length scale equation, although the most empirical element of the complete model, does seem to perform in a more satisfactory manner than the simple algebraic equation associated with the Level 2 model." According to Holt and Raman (1988), the basic advantage of such a model is that it includes much of the physics of second order turbulence models without the complexity of solving the ten second-moment differential equations. They also state TKE closure shows closer agreement with the observed turbulence structure in the boundary layer than first-order schemes. We have adopted this form for two main reasons: (1) by allowing diffusion to be based on a TKE budget, turbulence is not totally suppressed above $R i_{c}$, so it is allowed to exist cver a wider range of stabilities; and (2) by adding an equation for $l$ coupled with $q^{2}$, local increases/decreases of mixing length are allowed within stable/mixed layers, which is felt to be particularly important as haze layers introduced to the model domain will affect local stability.

The one-dimensional momentum and thermodynamic equations for both the Level 2 and 2.5 models are

$$
\begin{aligned}
& \frac{\partial U}{\partial t}=-\frac{1}{\rho} \frac{\partial}{\partial z} \rho(\overline{u w})+f\left(V-V_{g}\right) \\
& \frac{\partial V}{\partial t}=-\frac{1}{\rho} \frac{\partial}{\partial z} \rho(\overline{v w})-f\left(U-U_{\vartheta}\right) \\
& \frac{\partial \theta}{\partial t}=-\frac{1}{\rho} \frac{\partial}{\partial z} \rho(\overline{\theta w})+\left(\dot{Q}_{R}+\dot{Q}_{D}\right) .
\end{aligned}
$$

Here $U, V$, and $\theta$ are mean quantities; $u, v$, and $\theta$ denote turbulent perturbations from the mean; $\rho=\rho(z)$ is density; and $f$ is the coriolis parameter (a full list of symbols is given in Appendix A). Geostrophic wind components ( $)_{g}$ are specified in this model and represent the horizontal pressure gradient term set up by some synoptic scale process. The radiative heating rate $\dot{Q}_{R}$ in the thermodynamic equation represents radiative flux 
convergence/divergence. We assume the initial profile of temperature exists in large-scale dynamic and radiative equilibrium. We therefore include the synoptic dynamic heating rate $\dot{Q}_{D}$, which is equal in magnitude, but opposite in sign, to the first 24-hour-average clear-sky $\dot{Q}_{R}(z)$ profile above the boundary layer. This $\dot{Q}_{D}$ profile is kept constant in time to keep the temperature above the PBL from cooling and destabilizing the troposphere over our long integration periods to equilibrium.

Vertical turbulent fluxes are closed by K-theory:

$$
\begin{aligned}
& \overline{u w}=-K_{M} \frac{\partial U}{\partial z} \\
& \overline{v w}=-K_{M} \frac{\partial V}{\partial z} \\
& \overline{\theta w}=-\dot{K}_{H} \frac{\partial \theta}{\partial z},
\end{aligned}
$$

where $K_{M}$ and $K_{H}$ are the eddy momentum and heat diffusion coefficients, respectively.

The improvement in the turbulence parameterization, however, is related to the prediction of TKE and mixing length via the following additional equations (Level 2.5 (Mellor and Yamada, 1982]):

$$
\begin{aligned}
\frac{\partial q^{2}}{\partial t} & =\frac{1}{\rho} \frac{\partial}{\partial z}\left(\rho K_{q} \frac{\partial q^{2}}{\partial z}\right)+2\left(P_{b}+P_{b}\right)-2 \epsilon \\
\frac{\partial\left(q^{2} l\right)}{\partial t} & =\frac{1}{\rho} \frac{\partial}{\partial z}\left[\rho K_{l} \frac{\partial\left(q^{2} l\right)}{\partial z}\right]+l E_{1}\left(P_{s}+P_{b}\right)-\frac{q^{3}}{B_{1}}\left[1+E_{2}\left(\frac{l}{k z}\right)^{2}\right],
\end{aligned}
$$

where $k$ is Von Karman's constant, and $B_{1}, E_{1}$, and $E_{2}$ are constants. Dissipation of TKE, and the production terms due to shear and buoyancy effects, are

$$
\begin{aligned}
\epsilon & =\frac{q^{3}}{B_{1} l} \\
P_{s} & =K_{M}\left[\left(\frac{\partial U}{\partial z}\right)^{2}+\left(\frac{\partial V}{\partial z}\right)^{2}\right] \\
P_{b} & =-\beta g K_{H} \frac{\partial \theta}{\partial z}
\end{aligned}
$$

where $\beta$ is the coefficient of thermal expansion and $g$ is gravitational acceleration. Overland (1988) also included a predictive equation for TKE in his simple winter Arctic PBL model, 
and stated the specification of a minimum non-zero value of TKE represented the influence of unresolved processes in strongly stratified flow, such as turbulent bursts. A minimum value of TKE is therefore specified consistent with his value:

$$
q^{2} \geq 0.001 \mathrm{~m}^{2} \mathrm{~s}^{-2}
$$

Mixing length $l$ is found by taking the quotient of the newly predicted values of $q^{2} l$ and $q^{2}$. The initial profiles of $q^{2}$ and $q^{2} l$ are set to zero, and allowed to evolve with time from the surface upward during a spin-up period.

All diffusivities for the Level 2.5 TKE closure are calculated from the turbulent length scale, TKE, and stability functions;

$$
\begin{aligned}
K_{M} & =l q S_{M} \\
K_{H} & =l q S_{H} \\
K_{q} & =l q S_{q} \\
K_{l} & =l q S_{l} .
\end{aligned}
$$

Stability functions $S_{q}$ and $S_{l}$ are specified and remain constant throughout the run, but $S_{M}$ and $S_{H}$ are calculated from

$$
\begin{aligned}
S_{M} & =\frac{3 A_{1} A_{2}\left(4 A_{1}+3 A_{2}\right) G_{H}+A_{1}\left(1-3 C_{1}\right)\left[1-3 A_{2}\left(B_{2}+4 A_{1}\right) G_{H}\right]}{\Delta} \\
S_{H} & =\frac{A_{2}-9 A_{1} A_{2}^{2} G_{H}+18 A_{1}^{2} A_{2} C_{1} G_{M}}{\Delta}
\end{aligned}
$$

where

$$
\Delta=1+6 A_{1}^{2}\left[1-3 A_{2}\left(B_{2}-3 A_{2}\right) G_{H}\right] G_{M}-3 A_{2}\left[B_{2}+7 A_{1}-9 A_{1} A_{2}\left(B_{2}+4 A_{1}\right) G_{H}\right] G_{H},
$$

and where

$$
\begin{aligned}
& G_{M}=\left(\frac{l}{q}\right)^{2}\left[\left(\frac{\partial U}{\partial z}\right)^{2}+\left(\frac{\partial V}{\partial z}\right)^{2}\right] \\
& G_{H}=-\left(\frac{l}{q}\right)^{2} \beta g \frac{\partial \theta}{\partial z} .
\end{aligned}
$$


Ait the lowest grid point, boundary conditions are applied to the momentum and thermodynamic equations to parameterize fluxes within the non-neutral surface layer. Surface layer momentum and sensible heat fluxes are specified as:

$$
\begin{aligned}
& K_{M} \frac{\partial U}{\partial z}=\frac{U_{a} u_{*}^{2}}{\left(U_{a}^{2}+V_{a}^{2}\right)^{1 / 2}} \\
& K_{M} \frac{\partial V}{\partial z}=\frac{V_{a} u_{*}^{2}}{\left(U_{a}^{2}+V_{a}^{2}\right)^{1 / 2}} \\
& K_{H} \frac{\partial \Theta}{\partial z}=\theta_{*} u_{*} .
\end{aligned}
$$

Friction velocity and temperature are given by

$$
\begin{aligned}
& u_{*}=\frac{k}{\ln \frac{\Sigma_{a}}{z_{0}}-\psi_{m}}\left(U_{a}^{2}+V_{a}^{2}\right)^{1 / 2} \\
& \theta_{*}=\frac{k}{\ln \frac{z_{a}}{x_{0}}-\psi_{h}}\left(\theta_{a}-\theta_{a}\right),
\end{aligned}
$$

where $z_{0}$ is roughness height, $\left(_{a}\right.$ is the lowest model grid point value (i.e. the value at $1 \mathbf{~ m}$ above the surface for these applications), and (), is a surface value. $\psi_{m}$ and $\psi_{h}$ are stability parameters from Monin-Obukhov similarity theory, and are calculated using a non-iterative scheme for very stable $\left(R i \geq R i_{c}\right)$, mechanically mixed $\left(0 \leq R i<R i_{c}\right)$, and unstable $(R i<0)$ regimes:

$$
\begin{aligned}
& \psi_{m}=\left\{\begin{array}{lr}
0, & R i \geq R i_{c} \\
\left(1-\alpha_{m}\right) \ln \frac{z_{a}}{z_{0}}-\beta_{m}\left(\frac{z_{a}}{L}-\frac{z_{0}}{L}\right), & 0 \leq R i<R i_{c} \\
0.0954-1.86 \frac{z_{a}}{L}-1.07\left(\frac{z_{a}}{L}\right)^{2}-0.249\left(\frac{z_{a}}{L}\right)^{3}, & R i<0
\end{array}\right. \\
& \psi_{h}=\left\{\begin{array}{lr}
0, & R i \geq R i_{c} \\
\left(1-\alpha_{h}\right) \ln \frac{z_{a}}{z_{0}}-\beta_{h}\left(\frac{z_{a}}{L}-\frac{z_{0}}{L}\right), & 0 \leq R i<R i_{c} \\
0.201-3.23 \frac{z_{a}}{L}-1.99\left(\frac{z_{a}}{L}\right)^{2}-0.474\left(\frac{z_{a}}{L}\right)^{3}, & R i<0
\end{array}\right.
\end{aligned}
$$

Here, ()$_{m}$ and ()$_{h}$ are known constants and $L$ is the Monin-Obukhov stability length.

The lower boundary conditions for the TKE and mixing length equations are simple specifications following Mellor and Yamada (1982);

$$
q^{2}=B_{1}^{2 / 3} u^{2}
$$




$$
q^{2} l=0
$$

Upper boundary conditions ensure all five fluxes are zero at the top of the model.

The model contains a vertical coordinate transformation routine, which scales variables to an analytical height coordinate system. This allows the total number of gridpoints, the height-dependency of resolution, and the heights of the lowest and uppermost gridpoints to be easily manipulated. Conversion to some linear height $\xi$ starts with

$$
\frac{\partial}{\partial z}=\frac{1}{\nu_{m}} \frac{\partial}{\partial \xi}
$$

where $\nu_{m} \equiv \partial z / \partial \xi$, and is called a vertical "metric." Letting

$$
\xi=a_{1} z+a_{2} \ln \frac{z}{a_{3}}
$$

where $z$ must be found iteratively and the $a_{()}$'s are arbitrary constants selected by the investigator, the vertical metric becomes

$$
\nu_{m}=\frac{z}{a_{1} z+a^{2}}
$$

Variables are then scaled by letting $\rho^{\prime}=\nu_{m} \rho$, any prognostic quantity $\Phi=\rho^{\prime}\left(U, V, \theta, q^{2}\right.$, or $q^{2} l$ ), and any diffusion coefficient $K^{\prime}=\nu_{m}^{-2} K$, where primed quantities represent scaled variables. This allows all five predictive equations to be written in the general form

$$
\frac{\partial \Phi}{\partial t}=\frac{\partial}{\partial \xi}\left[\rho^{\prime} P \frac{\partial}{\partial \xi}\left(\frac{\Phi}{\rho^{\prime}}\right)\right]+Q \Phi+R
$$

The expressions represented by the generic variables $\Phi, P, Q$, and $R$ are:

\begin{tabular}{cccc}
\hline \hline$\Phi$ & $P$ & $Q$ & $R$ \\
\hline$U^{\prime}$ & $K_{M}^{\prime}$ & 0 & $f\left(V^{\prime}-V_{g}^{\prime}\right)$ \\
$V^{\prime}$ & $K_{M}^{\prime}$ & 0 & $-f\left(U^{\prime}-U_{g}^{\prime}\right)$ \\
$\Theta^{\prime}$ & $K_{H}^{\prime}$ & 0 & $\rho^{\prime}\left(\dot{Q}_{R}+\dot{Q}_{D}\right)$ \\
$\left(q^{2}\right)^{\prime}$ & $K_{q}^{\prime}$ & $-2 q / B_{1} l$ & $2 \rho^{\prime}\left(P_{a}+P_{b}\right)$ \\
$\left(q^{2} l\right)^{\prime}$ & $K_{l}^{\prime}$ & $-\frac{q}{B_{1} l}\left[1+E_{2}\left(\frac{l}{k x}\right)^{2}\right]$ & $\rho^{\prime} l E_{1}\left(P_{a}+P_{b}\right)$ \\
\hline \hline
\end{tabular}

The grid for this particular study is designed such that vertical resolution decreases logarithmically away from the ground and contains 40 layers below $3000 \mathrm{~m}$ with the lowest 

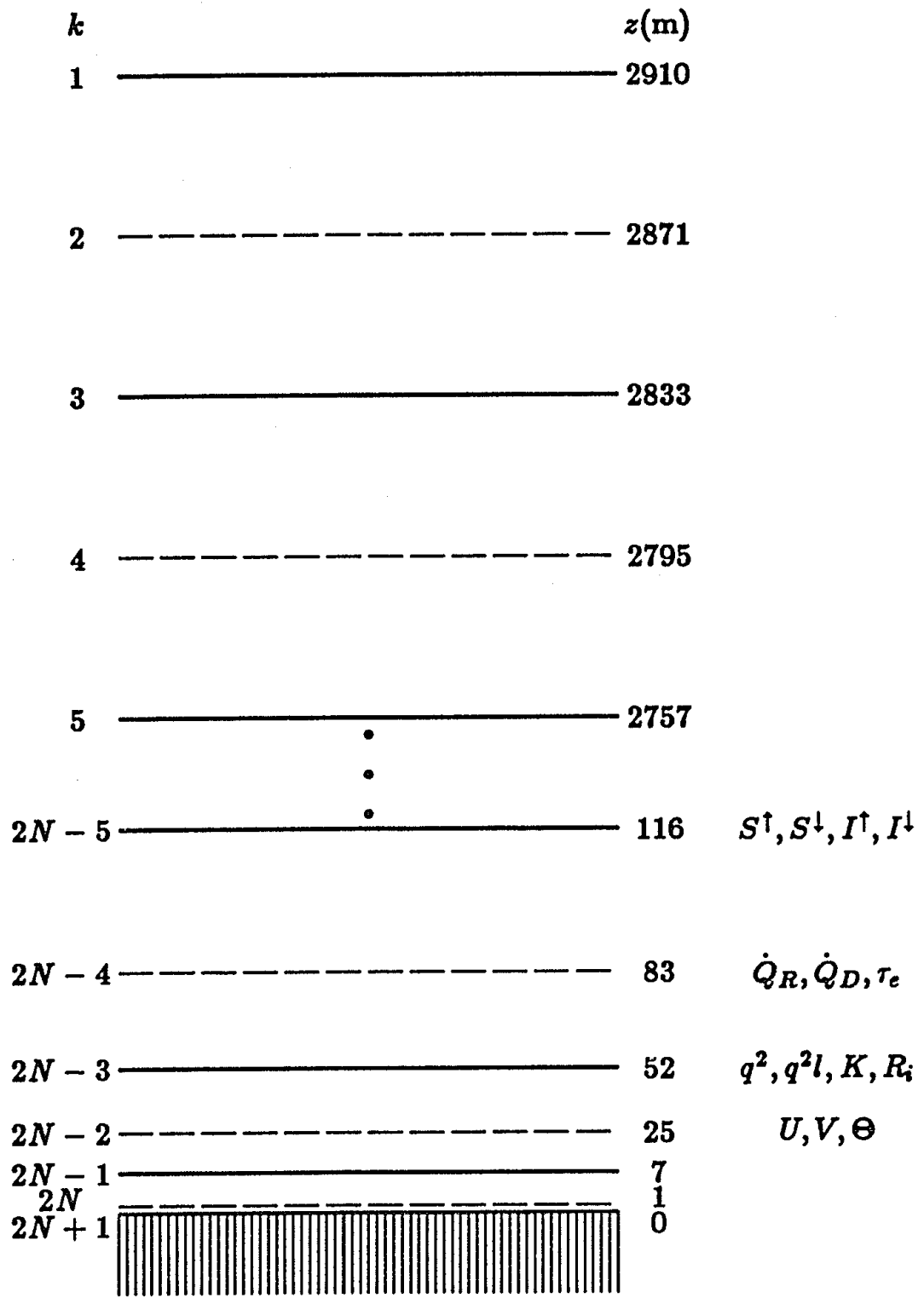

Figure 4-1: The PBL/radiation grid used for the finite difference algorithms. See text for explanation of symbols and indices. 
layer midpoint located at just about $1 \mathrm{~m}$ above the surface (Fig. 4-1). The same grid is used for the radiation routine, to be discussed in Section 4.3. The five differential equations are finite differenced on the specified grid using a Crank-Nicholson implicit scheme (Appendix B). Turbulence variables such as diffusion coefficients, TKE, mixing length, and all variables needed to calculate them are carried at 39 layer interfaces (odd numbered levels). The prognostic hydrodynamic variables are carried at the $\mathbf{4 0}$ layer midpoints (even numbered levels). The model is initialized by interpolation of temperature, dewpoint, and windspeed/direction data given on a rough pressure grid (for use with data in radiosonde format). Geostrophic wind within the model is set equal to the interpolated initial windspeed data, and must be specified within the mixed layer. The resulting system of equations is integrated forward with constant timesteps of 1 minute.

\subsection{Heat Conduction Through Ice}

Since sea ice often amplifies small changes in climate through a number of positive feedback mechanisms, it is a significant component of Polar climate (Kellogg, 1975). Heat exchange in the Arctic is strongly dependent on the presence or absence of sea ice. For example, turbulent heat input to the atmosphere over a refreezing lead (an area of open water) has been found to be 2 orders of magnitude larger than over perennial ice (Badgley, 1966). Thus, effects of leads can dominate the large-scale heat exchange and alter boundary layer stability, even in winter, where open water accounts for a maximum $1 \%$ surface area in the Central Arctic. The heat exchange processes are also affected by ice thickness, penetration of solar energy into ice, and the typical existence of an insulating layer of snow on top, which is both more optically thick and less conductive. Many forms and thicknesses of ice coexist in the Arctic ice pack: a typical mesoscale region may consist of young ice only tens of centimeters thick, perennial ice averaging 3 meters thick, and pressure ice tens of meters thick. Heat losses over young ice ( 8 to $12 \%$ of the winter surface area) are not as large as those for open water, but are much more substantial than over 1-meter ice, from which heat loss is much less dependent on ice thickness or form.

The PBL model originally contained the "force-restore method" (Deardorff, 1978) to predict soil surface temperature. This method solved a surface heat balance equation, 
in which a diurnal solar cycle, an annual "deep soil" temperature wave, latitude, and soil thermal properties were specified (Bhumralker, 1975; Blackadar, 1976). One very important part of this project is to develop a sea ice model that can predict ice surface temperature in a similar manner (i.e. through a surface heat balance) while also predicting ice equilibrium depth. Since springtime ice temperature profiles are nonlinear, a complete thermodynamic system for ice must be modeled and include such quantities as heat flux from the oceanic mixed layer under the ice, conduction through the ice and snow, and absorption/emission of atmospheric heat fluxes.

The most popular detailed model of this process was developed by Untersteiner (1964), which evolved during extensive applications in studies by Maykut and Untersteiner (1971), and Maykut (1978 and 1982). The model allowed for the penetration of solar radiation into the snow or ice, where it was absorbed as a function of depth and used as an internal heat source. Equations were developed to include variations in density, conductivity, and heat capacity due to a specified salinity profile in sea ice (but not for fresh water snow). The lower boundary conditions matched the oceanic heat flux with the heat conducted into the ice away from the bottom surface. The upper boundary conditions matched the atmospheric heat fluxes (solar, longwave, sensible and latent) with the heat conducted to the surface. Equations were also included to parameterize such processes as effects of brine pockets within the ice and the increase in snow density as it melts. Like the PBL model, initial ice/snow depth and profiles of temperature and salinity were required to begin timemarching the system of equations on a vertical $10 \mathrm{~cm}$ grid.

A simpler approach is adopted here. It is called the Vertically Integrated Formulation (VIF), and was developed by Neeman et al. (1988) for use in climate modeling in order to incorporate an ice model that captured non-linear heat storage while reducing model computations. From Fig. 4-2 it is evident this model also includes a snow/ice system, a mixed layer heat flux, and boundary conditions similar to the full conduction model. The conduction equations are simplified by neglecting the salinity profile (thus density, conductivity, and heat capacity are not depth-dependent), and neglecting solar absorption below the snow surface. But the major simplification, which concerns the temperature profile, removes the need for a grid system. It was recognized ice/snow temperature $T(z)$ and 


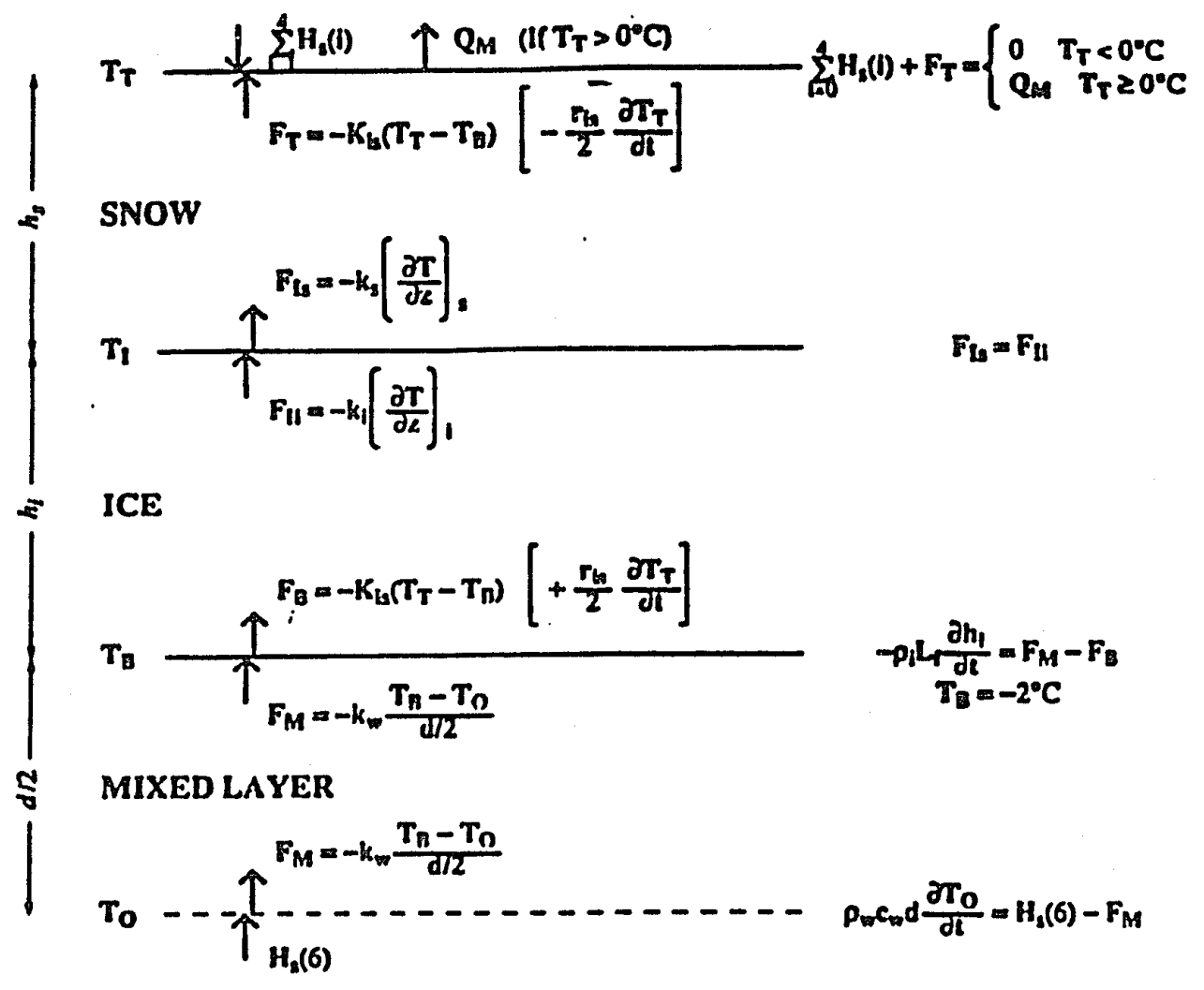

Figure 4-2: Schematic diagram of the VIF sea ice model of Neeman et al. (1988). See Appendix A for description of symbols. 
$\partial T / \partial z$ are nonlinear with depth during times of rapid temperature change, i.e. in spring and fall. However, $\partial T / \partial t$ is nearly linear with height such that $\partial(\partial T / \partial t) / \partial z$ is approximately constant. Exploiting this, integration of the heat conduction equations throughout the depth of the snow/ice layer is possible. Holding the bottom temperature $T_{B}$ constant at the freezing point of sea water, the conduction equations reduce to only two equations for heat fluxes at snow top $Q_{C}$ and ice bottom $F_{B}$ as functions of surface temperature $T_{s}$ (Fig. 4-2);

$$
\begin{aligned}
& Q_{C}=-K_{i s}\left(T_{s}-T_{B}\right)-\frac{r_{i s}}{2} \frac{\partial T_{s}}{\partial t} \\
& F_{B}=-K_{i s}\left(T_{s}-T_{B}\right)+\frac{r_{i s}}{2} \frac{\partial T_{s}}{\partial t}
\end{aligned}
$$

Bulk conductivity $K_{i a}$ is given by

$$
K_{i s}=\frac{k_{\theta} k_{i}}{k_{a} h_{i}+k_{i}} \overline{h_{s}}
$$

where $k_{s}$ and $k_{i}$ are conductivities of snow and ice, respectively, and $h_{s}$ and $h_{i}$ are depths of snow and ice, respectively. Integration coefficient $r_{i s}$ is computed from

$$
r_{i s}=\frac{\rho_{i} c_{i} h_{i}^{2} k_{s}+\rho_{s} c_{s} h_{s}\left(2 h_{i} k_{s}+h_{s} k_{i}\right)}{2\left(h_{i} k_{s}+h_{s} k_{i}\right)}
$$

where $\rho_{\theta}$ and $\rho_{i}$ are densities of snow and ice, and $c_{b}$ and $c_{i}$ are specifiec heat capacities of snow and ice, respectively. Surface temperature $T_{s}$ at the next time step is obtained from solving the surface energy balance (Appendix B);

$$
Q_{S}+Q_{I}+Q_{H}+Q_{L}+Q_{C}= \begin{cases}0, & T_{\bullet}<273 \mathrm{~K} \\ Q_{M}, & T_{\Delta}=273 \mathrm{~K}\end{cases}
$$

Positive fluxes are specified to be absorbed by the surface, while negative fluxes are specified to be emitted by the surface. $Q_{S}$ and $Q_{I}$ are net solar and net longwave fluxes at the surface, while sensible and latent heat fluxes are calculated by using friction velocity, temperature and moisture;

$$
\begin{aligned}
& Q_{H}=\rho c_{p} u_{*} \theta_{*} \\
& Q_{L}=\rho L u_{*} q_{*},
\end{aligned}
$$


where

$$
q *=\frac{k}{\ln \frac{z_{a}}{z_{0}}-\psi_{h}}\left(q_{a}-q_{s}\right),
$$

and $q$ is specific humidity. Since liquid water at the surface is assumed to exist uniformily among snow crystals when surface temperature approaches $273 \mathrm{~K}$, the latent heat flux from evaporation and sublimation is parameterized by specifying that the weighted latent heat $L$ is given by the ramp function

$$
L=\frac{L_{v}-L_{s}}{10}\left(T_{s}-268\right)+L_{s}
$$

where $L_{v}$ and $L_{s}$ are the latent heats of vaporization and sublimation, respectively. For $T_{\text {. }}<268 \mathrm{~K}$, only snow exists at the surface, but for $268<T_{0}<273 \mathrm{~K}$, liquid water increases linearly at the surface, with equal amounts of ice and water existing at $273 \mathrm{~K}$. This parameterization also eliminates the shock the surface system would experience if $L_{s}$ was suddenly allowed to change to $L_{v}$ at $273 \mathrm{~K}$.

When atmospheric fluxes force an equilibrium surface temperature above $273 \mathrm{~K}$, the temperature is set to $273 \mathrm{~K}$ and the excess heat $Q_{M}$ is used to melt the top of snow (or ice, if all snow has melted). All of the liquid water is assumed to evaporate so snow density is not affected (i.e. no water drains into the snow). New snow/ice thicknesses $h_{s}$ or $h_{i}$ can then be calculated from

$$
\frac{\partial h_{o(i)}}{\partial t}=-\frac{Q_{M}}{\rho_{o(i)} L_{f}}-\frac{Q_{L}}{\rho_{s(i)} L}
$$

where $L_{f}$ is the latent heat of fusion.

Melting is also allowed from the bottom of the ice by specifying that any excess heat added to (released from) the bottom of the ice layer, due to the difference between $F_{B}$ and the oceanic heat flux $F_{M}$, is used to melt ice from (freeze ice onto) the bottom. To find $F_{M}$, oceanic mixed layer temperature $T_{O}$ must be predicted at each timestep:

$$
\frac{\partial T_{o}}{\partial t}=\frac{F_{\text {sea }}-F_{M}}{\rho_{w} c_{w} d}
$$

where $F_{s e a}$ is a specified large-scale ocean current heat flux, $\rho_{w}$ is saline water density, $c_{w}$ is specific heat capacity of water, and $d$ is the specified mixed layer depth. The current value of $F_{M}$ is used to calculate $T_{O}$, while the new oceanic heat flux is found from the difference 
between $T_{B}$ and the updated value of $T_{O}$ using

$$
F_{M}=-k_{w} \frac{T_{B}-T_{O}}{d / 2}
$$

where $k_{w}$ is water conductivity. Melt from the bottom of the ice is then

$$
\frac{\partial h_{i}}{\partial t}=-\frac{F_{M}-F_{B}}{\rho_{i} L_{f}}
$$

The VIF predicts surface temperature within a few tenths of a degree of a full 100 layer conduction model in seasonal applications. The model has advantages over the full conduction model in that it does not need a separate grid system, it is more computationally stable, and it does not require extensive computing time. However, accuracy of the VIF depends on the time-scale of the forcing, a product of assuming linearity of temperature tendency. On diurnal time scales, Neeman et al. (1988) state snow and ice layers cannot be deeper than about $10 \mathrm{~cm}$ to keep errors of the solution to within $10 \%$. Applications with the VIF in this study produce diurnal temperature ranges of 2-3 $\mathrm{K}$, which are about half of what is observed during the spring season $(\sim 6-8 \mathrm{~K})$. Yet this study is not so concerned with the diurnal wave as much as the daily-mean temperature. Annually, surface temperature varies as much as $40 \mathrm{~K}$, whereas the diurnal range in the springtime is less than $10 \mathrm{~K}$. Therefore, the annual wave is stronger than the diurnal wave during the entire year - thus the daily average temperature is not significantly dependent on the diurnal range.

\subsection{Radiative Transfer Model}

The basis of the study is to investigate aerosol effects on the Arctic heat exchange process in detail. Radiative transfer is the largest contributor to this process and, particularly for solar wavelengths, is most directly affected by the haze. The need for a model to simulate the complex interactions between various forms of radiant energy and the Arctic environment, therefore, is quite clear. The use of parameterizations derived from the wealth of previous studies would be possible but would sacrifice the ability to conduct sensitivity studies.

A $\delta 2$-stream radiative transfer model used by Ackerman and Toon (1981) is used for this study. The model allows for radiative attenuation and emission by various atmospheric gases, and by absorbing and scattering materials such as aerosols and water droplets. Since 
optical properties and temperature are strongly altitude dependent, the atmosphere is divided into a set of layers, which are interfaced by a predetermined pressure grid. Each layer is considered to be homogeneous and to contain representive values of temperature, radiatively active gas concentrations, and aerosol absorbtion/scattering.

The model computes both upward and downward fluxes of solar and IR radiation through the Arctic troposphere. The solar spectrum is divided into 26 wavelength intervals $(0.25-4.29 \mu \mathrm{m}), 18$ of which account for absorption by $\mathrm{O}_{3}, \mathrm{O}_{2}, \mathrm{CO}_{2}$, and $\mathrm{H}_{2} \mathrm{O}$. Besides calculating Rayleigh and aerosol scattering in each interval, absorption by gases or aerosols is computed from a weighted exponential sum of pressure-dependent absorption coefficients; absorption by multiple gases in the same interval is calculated by assuming random overlap. Solar radiation is calculated at each wavelength by solving the 2-stream equations (Liou, 1974) in each atmospheric layer. Total column solar radiation is computed from matching the streams at layer interfaces and applying boundary conditions of a Lambertian reflector at the surface and incident solar flux at the "top of the atmosphere." Incident solar radiation at the top of the model (tropopause) is attenuated by climatological concentration values of absorbing gases above that level.

The infrared spectrum is divided into 19 wavelength intervals $(60-2500 \mu \mathrm{m})$ in which the model calculates absorption due to $\mathrm{O}_{3}, \mathrm{CO}_{2}$, and $\mathrm{H}_{2} \mathrm{O}$. Overlap between $\mathrm{H}_{2} \mathrm{O}$ and the other two absorbers in the IR is also calculated assuming random overlap, but overlap in other bands is neglected. Infrared radiative transfer is computed from the basic band-model formalism of Rodgers and Walshaw (1966). The vertical integration scheme, however, is a combination of an analytic strong-line approximation and a numerical integration technique. The surface boundary condition applies the Stefan-Boltzman law for grey-body emission (the same emisivity is used for absorption), and the upper boundary condition assumes incoming IR is produced from an isothermal atmosphere above the upppermost layer.

The radiative transfer model requires input of spectral properties and a $\tau_{e}$ profile at a reference wavelenth $\left(\lambda_{r}=0.55 \mu \mathrm{m}\right)$ for absorbing particles and droplets. Spectral properties are computed from an Mie scattering code developed by Ackerman and Toon (1981), and used in the Arctic acrosol studies of Valero and Ackerman (1985), Valero et al. (1987), and Francis et al. (1989). The model also requires input of temperature and humidity profiles, 
surface temperature, surface albedo, and solar zenith angle. Therefore, the radiation pressure grid must be vertically interfaced with the driving PBL grid to facilitate the passing of required data. To do this, geometric height at each PBL level is converted to pressure using scale height within each PBL layer. Scale height in turn is calculated from the mean temperature between two consecutive levels. Since the top of the PBL model is at $\approx 3 \mathrm{~km}$, ten more layers, each $1 \mathrm{~km}$ thick, are added to bring the entire grid to $\approx 13 \mathrm{~km}$ (just into the stratosphere) so both streams of radiation may be attenuated throughout the troposphere. Representative temperature and humidity are carried in each of the homogeneous layers.

The pressure grid is maintained through all experiments, allowing the grid to be initialized only once at the beginning of each run. This appears somewhat inconsistent when one considers the change in mass when haze-induced diabatic heating warms the lower atmosphere on the order of ten degrees. Yet simple computations suggest that if the troposphere warms an average of $15 \mathrm{~K}$ by some process and the surface pressure is held constant at $1000 \mathrm{mb}$, pressure at the top of the model would undergo only a $10 \%$ difference. The actual average heating from experiments yet to be discussed is closer to 5 degrees, and since the bulk of this study is within $3 \mathrm{~km}$ of the surface, effects of holding the pressure grid constant should not impact radiative transfer significantly.

The PBL model passes aerosol extinction optical depth, temperature, albedo, humidity, and solar angle information in each layer to the radiation model, which returns wavelengthintegrated upward and downward solar $\left(S^{\dagger}, S^{\downarrow}\right)$ and IR $\left(I^{\dagger}, I^{\downarrow}\right)$ fluxes at each level. Net radiative flux divergence is then calculated from

$$
\dot{Q}_{R}=\frac{g}{c_{p}}\left(\frac{\partial S^{N}}{\partial p}+\frac{\partial I^{N}}{\partial p}\right),
$$

where $c_{p}$ is specific heat capacity of air at constant pressure and

$$
\begin{aligned}
& S^{N}=S^{\dagger}-S^{\downarrow} \\
& I^{N}=I^{\dagger}-I^{\downarrow} .
\end{aligned}
$$

Surface values of net solar $\left(Q_{S}=S_{o f c}^{N}\right)$ and downward longwave $\left(Q_{I}^{\downarrow}=I_{\Delta f c}^{\downarrow}\right)$ fluxes are used in calculating the surface energy balance in the ice model. 


\subsection{Aerosol Properties}

Mie theory is used to calculate the single-scattering properties of the haze as a function of solar wavelengths only - the aerosols are assumed to be transparent in the IR. The Mie formulation requires knowledge of the wavelength-dependent complex index of refraction (determined by aerosol composition), and the aerosol size distribution. Once physical and optical properties are established, a reference $\tau_{e}(z)$ profile is constructed based on optical properties at $\lambda_{r}$ and an assumed extinction (concentration) profile. These are compared to observational values.

Computation of the index of refraction is complicated for aerosols with two or more components. Composites may be external mixtures, in which each particle is homogeneously composed of one material, or they may be internal mixtures, in which each particle contains several or all components. For internal mixtures, it is commonly assumed: (1) an average index of refraction can be computed based on the volume or mass weighted fractions of the different components in a uniformily mixed aerosol (Patterson et al., 1982; hereafter referred to as P82), or (2) the aerosol consists of spherical shells and cores (Ackerman and Toon, 1981; Valero and Ackerman, 1985; Valero et al., 1987; hereafter referred to as V87). The absorption of solar radiation is far greater for internal mixtures than for external mixiures of the same mass fraction because the scattering materials within each aersosol can focus more radiation onto the absorbing materials. As previously discussed, hydration is another complication. Particles composed of hygroscopic substances such as salts and some acids grow in size when relative humidity increases. This affects the particle size and the index of refraction, both of which independently tend to make each aerosol a better scatterer.

The core-shell Mie scattering program of Ackerman and Toon (1981) is used for this study. It calculates single-scattering properties of haze aerosols and cloud droplets as a function of wavelength $\lambda$, which are required by the 2-stream radiation model to calculate radiant flux profiles. The Mie program in turn requires input of the indices of refraction for both core and shell materials, geometric volume or number mean radius $\left(r_{g v}\right.$ and $r_{g n}$, respectively), and a standard deviation $\sigma_{g}$ for a log-normal size distribution. The number 
distribution is normalized and assumes the form

$$
\frac{\mathrm{d} N}{\mathrm{~d} \ln r}=\frac{1}{\sqrt{2 \pi} \ln \sigma_{g}} \exp \left[\frac{-\left(\ln r-\ln r_{g n}\right)^{2}}{2\left(\ln \sigma_{g}\right)^{2}}\right],
$$

where $N$ is the normalized number of particles in each of 21 radius bins centered on $r$. Once the distribution of $r$ is calculated, core radius $r_{c}$ is calculated from

$$
r_{c}=R_{V}^{1 / 3} r
$$

where $R_{V}$ is a specified core-to-shell volume ratio. The program calculates Mie scattering phase functions and moments for 61 angles, and outputs extinction and scattering crosssections, $\varpi_{0}, g$, and extinction efficiencies for each wavelength in the radiation model.

The values selected for the size distribution input parameters are based on the properties discussed in the introduction and on the values used in the modeling studies of V87 and P82. A number mean radius of $r_{g n}=0.1 \mu \mathrm{m}$ is chosen since many of the observational references have found accumulation modes in a majority of number distributions to peak at $\sim 0.2 \mu \mathrm{m}$ diameter and remain fairly constant in time and space (Shaw, 1984; Bodhaine et al., 1984; Joranger and Ottar, 1984; Radke et al., 1984). A standard deviation of $\sigma_{g}=1.6$ is chosen to represent the characteristicly steep slope commonly reported at radii higher than the mean; it is weighted by 1.5 used by V87. The values of $r_{g n}$ and $\sigma_{g}$ yield a volume mean radius of $r_{g v}=0.2 \mu \mathrm{m}$, which is smaller than $0.25-0.5 \mu \mathrm{m}$ caluculated by $V 87$.

Similarly to V87, aerosols for the experiments reported here are assumed to consist simply of a spherical core of $\mathrm{Cg}$ surrounded by a spherical shell of liquid water. The index of refraction for water is wavelength dependent, and values are taken from Hale and Querry (1973). Except in the near-IR, liquid water is almost exclusively a scatterer with an index of refraction at $\lambda_{r}$ of $n=1.33-\left(1.96 \times 10^{-9}\right) i$. The wavelength-independent index of refraction $n=2-0.66 i$ for the $\mathrm{Cg}$ core is based on P82.

Since the physical properties mentioned above are constrained by measurements, the only "tunable" variable is $R_{V}$. Its value is experimentally chosen to yield an $\varpi_{0}$ at $\lambda_{r}$ that falls within the observed range shown in Table 2-1. The V87 study varied $R_{V}$ from 0.001 to 0.05 ; we find that when $R_{V}=0.03$, meaning the Cg core occupies only $3 \%$ of the total particle volume, an absorbing haze aerosol results with $\varpi_{0}=0.86$ at $\lambda_{r}$. Although this value falls at the high end of the $\varpi_{0}$ range in Table 2-1 and is higher than 0.8 used in most 
previous modelling studies, it agrees exactly with the observed mean for AGASP I and is a better representation of all Arctic haze messurements taken in a variety of atmospheric humidity conditions. At $\lambda_{r}$ our aerosol has an asymmetry factor $g=0.67$, and a volume weighted index of refraction of $n=1.35-0.020 i$. P82 constructed a physically similar, but wettable multi-component aerosol with $r_{g n}=0.113, \sigma_{\theta}=1.56$, and a volume weighted index of refraction of $n=1.39-0.021 i$. Using a Mie scattering model, these input parameters at $95 \%$ relative humidity led to $g=0.70$ and $\varpi_{0}=0.87$ at $\lambda_{r}$. Hence it appears the aerosol in the current study appears most valid for high humidity conditions.

The reference profile of $\tau_{e}$ at $\lambda_{r}$ is calculated from a representative $\sigma_{c}$ profile, which is held constant in time to obtain equilibrium conditions. This further requires the optical properties to be held constant with height and time, equivalent to specifying the height dependency of extinction is due solely to a concentration profile. Thus, all integrations with haze are simplified by characterizing only this one representative set of haze optical propertier. In this way, systematic changes in environmental conditions allow examination into how a single form of haze aerosol impacts the surface-atmosphere heat transfer process for a range of environmental conditions.

It is assumed the vertical $\sigma_{e}$ profile is reasonably represented by a simple analytic lognormal vertical distribution similar to the size distribution equation above;

$$
\sigma_{e}=\frac{\left(\sigma_{e}\right)_{\max }}{\sqrt{2 \pi} \log \sigma_{s}} \exp \left[\frac{-\left(\log z-\log z_{\operatorname{maz}}\right)^{2}}{2\left(\log \sigma_{s}\right)^{2}}\right],
$$

where $z_{\max }$ is the height of maximum extinction. Accordingly, $z_{\max }$ is also the height of maximum concentration since we specify height-independent optical properties. The standard deviation of this distribution is given by $\sigma_{\boldsymbol{z}}$.

The Cg mass concentration profile can also be estimated from the $\sigma_{e}$ profile since all absorption by our aerosol is due to the $\mathrm{Cg}$ component at $\lambda_{r}$. Although the model does not explicitly require $\mathrm{Cg}$ concentration, its estimated profile is used as an easy way to constrain the extinction profile. It is assumed the absorption cross section $a$ is $12 \mathrm{~m}^{2} \mathrm{~g}^{-1}$ when a water-Cg configuration is used. The accepted value for absorption cross section of graphitic carbon is 8-10 $\mathrm{m}^{2} \mathrm{~g}^{-1}$ (Roessler and Faxvog, 1980; Szkarlat and Japar, 1981); but if the carbon is internally mixed within an aerosol of a mostly scattering material, in our case a water shell, absorption is enhanced (Ackerman and Toon, 1981; Valero and Ackerman, 


\section{Cg profile}

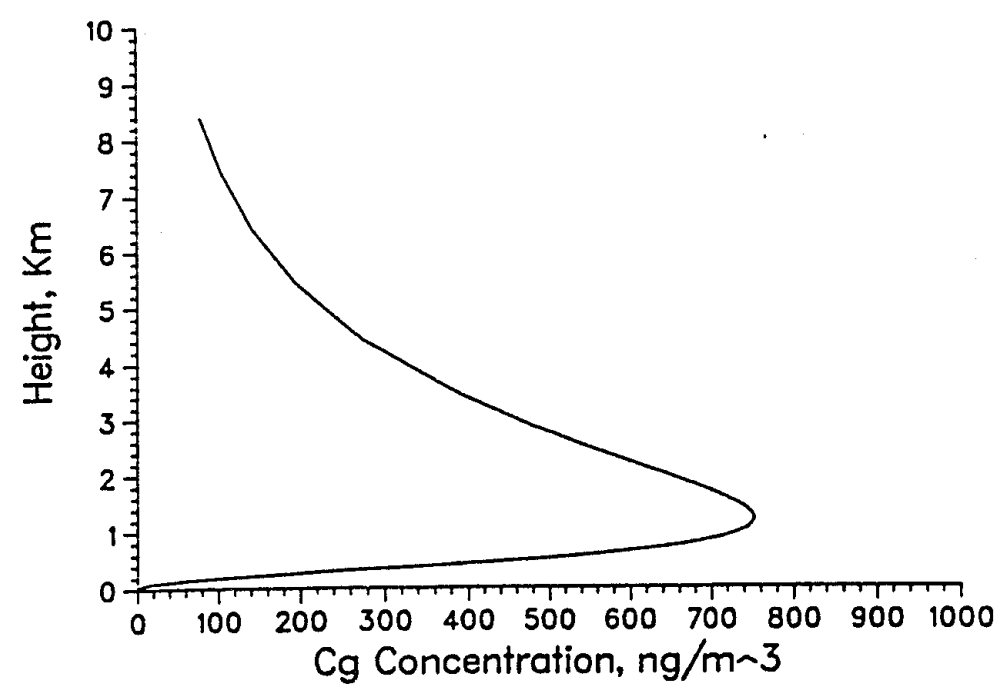

Figure 4-3: The analytic Cg mass concentration profile calculated from a log-normal height distribution of the extinction coefficient using $a=12 \mathrm{~m}^{2} \mathrm{~g}^{-1}$ and $\varpi_{0}=0.86$.

1985). The value used here is based on V87, who calculated $11.2-12.2 \mathrm{~m}^{2} \mathrm{~g}^{-1}$, and Hansen and Novakov (1988), who used $12.0 \mathrm{~m}^{2} \mathrm{~g}^{-1}$.

The values of $\left(\sigma_{e}\right)_{\max }, z_{m a z}$, and $\sigma_{\Delta}$ are adjusted to obtain a vertical distribution and integrated column burden of $\mathrm{Cg}_{\mathrm{g}}$ that agrees with observations. The mass concentration $m$ of $\mathrm{Cg}_{\mathrm{g}}$ at each level $k$ is obtained by

$$
m(k)=\frac{\left(1-\omega_{0}\right) \sigma_{e}(k)}{a}
$$

Figure 4-3 shows the $\mathrm{Cg}$ mass concentration profile that results from selecting $\left(\sigma_{e}\right)_{\max }=$ $6.7 \times 10^{-5} \mathrm{~m}^{-1}, z_{\max }=1200 \mathrm{~m}$, and $\sigma_{g}=2.5$. No amount of $\mathrm{Cg}_{\mathrm{g}}$ is allowed to exist in the stratosphere (above the model domain), so the profile is cut off at $\sim 8.5 \mathrm{~km}$ for these experiments. Within each model layer the layer mass loading is calculated; by summing over all layers, a total tropospheric $\mathrm{Cg}$ column burden is obtained. For the profile in Fig. 4-3, the total column burden is $2.8 \times 10^{-3} \mathrm{~g} \mathrm{~m}^{-2}$, which exactly agrees with a value from Rosen and Hansen (1984) for a particular experimental flight.

Several advantages for using a log-normal vertical distribution are quite evident from 
Fig. 4-3. The major advantage is simplicity, yet we obtain a few characteristics commonly found with the concentration profiles. First, the maximum $\mathrm{Cg}$ value of $750 \mathrm{ng} \mathrm{m}^{-3}$ is quite representative in both magnitude and height. Second, the equation yields a strong concentration gradient from the low tropospheric maximum to the surface. Third, a realistic Cg tropospheric column burden is obtained from specifying a representative peak concentration at low tropospheric altitudes and a gentle continuous decrease in $\mathrm{Cg}$ concentration above the maximum. Observations suggest a large mass loading is often found up to $5 \mathrm{~km}$, and even in some extreme circumstances, as high as the tropopause. Even though strong layering is occasionally observed to be interspersed throughout the upper troposphere, the analytic profile can roughly account for the large mass aloft.

Finally, the extinction optical depth within each layer is calculated from

$$
\tau_{e}(k)=\sigma_{e}(k) \Delta z(k)
$$

this profile is used for all experiments. Maximum $\sigma_{s}$ and $\sigma_{a}$ values at $\sim 1.2 \mathrm{~km}$ are $5.8 \times 10^{-5}$ $\mathrm{m}^{-1}$ and $9.1 \times 10^{-6} \mathrm{~m}^{-1}$, respectively, while tropospheric averages are $2.4 \times 10^{-5} \mathrm{~m}^{-1}$ and $3.9 \times 10^{-6} \mathrm{~m}^{-1}$, respectively. These values fit well within the limits reported in Table 2-1. The integrated optical depths are $\tau_{a}=0.034$ and $\tau_{e}=0.25$. Absorption fits well within the limits reported in Table 2-1. Extinction is lower than values usually reported during earlyspring field experiments (e.g. Dutton et al., 1984), yet it is about the maximum reported for late-spring. Extinction agrees well with $\tau_{e}$ calulated similarly by Valero and Ackerman (1985) using radiometric data from AGASP I and an internal mixture of sulphate and $\mathrm{Cg}$.

\subsection{Numerical Procedure}

Two significant parameters have been identified for haze-induced radiative perturbations. The first is surface albedo, which determines the solar impacts on the surface-atmosphere system. Observations reported by Orvig (1970) indicate a wide range of surface albedos for snow/ice surfaces in the Arctic, depending on snow density and water content, areas of exposed ice, and distribution of melt puddles. For example, the highest average albedo for an established snowpack is 0.80 (the model does not predict freshly fallen or drifted snow, which has an even higher albedo). Dense snow has an albedo of about 0.70 , while very wet 
snow during intense thaw can have an albedo as low as 0.35 . When all snow has melted, exposed ice has an average albedo of 0.55 .

The second important parameter is relative humidity, which in this study is concerned only with effects on the IR streams, rather than effects on optical properties. Since aerosols are assumed IR-transparent, no direct haze-induced IR forcing occurs in this model system. Therefore, all changes to IR streams are considered a result of a negative feedback mechanism. It is considered negative because increased IR surface absorption from the warmer and wetter (by specifying constant relative humidity) atmosphere opposes the reduced surface solar absorption. Estimates from dewpoint profiles taken during AGASP I show in general, the mid- and upper-troposphere are usually quite dry, with dewpoint depressions of 15-30 K (RH 20-40\%). But this region can also exhibit dewpoint depressions of only a few degrees ( $\mathrm{RH} \sim 75-90 \%$ ) with the movement of various air masses. Near the surface, relative humidities are usually much higher, existing in the $70-100 \%$ range. This variation of humidity could lead to a large variation in the haze-induced negative IR feedback process.

All experiments are initialized from the same set of data in pressure format (Table 4-1). These profiles of temperature, dewpoint, and windspeed/direction are linearly interpolated to each layer, and dewpoint is converted to specific humidity. The model is set up to be run with either a height- and time-independent relative humidity $(\mathrm{RH})$, which ignores the dewpoint profile, or the time-independent specific humidity profile.

Preliminary runs with the specified dewpoint profile and surface albedo $A_{s}=0.65$ indicated the surface heat balance tended to a 24-hour mean surface temperature of 270 K. Since we require the PBL model construct its own equilibrium profiles of temperature and wind, we specify an isothermal layer at $270 \mathrm{~K}$ from the surface to $925 \mathrm{mb}(\sim 550$ $\mathrm{m})$, about twice as deep as the daytime adiabatic layer. The sounding above $925 \mathrm{mb}$ is based on a composite of late spring and summertime Arctic soundings from Greenland's eastern coast during strong northerly flow, which are taken from Weather in Home Fleet Waters (1964). Although below $700 \mathrm{mb}$ the soundings on which the composite is based exhibit much variability depending on each station's position (e.g. each station's latitude and surface conditions), the soundings were exceptionally similar aloft, especially near the tropopause $(300 \mathrm{mb})$ and into the stratosphere. This suggests that during northerly flow, all 
Table 4-1: Initial profiles of pressure, temperature, dewpoint (and resulting specific humidity), and winds, where $d d$ represents wind direction.

\begin{tabular}{cccccc}
\hline \hline$p(\mathrm{mb})$ & $T\left({ }^{\circ} \mathrm{C}\right)$ & $T_{d}\left({ }^{\circ} \mathrm{C}\right)$ & $q\left(\mathrm{~g} \mathrm{~kg}^{-1}\right)$ & $V\left(\mathrm{~m} \mathrm{~s}^{-1}\right)$ & $d d$ \\
\hline 1000 & -3.0 & -5.0 & 2.6 & 10.0 & 270 \\
975 & -3.0 & -5.5 & 2.6 & 10.0 & 270 \\
950 & -3.0 & -6.5 & 2.5 & 10.0 & 270 \\
925 & -3.0 & -7.5 & 2.3 & 10.0 & 270 \\
900 & -4.0 & -8.5 & 2.2 & 10.0 & 270 \\
875 & -5.0 & -9.5 & 2.1 & 10.0 & 270 \\
850 & -5.5 & -10.5 & 2.0 & 10.0 & 270 \\
800 & -6.5 & -13.0 & 1.8 & 10.0 & 270 \\
700 & -9.0 & -19.0 & 1.2 & 10.0 & 270 \\
600 & -15.0 & -25.0 & 0.86 & 10.0 & 270 \\
500 & -23.0 & -34.0 & 0.45 & 10.0 & 270 \\
400 & -33.0 & -43.0 & 0.23 & 10.0 & 270 \\
300 & -50.0 & -60.0 & 0.05 & 10.0 & 270 \\
250 & -45.0 & $* *$ & 0.03 & 10.0 & 270 \\
150 & -45.0 & $* *$ & 0.005 & 10.0 & 270 \\
\hline \hline
\end{tabular}


stations recorded representative mid- and upper-tropospheric Arctic temperature profiles for that season. Between $700 \mathrm{mb}$ and $925 \mathrm{mb}$ the temperature profile is based heavily on profiles over ice or snow, and matched to the isothermal layer between the surface and 925 $\mathrm{mb}$. This results in a realistic, highly stable regime up to $700 \mathrm{mb}$.

The dewpoint profile is specified, but is representative of the moisture content of an Arctic airmass. For simplicity the dewpoint temperature is linear in pressure from the surface to $850 \mathrm{mb}$, and from $850 \mathrm{mb}$ to $300 \mathrm{mb}$. If specific humidity is used, it is able to be adjusted to $99 \%$ RH near the surface if the diurnal range of temperature creates saturation conditions during the evening or morning. Above the tropopause specific humidity must be specified, taken from a standard atmospheric subarctic summer profile (the same profile that the radiation model uses above the model domain to attenuate solar and IR fluxes from the "top of the atmosphere"). The windspeed is specified westerly at $10 \mathrm{~m} \mathrm{~s}^{-1}$ throughout the domain. In the mid and lower troposphere, winds for late spring tend to be more easterly, but this is unimportant for a one-dimensional model. This windspeed is interpolated as the geostrophic wind; the non-geostrophic wind near the surface is allowed to spin-up via the PBL model.

Integrations during model development indicated the initial profile of temperature existed far from radiative equilibrium. The model consistently cooled the surface-atmosphere system radiatively to conditions similar of Arctic winter, but with no signs of approaching equilibrium. This was certainly too cold to be considered representative of springtime in the Arctic. It was recognized that the initial temperature data was in radiative and dynamic equilibrium, and that the model required some parameterization of meridional heat flux so equilibrium conditions typical of spring could be attained. The large-scale dynamic heating rate $\dot{Q}_{D}$ was included to help hold the temperature profile above the PBL constant.

Each time the model is run for a clear atmosphere, it is first run for 1 day to determine the first 24-hour-average radiative heating rate profile ${\overline{\dot{Q}_{R}}}_{(z)}$. Above $1 \mathrm{~km}$ the same profile, with the opposite sign, is specified as the dynamical heating rate profile: $\dot{Q}_{D}(z)=-{\overline{\dot{Q}_{R}}}_{(z)}$. In this way we may considerably shorten the time required to reach equilibrium. This is equivalent to specifying that this 1-dimensional system is in equilibrium with respect to net radiative cooling and large-scale heating by dynamic processes. The same $\dot{Q}_{D}$ profile is 
used for each respective haze run so the change to atmospheric fluxes can be differentiated purely on the basis of inclusion of haze.

Typical values for $\dot{Q}_{D}$ are calculated between 0.1 and $1.0 \mathrm{~K} \mathrm{day}^{-1}$ and average around $0.4 \mathrm{~K} \mathrm{day}^{-1}$ for the experiments to be discussed. Porch and MacCracken (1982) report the annual average large scale heat budget for the Arctic consists, in part, of a dynamical heating rate due to meridional heat transport of about $0.6 \mathrm{~K} \mathrm{day}^{-1}$, based on results from a number of GCMs. Specification of a dynamic heating rate is therefore reasonable and the values for $\dot{Q}_{D}$ required to balance radiative cooling are realisitic. Equilibrium is defined as the time when the 24-hour average total (radiative + turbulent + dynamic) heating rate profile for the system exists within $\pm 0.1 \mathrm{Kday}^{-1}$, a point when no appreciable changes in atmospheric structure occur.

Values of the various constants for all experiments are given in Table 4-2. The value for surface roughness $z_{0}$ is taken from Overland (1988) and exists within the range reported by Munn (1966) for snow/ice surfaces. Turbulence constants for the Level 2.5 model are from Mellor and Yamada (1982). Mixed layer depth $d$ is taken as the average mixed layer depth during MIZEX 84 (Fig. 15 from Morisison et al. [1987]), while ice and snow constants are from Neeman et al. (1988). The model is run for a latitude $75^{\circ} \mathrm{N}$, the solar declination is $20^{\circ}$ (late May), and the initial time is midnight.

In the first experiment (control), the model system is integrated out to clear-sky equilibrium conditions (clear case). Although observed Arctic surface albedos during May are about 0.8 , we set surface albedo at 0.65 ; this value is based on a zonally averaged value of 0.64 for May at $75^{\circ} \mathrm{N}$ (Robock, 1981), and could be considered a $5 \%$ bias toward a lower surface albedo for an established snowpack $\left(A_{s}=0.70\right)$ after a spring season of aerosol deposition. Snow and ice thicknesses are initially 0.4 and $3.0 \mathrm{~m}$, respectively (Eicken and Lange, 1989; Maykut and Untersteiner, 1971). The humidity profile is set to a constant (in height and time) $\mathrm{RH}$ of $80 \%$, a value consistent with average late-spring conditions. This leads to a time- and height-dependent specific humidity profile. At equilibrium, we discuss the performance of the model in simulating the late-spring Arctic lower troposphere. From these clear-case profiles, the model is run with the $\tau_{e}$ profile (haze case) to haze equilibrium. Results are compared and discussed in the following section. 
Table 4-2: Values of constants for all experiments. See Appendix A for description of symbols.

\begin{tabular}{|c|c|c|c|}
\hline Variable & Value & Variable & Value \\
\hline$\Delta t$ & $300 \mathrm{~s}$ & $a_{2}$ & 0.211 \\
\hline$N$ & 50 & $a_{3}$ & 0.100 \\
\hline$p_{s}$ & $1000 \mathrm{mb}$ & $\alpha_{m}$ & 1.0 \\
\hline$\phi$ & $75^{\circ} \mathrm{N}$ & $\beta_{m}$ & 4.7 \\
\hline$\delta$ & $20^{\circ}$ & $\alpha_{h}$ & 0.74 \\
\hline$t_{0}$ & 0 (midnight) & $\beta_{h}$ & $R_{\mathrm{ic}}^{-1}$ \\
\hline$\mu$ & 1 & $\mu_{a}$ & 0.5 \\
\hline$z_{0}$ & $0.003 \mathrm{~m}$ & $\epsilon_{*}$ & 1.0 \\
\hline$k$ & 0.4 & $T_{B}$ & $271 \mathrm{~K}$ \\
\hline$A_{1}$ & 0.92 & $d$ & $10 \mathrm{~m}$ \\
\hline$A_{2}$ & 0.74 & $Q_{\text {sea }}$ & $2.0 \mathrm{~W} \mathrm{~m}^{-2}$ \\
\hline$B_{1}$ & 16.6 & $k_{i}$ & $2.0 \mathrm{~W} \mathrm{~m}^{-1} \mathrm{~K}^{-1}$ \\
\hline$B_{2}$ & 10.1 & $k_{s}$ & $0.3 \mathrm{~W} \mathrm{~m}^{-1} \mathrm{~K}^{-1}$ \\
\hline$C_{1}$ & 0.08 & $k_{w}$ & $400 \mathrm{~W} \mathrm{~m}^{-1} \mathrm{~K}^{-1}$ \\
\hline$E_{1}$ & 1.80 & $\rho_{i}$ & $900 \mathrm{~kg} \mathrm{~m}^{-3}$ \\
\hline$E_{2}$ & 1.33 & $\rho_{0}$ & $330 \mathrm{~kg} \mathrm{~m}^{-3}$ \\
\hline$S_{l}$ & 0.2 & $c_{s}=c_{i}$ & $2100 \mathrm{~J} \mathrm{~K}^{-1} \mathrm{~kg}^{-1}$ \\
\hline$S_{q}$ & 0.2 & $c_{w}$ & $4220 \mathrm{~J} \mathrm{~K}^{-1} \mathrm{~kg}^{-1}$ \\
\hline$a_{1}$ & 0.013 & & \\
\hline
\end{tabular}


Since the humidity specification is important for the IR feedback, a clear/haze case for constant specific humidity is also run to compare the relative importance of a variable-inspace, yet constant in time, specific humidity. Then a relative humidity sensitivity study is run. For these experiments, a number of model integrations are run to equilibrium for a clear atmosphere with constant $\mathrm{RH}$ of $60,70,80$, and $90 \%$. Each run requires a separate dynamical heating rate profile to be calculated according to the procedure above. When each run reaches clear equilibrium, 24-hour averages of certain variables are calculated, and each run continues with the haze $\tau_{e}$ profile until haze equilibrium.

A set of sensitivity studies has also been designed to investigate how the model reacts to a range of surface albedos. Unfortunately, we are limited by the fact that once snow begins to rapidly melt, surface albedo is drasticly lowered while snow density increases; this enhances solar absorption, increases conductivity, and further speeds the melting. Also, once all snow has melted, albedo again changes for exposed ice. The model in its present state does not account for this complex interaction, although some parameterization for this process could easily be implemented. For integrations out to equilibrium, surface albedo must be kept constant. Hence these cases are limited to albedos in which the respective diurnal surface temperature ranges remain below $273 \mathrm{~K}$. The moisture profile for these cases is again held constant at $80 \%$ relative humidity. Like the $\mathrm{RH}$ cases, the model is integrated for a clear atmosphere to equilibrium for snow/ice albedos of $0.6,0.7$, and 0.8 . At equilibrium, 24-hour averages are calculated, and each run continues with the haze $\tau_{e}$ profile until haze equilibrium. 


\section{Results}

\subsection{Control Runs}

\subsubsection{Clear Atmosphere}

The model was integrated with a clear atmosphere until equilibrium for $\mathrm{RH}$ of $80 \%$ and a surface albedo of 0.65 . Table 5-1 shows the 24-hour average surface temperature (K), planetary albedo, and heat fluxes $\left(\mathrm{W} \mathrm{m}^{-2}\right)$ for the surface, the atmosphere, and the surfaceatmosphere system (top of the model), and for both clear and haze cases. The signs of the net radiative and turbulent fluxes are positive for a gain of energy (or inward flux), and negative for a loss of energy (or an outward flux). For the clear case, surface temperature of 265.6 K agrees with Orvig (1970), who reports a May mean surface temperature of 265.7 $\mathrm{K}$ for Barrow, Alaska $\left(71^{\circ} \mathrm{N}\right)$ and $262.2 \mathrm{~K}$ for Mould Bay, Northwest Territories $\left(77^{\circ} \mathrm{N}\right)$. The model predicts a surface diurnal temperature range of only $2.8 \mathrm{~K}$ (Fig. 5-1, solid line), about half of the range reported by Orvig for both stations.

The daily averaged surface temperature also agrees with average May values computed from a number of previous ice modelling studies. For example, Maykut an Untersteiner (1971) calculate a daily mean surface temperature of $266 \mathrm{~K}$ for late May with $h_{s}=40$ $\mathrm{cm}$ and $h_{i}=310 \mathrm{~cm}$ (quite close to values used in this study). It therefore appears our daily averaged surface temperatures, based primarily on the annual temperature wave, are representative of Arctic conditions for this season.

We have compared our calculations of daily average radiative fluxes at the surface in Table 5-1 to mean clear-sky data from Orvig (1970) for the entire month of May at $75^{\circ} \mathrm{N}$. Orvig reports downward incident solar radiation $S_{s f c}^{\downarrow}=356 \mathrm{~W} \mathrm{~m}^{-2}$, downward incident IR $I_{s f c}^{!}=199 \mathrm{~W} \mathrm{~m}^{-2}$, and upward emitted IR from the surface $I_{s f c}^{\dagger}=305 \mathrm{~W} \mathrm{~m}^{-2}$ (for surface emissivity $\epsilon_{s}=1$, this corresponds to a May surface temperature of $271 \mathrm{~K}$, but may account for contributions from open water). The differences between these observed values and our values are 3,9 , and $8 \%$, respectively.

Figure 5-2 shows the surface heat balance, including net solar, net IR, conducted, turbulent sensible, and turbulent latent heat fluxes. Again, all fluxes into (or gained by) the surface layer are positive, regardless of vertical direction. Note that at this season and lat- 
Table 5-1: Equilibrium daily averages of surface temperature (K), planetary albedo, and heat fluxes $\left(\mathrm{W} \mathrm{m}^{-2}\right)$ for the surface, surface-atmosphere, and atmosphere.

\begin{tabular}{|c|c|c|c|}
\hline & Clear & Hase & Difference \\
\hline \multicolumn{4}{|c|}{ Surface } \\
\hline$T$ & 256.6 & 266.3 & +0.7 \\
\hline$s^{\downarrow}$ & 354.0 & 302.1 & -51.9 \\
\hline$s^{\dagger}$ & 230.1 & 196.4 & -33.7 \\
\hline$S^{N}$ & +123.9 & +105.7 & -18.2 \\
\hline$I^{\downarrow}$ & 181.0 & 202.1 & +21.1 \\
\hline$I^{\dagger}$ & 282.0 & 285.2 & +3.2 \\
\hline$I^{N}$ & -101.0 & -83.1 & +17.9 \\
\hline$R^{N}$ & +22.9 & +22.8 & -0.3 \\
\hline$Q_{H}$ & +2.1 & +4.5 & +2.4 \\
\hline$Q_{L}$ & -27.1 & -29.2 & -2.1 \\
\hline$Q_{c}$ & +2.2 & +2.1 & -0.1 \\
\hline \multicolumn{4}{|c|}{ Surface-Atmosphere } \\
\hline$A_{\mathrm{p}}$ & 0.543 & 0.494 & -0.049 \\
\hline$s^{\downarrow}$ & 448.6 & 448.6 & 0 \\
\hline$S^{\uparrow}$ & 243.0 & 218.8 & -24.2 \\
\hline$S^{N}$ & +205.7 & +229.8 & +24.2 \\
\hline$I^{\dagger}$ & 230.4 & 242.4 & +12.0 \\
\hline$I^{N}$ & -230.4 & -242.4 & -12.0 \\
\hline$R^{N}$ & -24.7 & -12.5 & +12.2 \\
\hline$Q_{C}$ & +2.2 & +2.1 & -0.1 \\
\hline$Q_{D}$ & +22.5 & +22.5 & 0 \\
\hline \multicolumn{4}{|c|}{ Atmosphere } \\
\hline$S^{N}$ & +81.8 & +124.1 & +42.3 \\
\hline$I^{N}$ & -129.4 & -159.3 & -29.9 \\
\hline$R^{N}$ & -47.6 & -35.1 & +12.5 \\
\hline$Q_{H}$ & -2.1 & -4.5 & -2.4 \\
\hline$Q_{L}$ & +27.1 & +29.2 & +2.1 \\
\hline$Q_{D}$ & +22.5 & +22.5 & 0 \\
\hline
\end{tabular}




\section{Surface and Air Temperature}

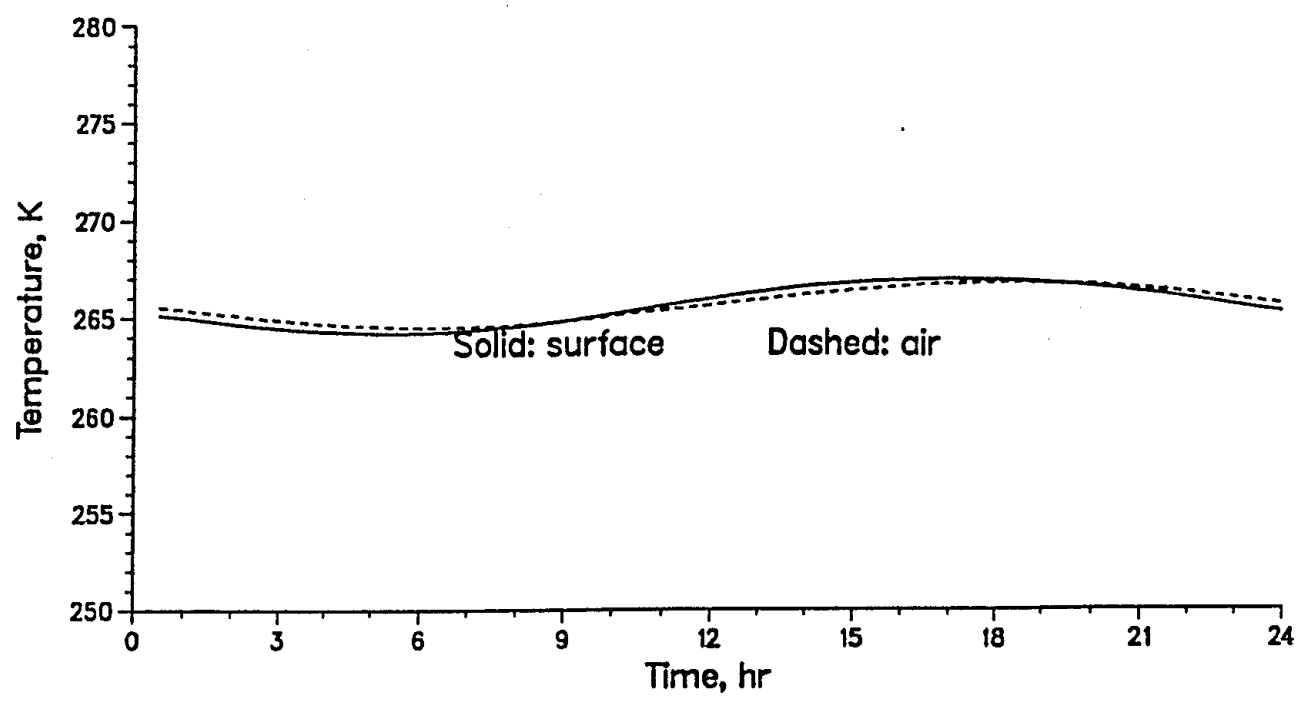

Figure 5-1: Clear-sky equilibrium temperature trend (K) over 24 hours at the surface (solid) and at $1 \mathrm{~m}$ above the surface (dashed).

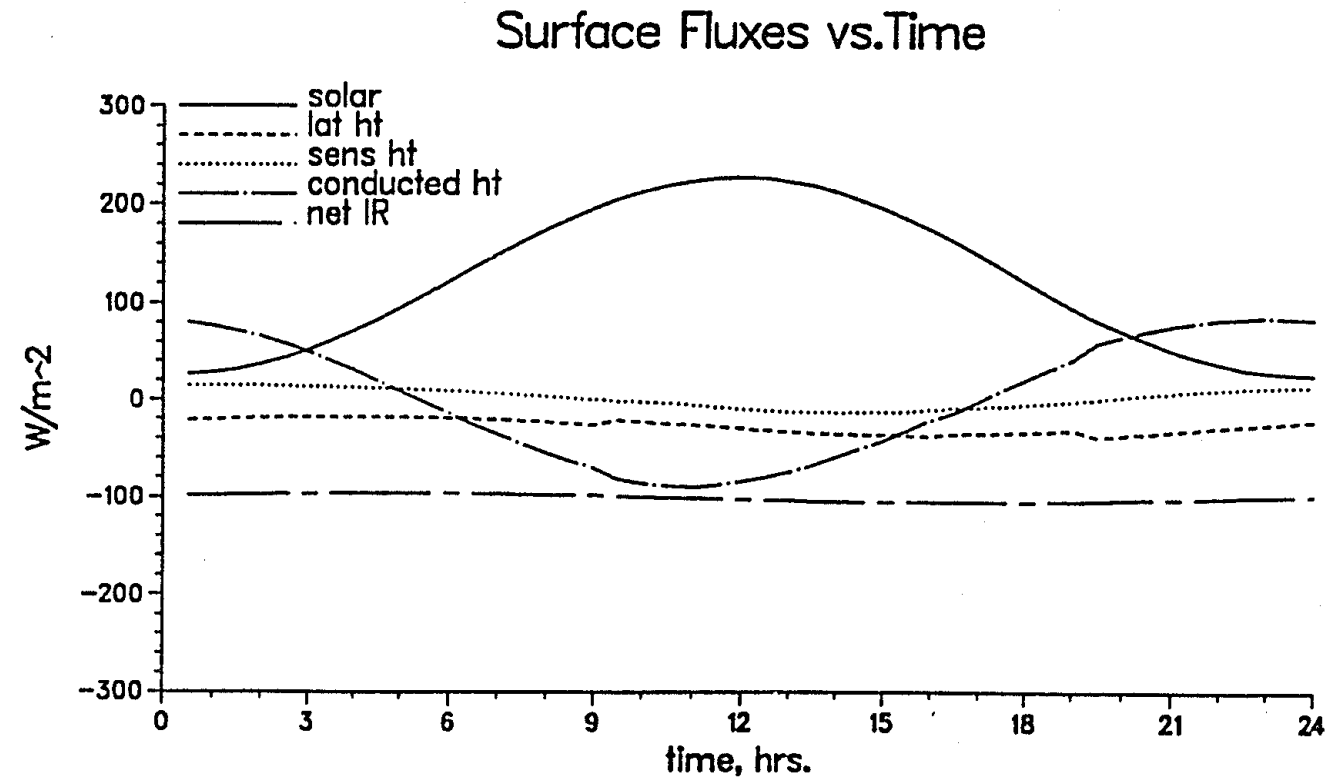

Figure 5-2: Clear-sky surface flux trend $\left(W^{-2}\right)$ for net solar (solid), net IR (line-dash), sensible heat (dotted), latent heat (dashed), and conductive heat (line-dot). A gain of heat is positive. 
itude, net solar flux (solid) is positive for 24 hours. On the other hand, net IR (line-dash) shows longwave emission by the surface dominates over longwave absorption by almost a constant rate of $100 \mathrm{~W} \mathrm{~m}^{-2}$.

The mean turbulent sensible heat flux $Q_{H}$ in Table 5-1 (Surface) is $+2.1 \mathrm{~W} \mathrm{~m}^{-2}$, but varies over the day from -13.3 to $14.3 \mathrm{~W} \mathrm{~m}^{-2}$ (Fig. 5-2, dotted). Since $Q_{H}$ is calculated from $T_{a}-T_{s}$, the daily average flux of heat into the surface shows the dominance of surface-based stability through much of the day. Most observations (Fletcher, 1965) show monthly mean sensible heat fluxes during the springtime change from +5 to $+10 \mathrm{~W} \mathrm{~m}^{-3}$ in April, to -2 to -7 $\mathrm{W} \mathrm{m}^{-2}$ during May. Only a few cases of positive fluxes during May are reported, depending on local conditions. Considering the model is run close to a seasonal stability reversal, and the time of this reversal is extremely sensitive to complex surface-atmosphere-ocean interactions, our small daily averaged value of $Q_{H}$ is acceptable.

The latent heat flux $Q_{L}$ remains negative throughout the entire 24 hours, since relative humidity is fixed. The daily mean value of $-27.1 \mathrm{~W} \mathrm{~m}^{-2}$ rests toward the high end of observed -10 to $-30 \mathrm{~W} \mathrm{~m}^{-2}$ for spring and summer (Overland, 1988; Andreas, 1988; Kellner et al., 1987). From Fig. 5-2 the diurnal range of latent heat is -17.8 to $-37.5 \mathrm{~W} \mathrm{~m}^{-2}$. Integrations with higher RH lead to lower diurnal variations of latent heat fluxes. It therefore appears $80 \% \mathrm{RH}$ at the surface is probably too low for May conditions even though this value is representative of the atmospheric moisture content above the PBL. Consequently, our specification of a constant RH profile certainly represents a simplification.

Heat conduction through the ice to the surface $Q_{C}$ averages $+2.2 \mathrm{~W} \mathrm{~m}^{-2}$ and varies over the day from -89.9 to $85.6 \mathrm{~W} \mathrm{~m}^{-2}$. Values for this flux are extremely sensitive to the snow/ice thickness because of differences between their conductivities and densities. It appears the wide diurnal range of conductive heat flux calculated by the simple VIF model is the component responsible for damping the diurnal temperature wave to about half that observed for this season and latitude. Thus when the surface heat balance is considered, the diurnal temperature variation is controlled by the conduction model. The surface albedo (i.e., net solar absorption), and to a lesser extent, sensible and latent heat fluxes, affect the maximum temperature.

The figures that follow are time sections during the last 24 hours of the simulation. In 
Fig. 5-3 the potential temperature pattern shows surface-based stability throughout the PBL domain $(3000 \mathrm{~m}$ ) between 23 hours the preceding day to 9.5 hours the following morning. During this time, the stable temperature gradient within the lowest $200 \mathrm{~m}$ is less than that above. This is due to mechanical mixing from the strong gradient of wind (Fig. 5-4) that this stable regime generates near the surface. Figure 5-5 shows indeed, Richarủbcrs $\overline{\text { Iümanbez }}$ during this time exists within the mechanically mixed limits of $0 \leq R i \leq 0.2$, but turbulence is light and $K_{M}$ is below $5 \mathrm{~m}^{2} \mathrm{~s}^{-1}$ (Fig. 5-6). This mixing creates a downward (negative) turbulent heat flux with a maximum nearest the surface (Fig. 5-7).

As the surface temperature increases, a super-adiabatic surface layer begins at 9.5 hours, increasing the depth of a convectively mixed layer to $200 \mathrm{~m}$ by 15 hours. At this time, increased mixing by convection increases wind and shear near the surface, decreases $R i$ to below -0.5 , increases $K_{M}$ up to $20 \mathrm{~m}^{2} \mathrm{~s}^{-1}$, and reverses the turbulent heat flux. This turbulent layer lasts until 23 hours, when again the surface temperature decreases, and stability grows upward. The contours of negative heat flux above the convective PBL between 15 and 16 hours seems to be related to an inherent problem with the Level 2.5 scheme (Helfand and Labraga, 1988) in that rapidly growing or decaying turbulence is not fully realizable in this particular formulation. This will be discussed further in Section 6.2. The specific humidity trends (Fig. 5-8) follow those of potential temperature since we have specified relative humidity. Note that water content is rather low in this cool environment, even with RH at $80 \%$. Above $1000 \mathrm{~m}$ the water profile is almost constant at $\sim 2 \mathrm{~g} \mathrm{~kg}^{-1}$.

The radiative heating rate is shown in Fig. 5-9. Above the mixed layer, the pattern is symmetric, while the radiative heating rate within the mixed layer depicts the surface nighttime cooling or daytime PBL warming. The symmetry aloft suggests a stable daily pattern, although it is apparent radiative cooling is dominant. The daily averaged radiative, turbulent and total heating rate profiles (Fig. 5-10) show our criterion of equilibrium is met; the total heating rate (solid line) is within -0.1 to $0 \mathrm{~K} \mathrm{day}^{-1}$. Note that in the mixed layer, radiative (dashed line) and turbulent (dotted line) heating rates almost exactly balance. In the free atmosphere, the imposed average dynamical heating rate (line-dot) nearly balances the radiative heating rate such that our criterion for equilibrium in that region can be met.

Calculations from Oort (1983) suggest the energy transported northward across $70^{\circ} \mathrm{N}$ 


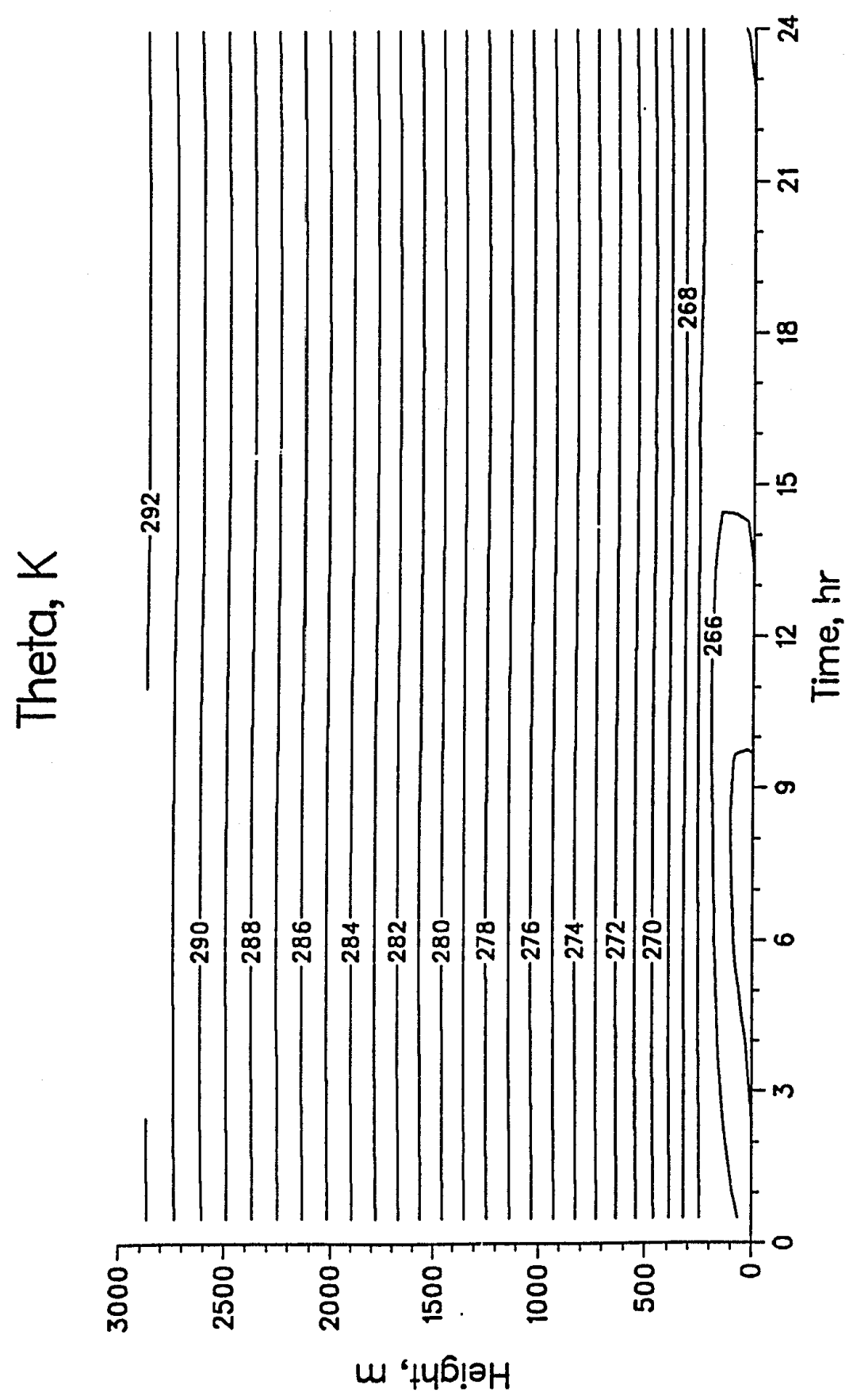

Figure 5-3: 24-hour time section of potential temperature (K) within the PBL domain for clear-sky equilibrium. Contours plotted every $1 \mathrm{~K}$. 


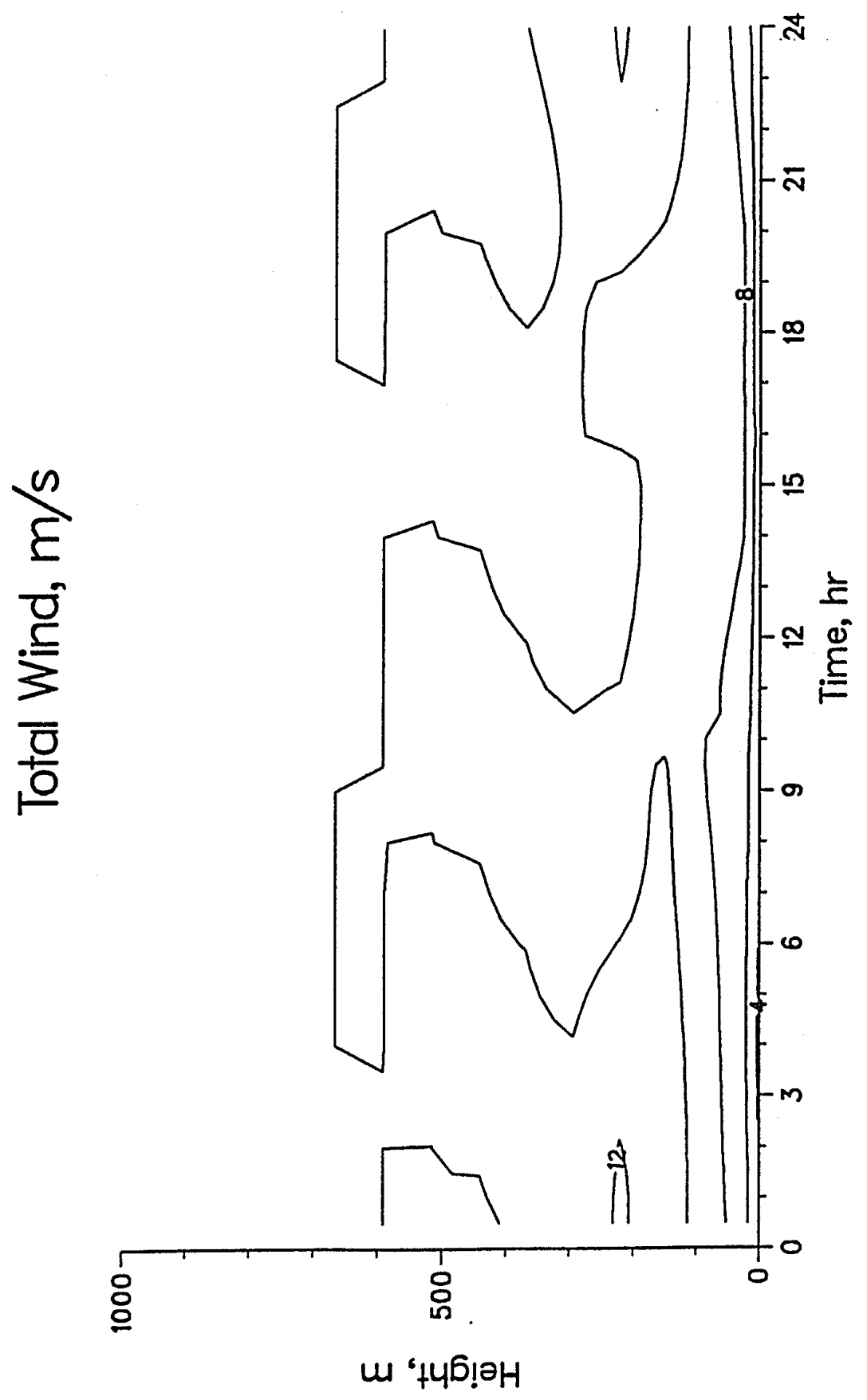

Figure 5-4: Same as Fig. 5-3, but for total wind $\left(\mathrm{ms}^{-1}\right)$. Contours plotted every $2 \mathrm{~ms}^{-1}$. 


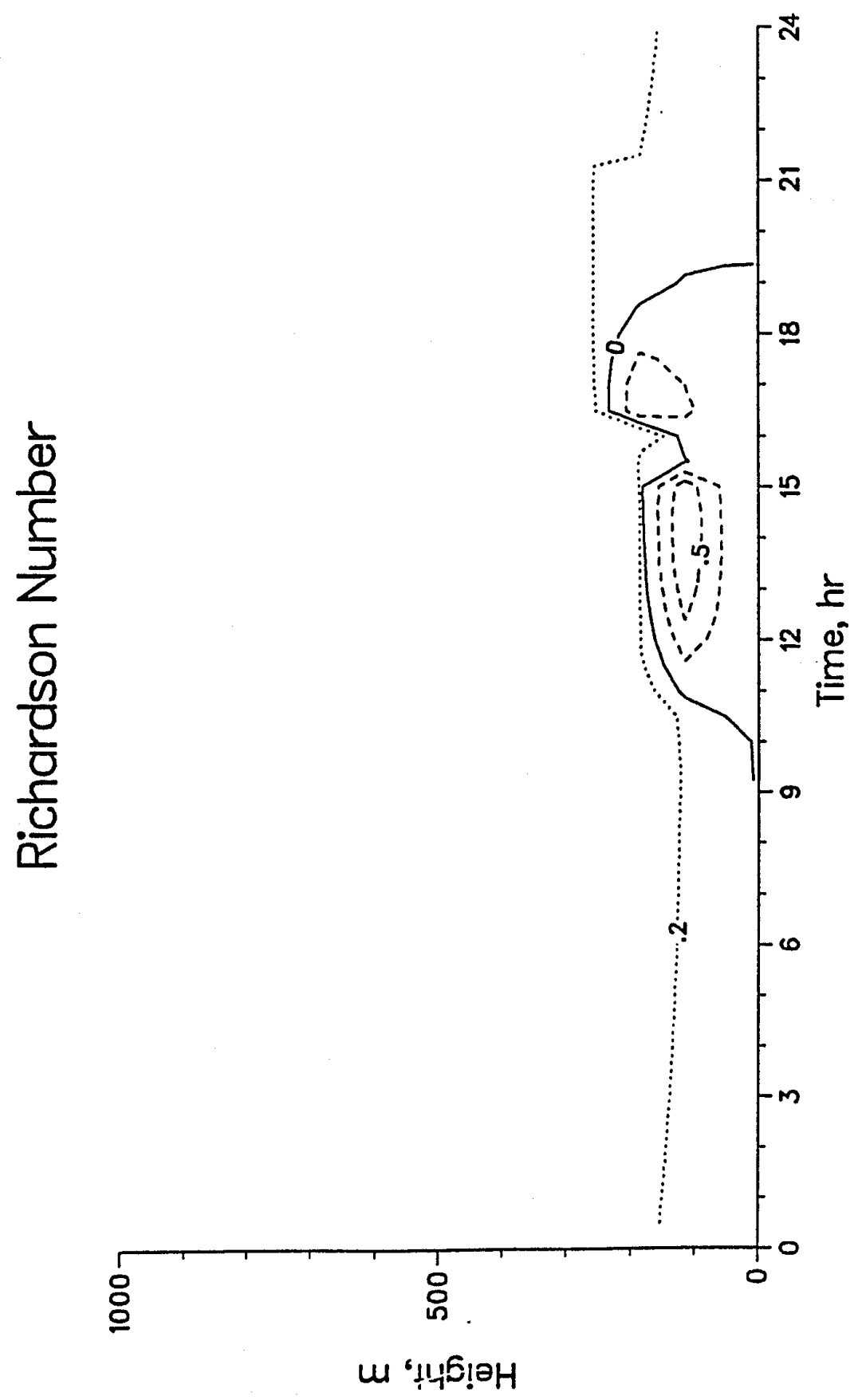

Figure 5-5: Same as Fig. 5-3, but for Richardson number. Dashed contours are negative, and the dotted contour is for $R i_{c}=0.2$. Contours plotted every 0.25 . 


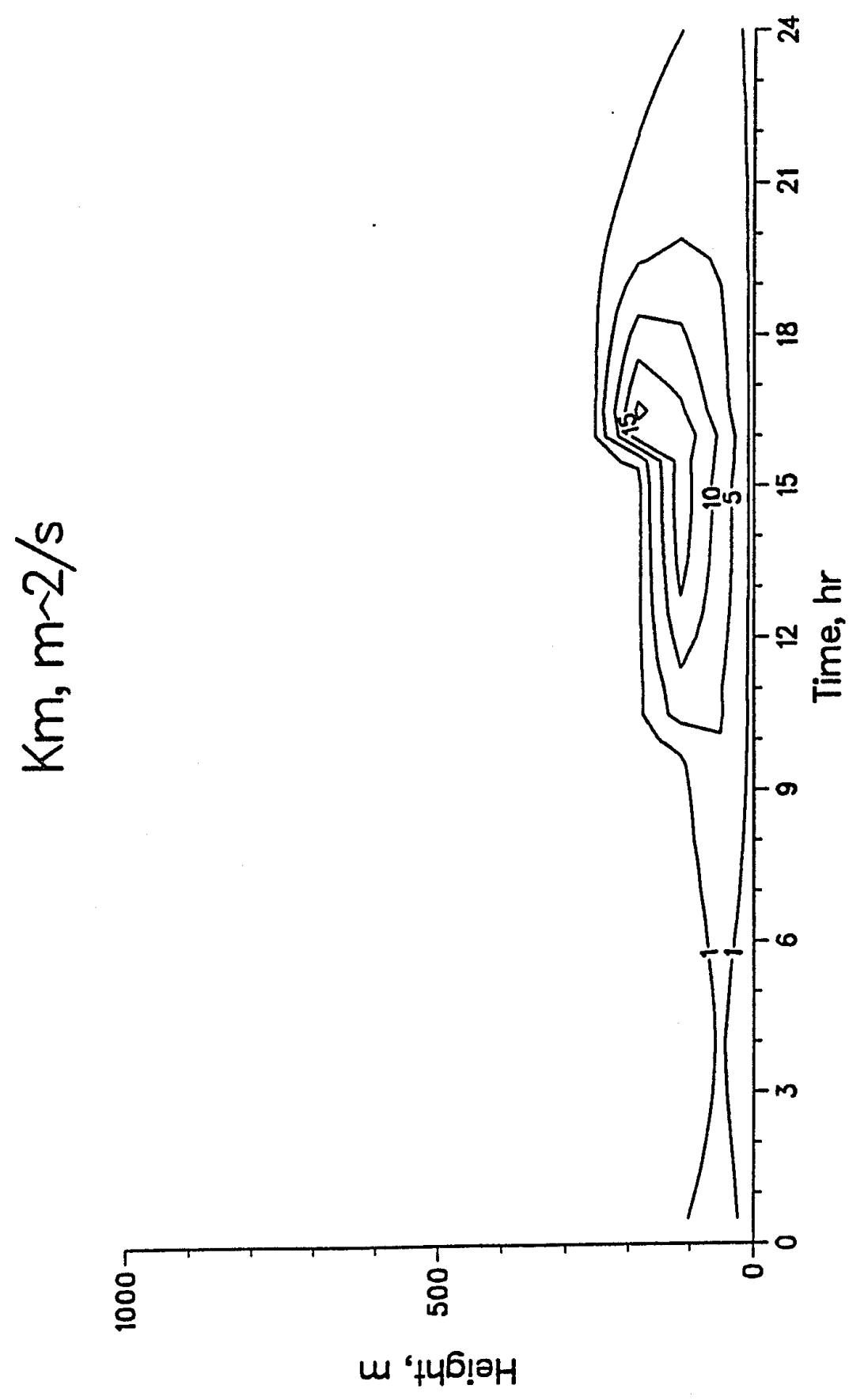

Figure 5-6: Same as Fig. 5-3, but for momentum diffusivity $\left(\mathrm{m}^{2} \mathrm{~s}^{-1}\right)$. Contours plotted every $5 \mathrm{~m}^{2} \mathrm{~s}^{-1}$. 


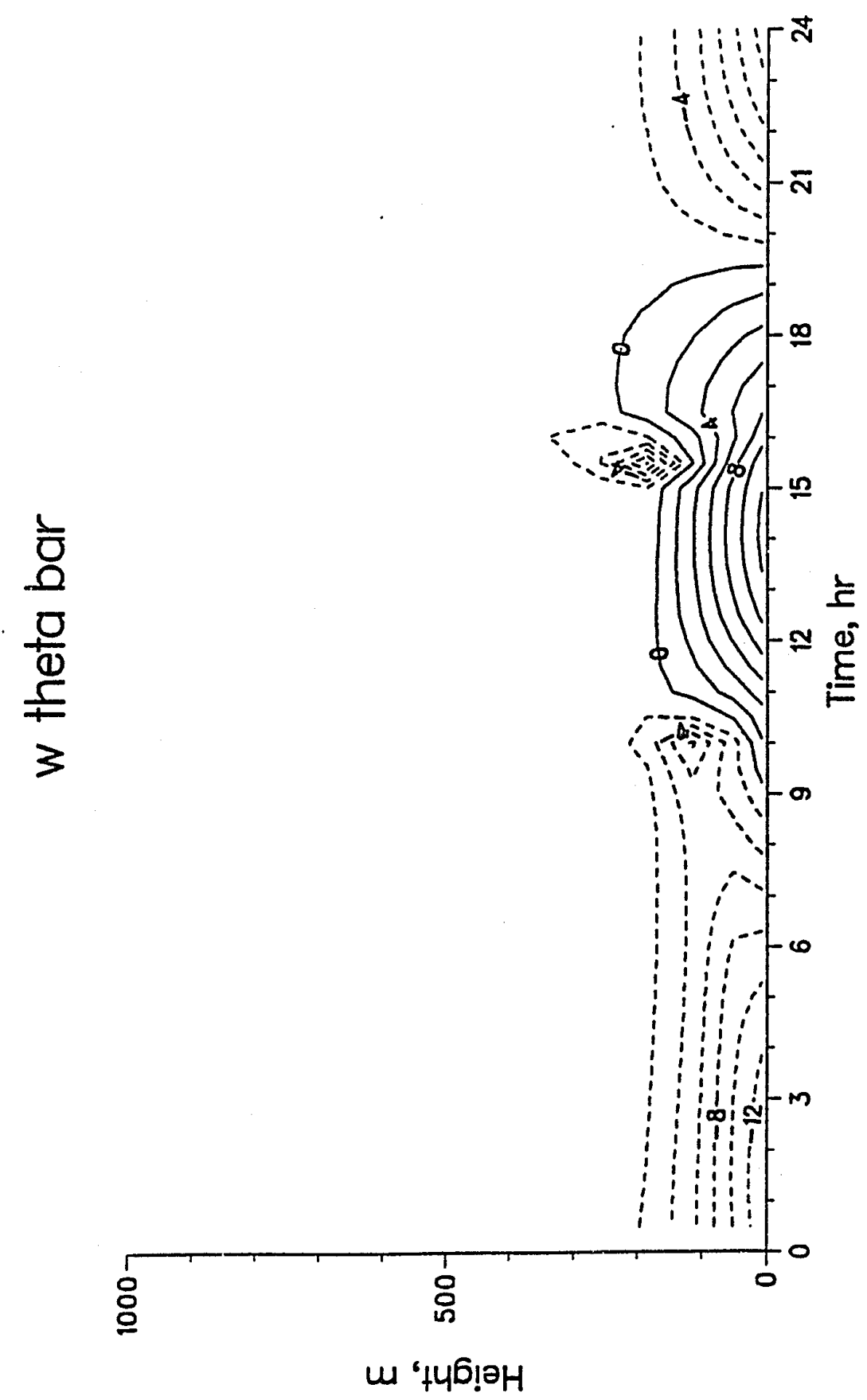

Figure 5-7: Same as Fig. 5-3, but for turbulent heat flux $\left(\mathrm{W} \mathrm{m}^{-2}\right)$. Positive contours are solid, negative contours are dashed, and they are plotted every $2 \mathrm{~W} \mathrm{~m}^{-2}$. 


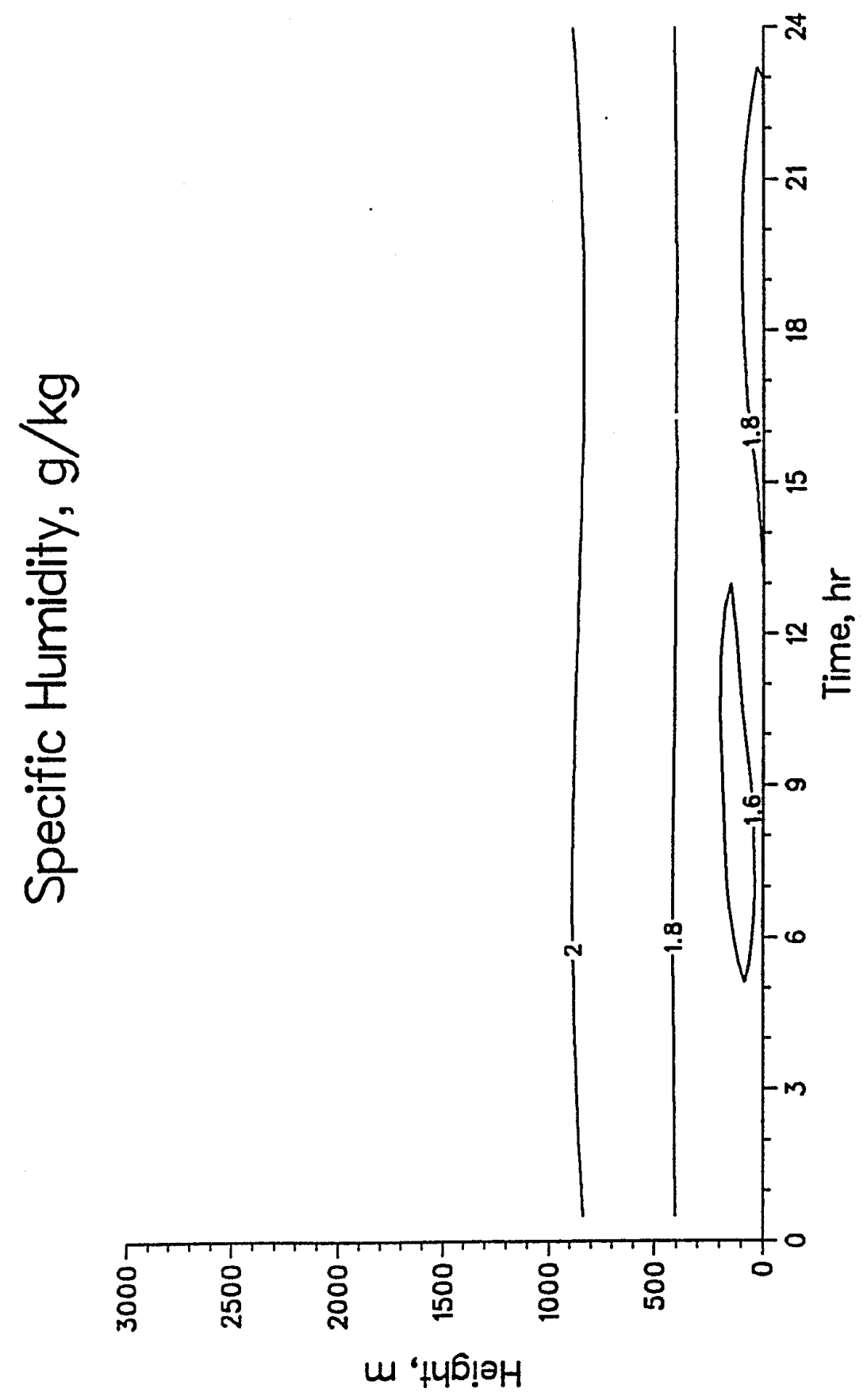

Figure 5-8: Same as Fig. 5-3, but for specific humidity $\left(\mathrm{g} \mathrm{kg}^{-1}\right)$. Contours plotted every 0.2 $\mathrm{g} \mathrm{kg}^{-1}$. 


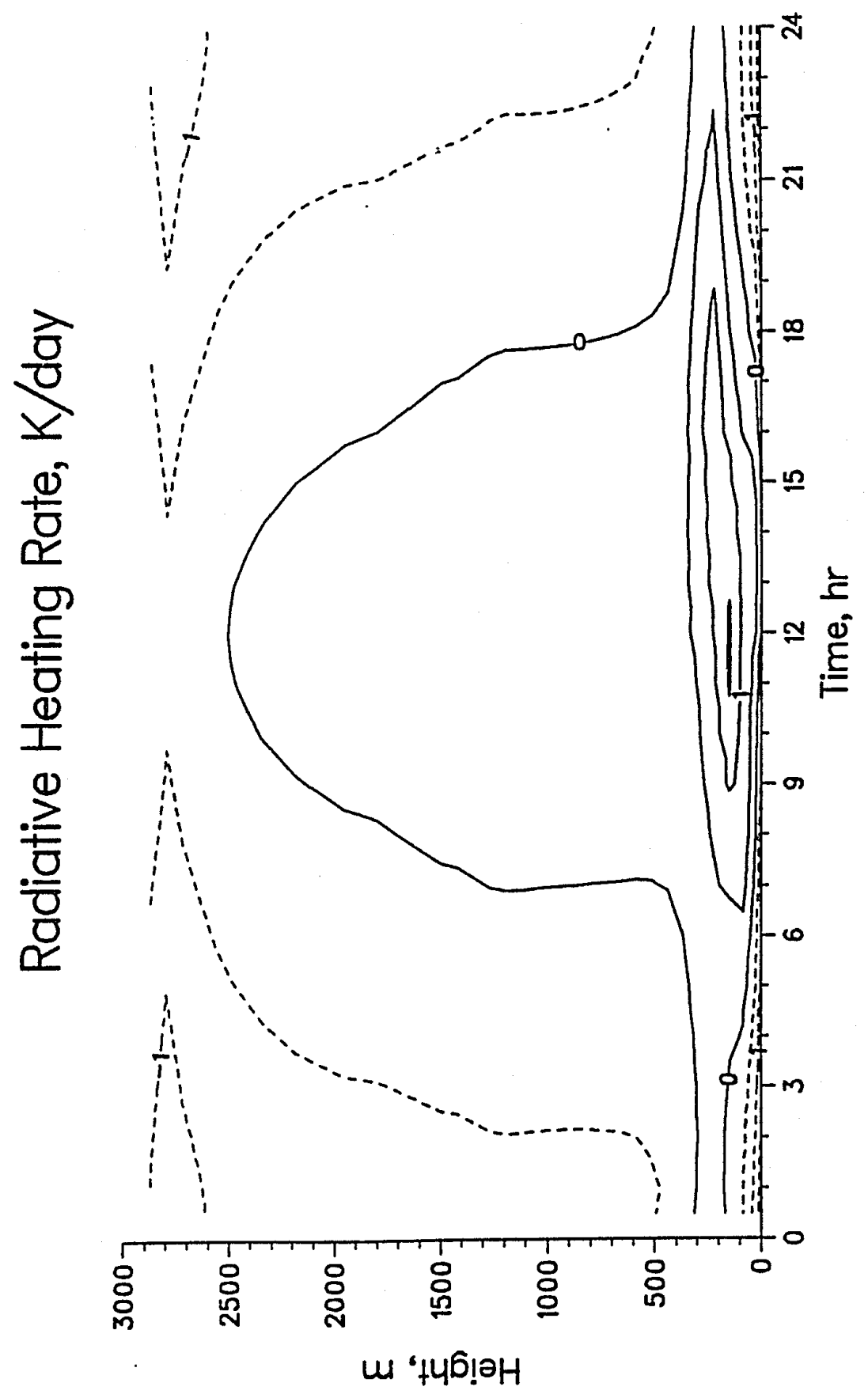

Figure 5-9: Same as Fig. 5-3, but for radiative heating rate $\left(\mathrm{K} \mathrm{day}^{-1}\right)$. Contours plotted every $0.5 \mathrm{~K} \mathrm{day}^{-1}$. 


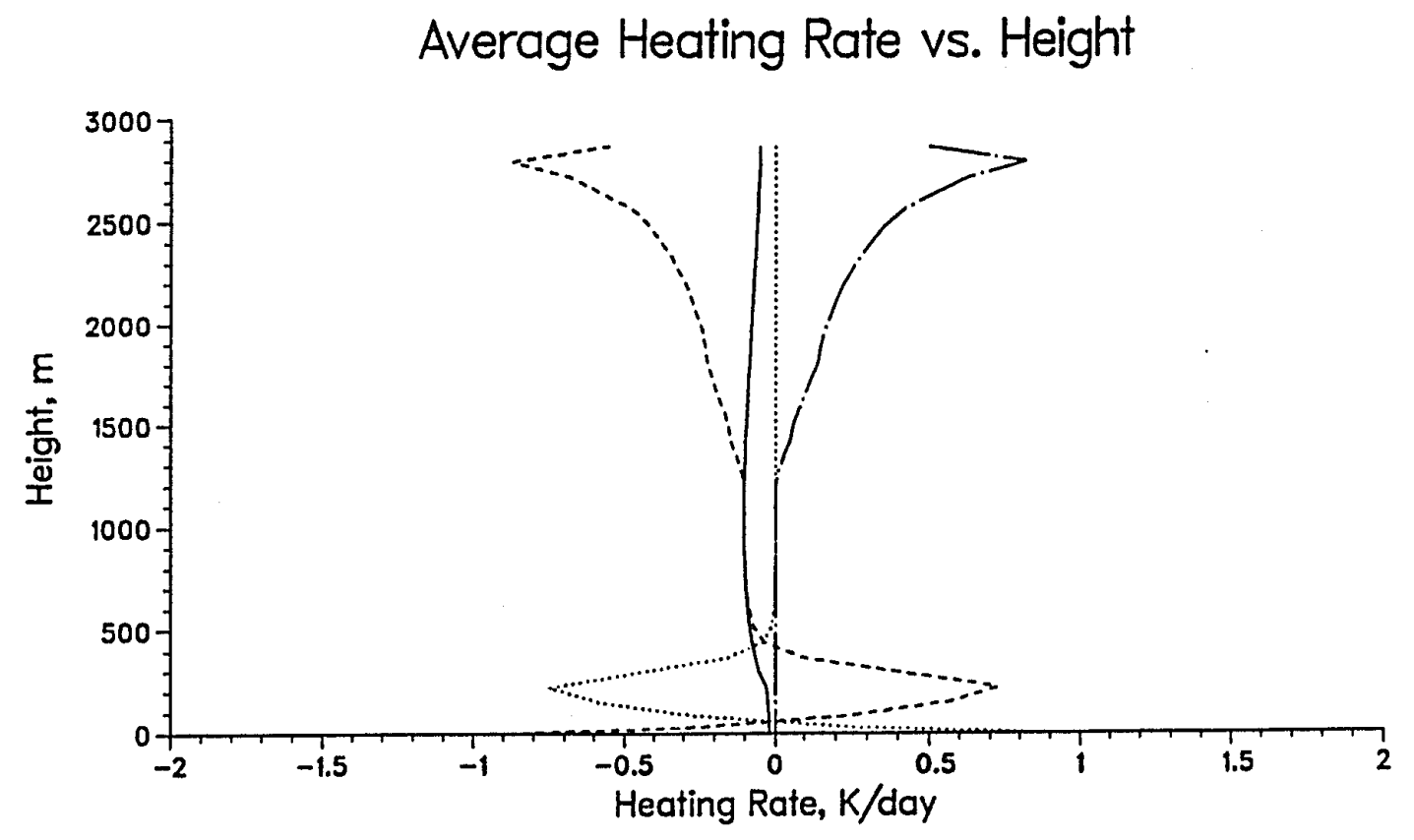

Figure 5-10: Daily averaged clear-sky equilibrium profiles of total (solid), radiative (dashed), turbulent (dotted), and imposed dynamic (line-dot) heating rates ( $\mathrm{K} \mathrm{day}^{-1}$ ) for the PBL domain. 
during the spring months by transient and standing eddies and mean meridional motions average $66 \mathrm{~W} \mathrm{~m}^{-2}$. From Table 5-1 (Surface-atmosphere) it is deduced that for equilibrium, heat lossed by radiation $\left(24.7 \mathrm{~W} \mathrm{~m}^{-2}\right)$ must be balanced by heat gained from the ocean through the ice $\left(2.2 \mathrm{~W} \mathrm{~m}^{-2}\right)$ and the dynamic heating rate profile. Therefore, the profile of $\dot{Q}_{D}$ corresponds to a horizontal flux of $Q_{D}=22.5 \mathrm{~W} \mathrm{~m}^{-2}$ for equilibrium, about a third lower than Oort's value. This is consistent with the discussion in Section 4.6, where it was noted the average dynamic heating rate is about $0.4 \mathrm{~K}$ day $^{-1}$, lower than GCM results reporting about $0.6 \mathrm{~K} \mathrm{day}^{-1}$. Considering the observed atmospheric structure and surface heat balance are impacted by several factors that this model does not take into account (e.g. effects from clouds, heat flux from open water, absorption of solar radiation below the snow surface, and changing synoptic state), the conditions selected for the control run lead to a satisfactorily representative Arctic environment.

\subsubsection{Hazy Atmosphere}

From the clear equilibrium conditions, the model was continued with the haze until a new equilibrium was achieved. Table 5-1 also lists the 24-hour average radiative and turbulent heat fluxes for haze equilibrium. Daily average surface temperature has increased by 0.7 K. The increases in $I^{N}$ and $Q_{H}$ are the only positive gains in the average surface energy budget. The reduction of net solar absorption $S^{N}$ is almost balanced by the gain in $I^{N}$ such that the net radiation gain at the surface $R^{N}$ decreases by $0.3 \mathrm{~W} \mathrm{~m}^{-2}$. The diurnal temperature range for both the air and surface (Fig. 5-11) is damped to about $2.3 \mathrm{~K}$. This damping, coupled to increases throughout the day of $I^{N}$ and $Q_{H}$, positively shifts the entire temperature wave throughout 24 hours.

The changes in surface heat fluxes due to haze are shown in Fig. 5-12. It clearly shows the significant reduction in solar absorption between hours 6 and 18 just about counterbalance the daylong increase in absorbed downward IR from the warmer atmosphere. The change in conductive heat flux shows variation around zero, meaning the daily variation of this flux is slightly damped. The change in latent heat flux, on the other hand, remains more negative throughout the day. The sudden jumps in both latent and conductive fluxes at hours 9 and 18 appear to be related to a change in time that the surface heat balance moves between 


\section{Change in Ta and Ts}

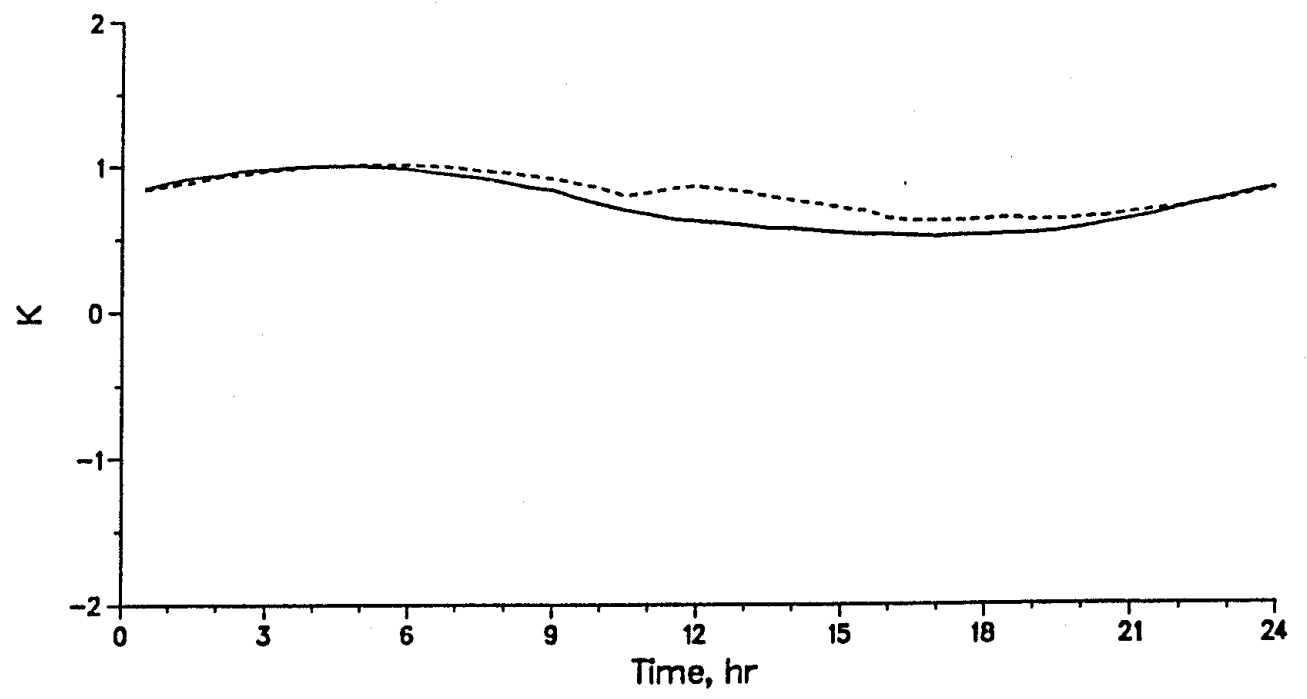

Figure 5-11: The haze-induced change in equilibrium temperature trend (K) at the surface (solid) and at $1 \mathrm{~m}$ above the surface (dashed).

stable and unstable regimes (these correspond to the different times that $R i$ moves between stable and unstable values in Fig. 5-5 and Fig. 5-14). The only other flux that remains positively changed during the entire day is sensible heat. During the daytime, changes to $S^{N}$ and $I^{N}$ are roughly comparable, so daytime radiative forcing is relatively unchanged. During the night, however, the radiative forcing is positively changed by $I^{N}-$ thus the diurnal damping of the net radiative heat flux is responsible for damping the temperature wave. Damping of the temperature wave in turn leads to damping the wave of conductive flux.

In the atmosphere a daily mean of about $42 \mathrm{~W} \mathrm{~m}^{-2}$ more solar energy is absorbed by the haze ( $S^{N}$ in Table 5-1). The warming caused by solar absorption during the interration to equilibrium has heated the free atmosphere, increasing average atmospheric IR emission by almost $30 \mathrm{~W} \mathrm{~m}^{-2}$. Since the bulk of the haze is placed near the surface, the surface gains most of the increased IR emitted from the atmosphere - about $21 \mathrm{~W} \mathrm{~m}^{-2}$ (see $I^{\dagger}$ at surface). This is nearly twice the increased IR to space where $I^{\dagger}$ at the top of the model has increased by only $12 \mathrm{~W} \mathrm{~m}^{-2}$ (see $I^{\dagger}$ for surface-atmosphere system). 


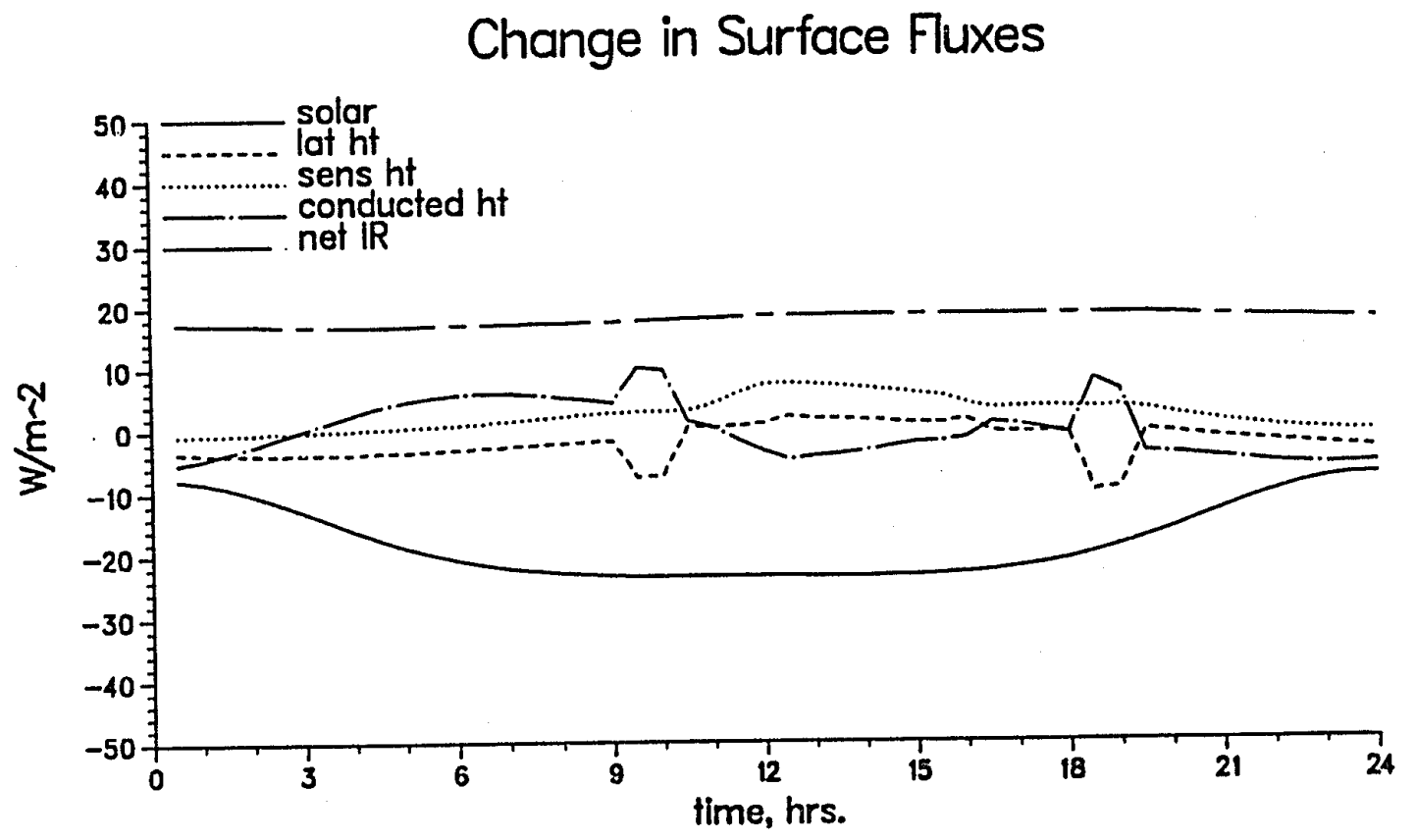

Figure 5-12: The haze-induced change in surface fluxes $\left(\mathrm{W} \mathrm{m}^{-2}\right)$ of net solar (solid), net IR (line-dash), sensible heat (dotted), latent heat (dashed), and conducted heat (line-dot). A gain of heat is postive. 
The atmospheric solar heating is not enough to reverse radiative cooling of the atmosphere. The daily average net radiation emitted from the atmosphere is reduced $12.5 \mathrm{~W} \mathrm{~m}^{-2}$ to $-35.1 \mathrm{~W} \mathrm{~m}^{-2}$. Hence, without imposed dynamical heating, the atmosphere would cool despite a gain of energy by the haze. With the dynamical heating from the clear case retained, however, the atmosphere warms.

The consequences of heating the atmosphere while holding the surface temperature relatively constant should lead to increased static stability. This is clearly the case when the plot of potential temperature is considered (Fig. 5-13). Heating by as much as $14 \mathrm{~K}$ at $2000 \mathrm{~m}$ and less than $1 \mathrm{~K}$ within the mixed layer has considerably stratified the lower troposphere. The mixed layer depth is compressed to about $100 \mathrm{~m}$, half the depth of the clear case, and exhibits more stability as $R i$ gets to just below 0 during the afternoon (Fig. 5-14). The shallower mixed layer inhibits the turbulent mixing of momentum ( $K_{M}$ is only 5-10 $\mathrm{m}^{2} \mathrm{~s}^{-1}$ during the afternoon, not shown), which in turn creates more shear near the surface and increases the value of windspeed just above the surface (not shown). Coupled to larger vertical gradient of temperature, turbulent flux of heat toward the surface is amplified during the night and morning - the increased stability during the afternoon reduces upward heat flux (compare Fig. 5-7 with Fig. 5-15). The net effect, as shown in Table 5-1 (Surface), is to increase the turbulent flux of heat toward the surface over the day.

When the atmosphere is heated as much as shown in Fig. 5-13, specific humidity for haze equilibrium (Fig. 5-16) shows over a two-fold increase in the actual amount of water vapor the atmosphere can hold. This relative humidity constraint leads to a considerable impact on longwave emissivity. An increase in atmospheric water vapor content will increases IR emission independent of atmospheric warming; we identify this as a very important part of the longwave feedback. Coupled to atmospheric warming, the relative humidity constraint produces a more significant negative longwave feedback on the surface heat budget. This will be shown more clearly in Section 5.2.

The variation throughout the day of radiative heating rate (Fig. 5-17) shows more than $1 \mathrm{~K} \mathrm{day}^{-1}$ heating at the level of maximum haze concentration. In this figure, warming and cooling aloft appear more balanced than for the clear case, and again, the symmetric 


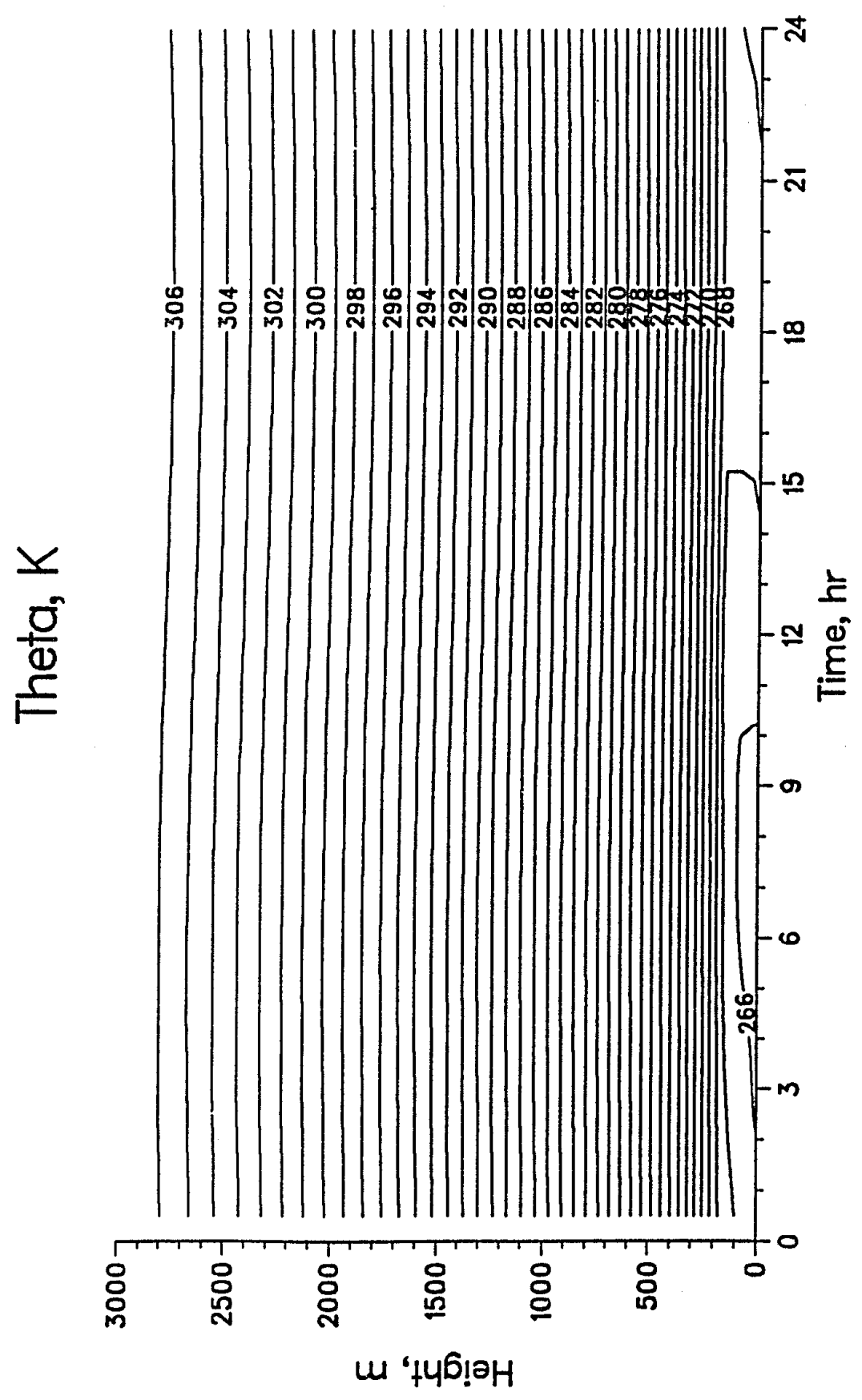

Figure 5-13: 24-hour time section of potential temperature $(K)$ within the PBL domain for haze equilibrium. Contours plotted every $1 \mathrm{~K}$. 


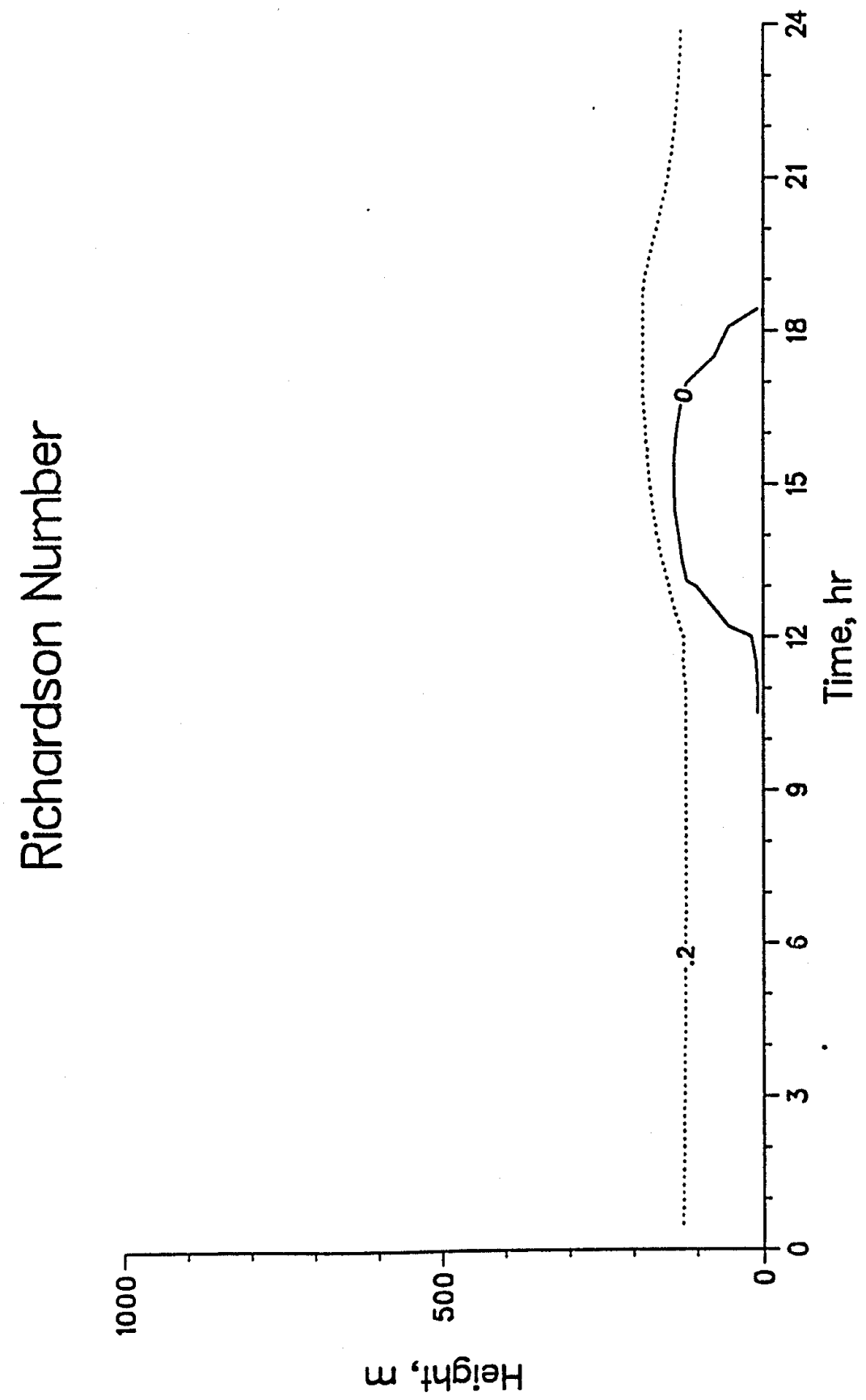

Figure 5-14: Same as Fig. 5-13, but for Richardson number. Dashed contours are negative, and the dotted contour is for $R i_{c}=0.2$. Contours plotted every 0.25 . 




Figure 5-15: Same as Fig. 5-13, but for turbulent heat flux $\left(\mathrm{W} \mathrm{m}^{-2}\right)$. Positive contours are solid, negative contours are dashed, and they are plotted every $2 \mathrm{~W} \mathrm{~m}^{-2}$. 


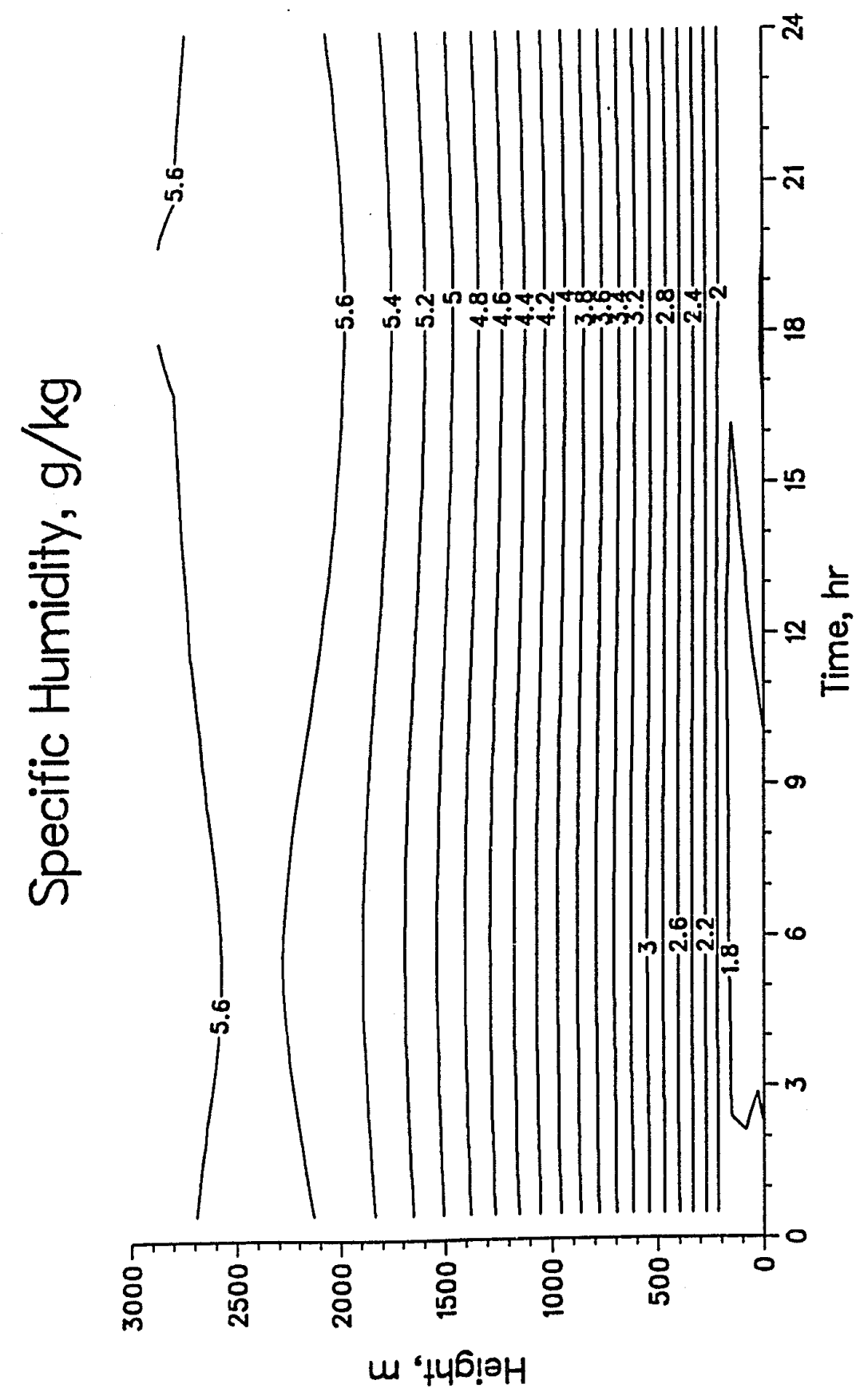

Figure 5-16: Same as Fig. 5-13, but for specific humidity $\left(\mathrm{g} \mathrm{kg}^{-1}\right)$. Contours plotted every $0.2 \mathrm{~g} \mathrm{~kg}^{-1}$. 


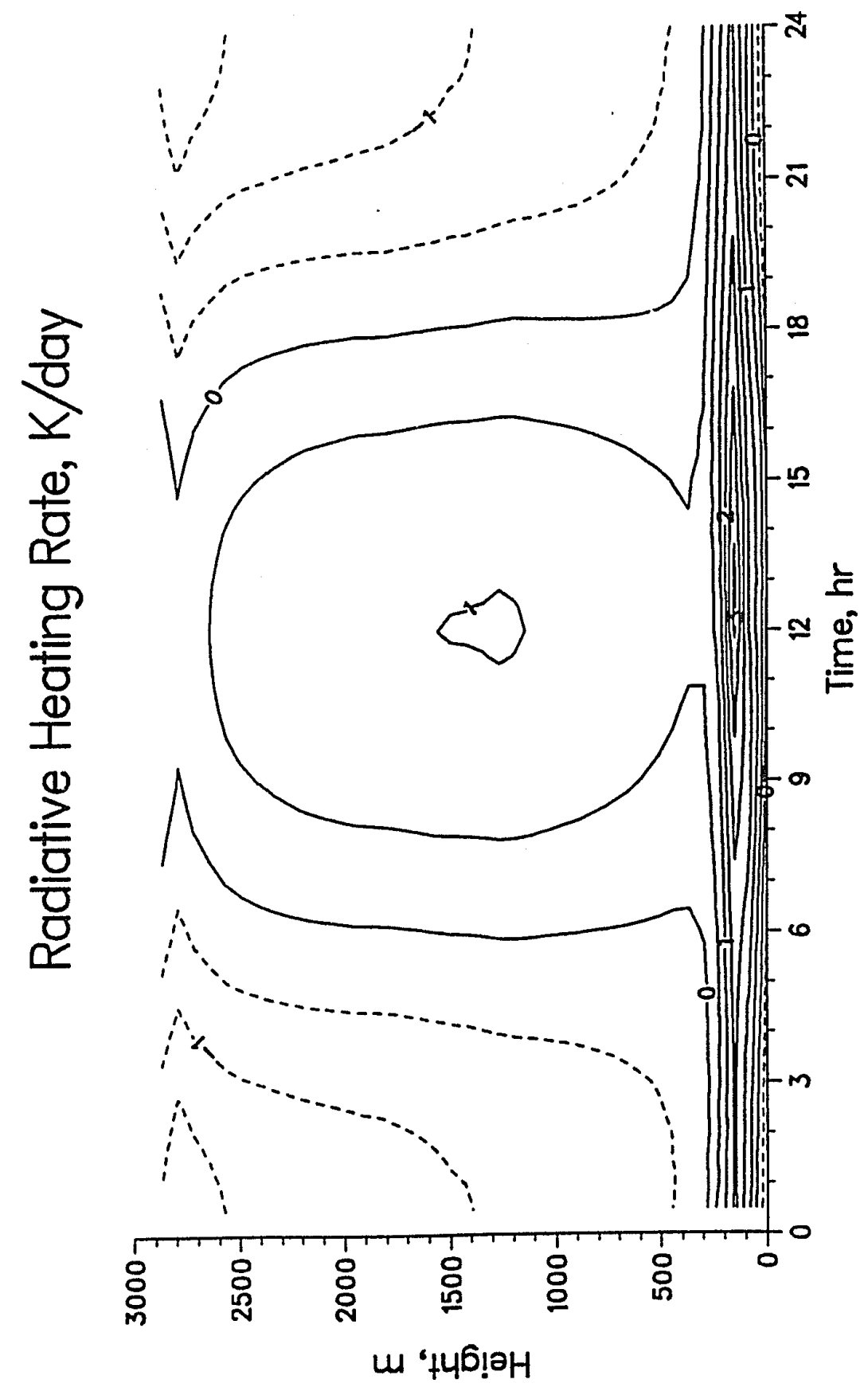

Figure 5-17: Same as Fig. 5-13, but for radiative heating rate $\left(\mathrm{K} \mathrm{day}^{-1}\right)$. Contours plotted every $0.5 \mathrm{~K} \mathrm{day}^{-1}$. 


\section{Average Heating Rate vs. Height}

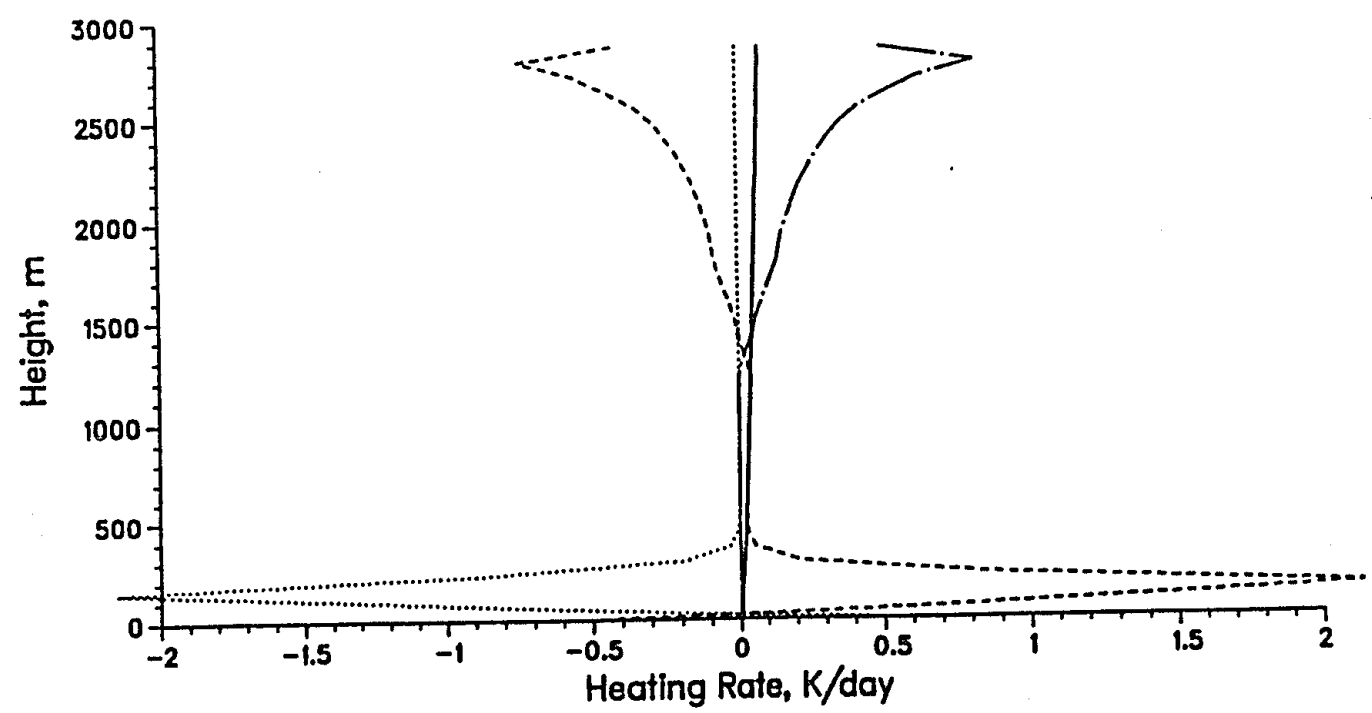

Figure 5-18: Daily averaged haze equilibrium profiles of total (solid), radiative (dashed), turbulent (dotted), and imposed dynamic (line-dot) heating rates ( $\mathrm{K} \mathrm{day}^{-1}$ ) for the PBL domain.

pattern indicates a stable daily pattern of warming and cooling. When averaged over the day, the total heating rate is shown to satisfy our equilibrium conditions, averaging about $0.05 \mathrm{~K} \mathrm{day}^{-1}$ within the PBL domain (Fig. 5-18). As with the clear case, equilibrium in the mixed layer is attained from the balance between turbulent cooling and radiative warming; with a more stable lower troposphere, these heating/cooling rates are amplified by almost a factor of 2. Equilibrium in the free atmosphere is attained from either a zero radiative heating rate or from a balance between radiative cooling and "dynamic" heating.

\subsection{Constant Specific Humidity vs. Relative Humidity}

A similar case was run with the representative specific humidity profile discussed in Section 4.6 to better isolate IR feedback due to water vapor. In this case, the profile represents a more realistic water vapor profile, typifying a humid lower Arctic troposphere capped by a dry mid- and upper-troposphere. Again, both clear and haze conditions were run out to equilibrium, but the specific humidity profile was held constant in time, so when haze 
forced atmospheric warming, the amount of water vapor remained constant. Daily averaged equilibrium surface temperature, planetary albedo, surface turbulent fluxes, and radiative fluxes are given in Table 5-2 .

The specific humidity approach leads to a higher clear equilibrium average surface temperature of $269.2 \mathrm{~K}$ (Table 5-2, Clear). There are two major reasons for this: (1) increased solar absorption by the surface, and (2) less latent heat flux from the surface. The atmosphere holds much less water for the specific humidity profile than for the constant relative humidity profile at $80 \%$ - this allows more solar radiation to pass through the atmosphere, as evidenced by the slightly higher planetary albedo. The daily range of latent heat flux increases from about $20 \mathrm{~W} \mathrm{~m}^{-2}$ for the relative humidity case, to almost $60 \mathrm{~W} \mathrm{~m}^{-2}$ - this greater range $\left(+13\right.$ to $\left.-44 \mathrm{~W} \mathrm{~m}^{-2}\right)$ leads to a lower daily average flux of latent heat from the surface. Also of interest to note is the fact that the atmosphere loses more net radiant energy $\left(R^{N}=-51.6 \mathrm{~W} \mathrm{~m}^{-2}\right)$ since less water vapor decreases the greenhouse effect.

When the model is integrated to haze equilibrium, we find the daily averaged surface temperature has cooled to $269.0 \mathrm{~K}$ (Table 5-2, Haze). Upon examination of the daily averaged surface heat balance, it is apparent the much larger net decrease in radiant energy of $-6.8 \mathrm{~W} \mathrm{~m}^{-2}$ is offset by an increased absorption of all three non-radiant fluxes. The deficit in radiation over the day, however, apparently dominates the other fluxes such that slight surface cooling results on average. In this case, the net IR increase from the warmer, but dryer, atmosphere cannot sufficiently balance the loss of solar absorption at the surface.

In the atmosphere, the haze-induced increase in solar absorption is about $30 \mathrm{~W} \mathrm{~m}^{-2}$, which is less than that for the relative humidity case. The warmer atmosphere increases IR emission by only $17.6 \mathrm{~W} \mathrm{~m}^{-2}$ which is also less than the previous case. An interesting point is that the increased upward IR flux to space $\left(10.6 \mathrm{~W} \mathrm{~m}^{-2}\right)$ is about twice the increase of downward IR flux to the surface $\left(5.7 \mathrm{~W} \mathrm{~m}^{-2}\right)-$ a complete reversal in the direction of IR propagation from the atmosphere. This damping of atmospheric solar absorption and IR emission with respect to the relative humidity case, however, balances such that the net increase of radiation gained by the atmosphere is $12.7 \mathrm{~W} \mathrm{~m}^{-2}$, nearly identical to the increase of $12.5 \mathrm{~W} \mathrm{~m}^{-2}$ for the relative humidity case. So for this model IR (and to a lesser extent solar) perturbations due to haze are sensitive to the degree of water vapor feedback. 
Table 5-2: Same as in Table 5-1, except for the case when constant (in time) specific humidity from the initial dewpoint profile is specified.

\begin{tabular}{|c|c|c|c|}
\hline & Clear & Hase & Difference \\
\hline \multicolumn{4}{|c|}{ Surface } \\
\hline$T$ & 269.2 & 269.0 & -0.2 \\
\hline$s^{\downarrow}$ & 356.6 & 317.2 & -39.4 \\
\hline$S^{\dagger}$ & 231.8 & 206.2 & -25.6 \\
\hline$S^{N}$ & +124.8 & +111.0 & -13.8 \\
\hline$I^{\downarrow}$ & 186.6 & 192.3 & +5.7 \\
\hline$I^{\dagger}$ & 297.6 & 296.3 & -1.3 \\
\hline$I^{N}$ & -111.0 & -104.0 & +7.0 \\
\hline$R^{N}$ & +13.8 & +7.0 & -6.8 \\
\hline$Q_{H}$ & +1.6 & +4.3 & +2.7 \\
\hline$Q_{L}$ & -15.9 & -11.9 & +4.0 \\
\hline$Q_{c}$ & +0.7 & +0.8 & +0.1 \\
\hline \multicolumn{4}{|c|}{ Surface-Atmosphere } \\
\hline$A_{\mathrm{p}}$ & 0.547 & 0.513 & -0.034 \\
\hline$s^{\downarrow}$ & 448.6 & 448.6 & 0 \\
\hline$S^{\top}$ & 244.9 & 228.4 & -16.5 \\
\hline$S^{N}$ & +203.7 & +220.3 & +16.5 \\
\hline$I^{\dagger}$ & 241.5 & 252.1 & +10.6 \\
\hline$I^{N}$ & -241.5 & -252.1 & -10.6 \\
\hline$R^{N}$ & -37.8 & -31.9 & +5.9 \\
\hline$Q_{c}$ & +0.7 & +0.8 & +0.1 \\
\hline$Q_{D}$ & +37.1 & +37.1 & 0 \\
\hline \multicolumn{4}{|c|}{ Atmosphere } \\
\hline$S^{N}$ & +78.9 & +109.3 & +30.4 \\
\hline$I^{N}$ & -130.5 & -148.1 & -17.6 \\
\hline$R^{N}$ & -51.6 & -38.9 & +12.7 \\
\hline$Q_{H}$ & -1.6 & -4.3 & -2.7 \\
\hline$Q_{L}$ & +15.9 & +11.9 & +4.0 \\
\hline$Q_{D}$ & +37.1 & +37.1 & 0 \\
\hline
\end{tabular}


This dryer case suggests warming of the atmosphere will increase IR to the surface, but the bulk of the increased IR will escape to space due to the relative absence of water vapor. The IR to the surface cannot balance the reduction in absorbed solar radiation, and the surface cools.

\subsection{Sensitivity Studies}

\subsubsection{Effect of Relative Humidity}

Sections 5.1 and 5.2 clearly suggest the model system is sensitive to how much water vapor exists in the atmoshere, and to the way in which the time and spatial variation of water vapor is handled. To better expand this sensitivity analysis, three more integrations with constant relative humidity of 60,70 , and $90 \%$ were performed to both clear and haze equilibrium conditions. All other parameter values were consistent with the control run. In all heat flux figures that follow, positive fluxes (or changes in fluxes) represent a gain of heat, and negative values represent a loss.

In the first part of this analysis, the daily averaged clear-equilibrium surface temperature $T_{a}$ as a function of RH is discussed. Keep in mind that changes to certain components that can be considered temperature-independent force a change in surface temperature, while the temperature-dependent components change to maintain the balance. It can be argued most components have some dependency on $T_{n}$, no matter how small or how indirect. The distinction between temperature-dependence and independence is made, however, to simply identify and qualify the components most responsible for temperature change.

The temperature-independent fluxes are the net surface solar absorption $Q_{S}$, the absorbed downward longwave radiation from the atmosphere $Q_{I}^{\downarrow}$, and the latent heat flux $Q_{L}$. The temperature-dependent fluxes are the emitted upward longwave radiation $Q_{I}^{\dagger}$ and conduction through the ice $Q_{C}$. Sensible heat $Q_{H}$, and to a lesser extent latent heat, complicate the analysis because these fluxes contain $T$, terms, but are more dependent on the surfaceatmospheric interactions, which are in turn dependent on how surface temperature affects local stability. Sensible heat can show remarkable changes with $T_{s}$ in a convectively coupled surface-atmosphere system. In this case, surface-based stability prevails and decouples the surface from the atmosphere. If the difference between atmospheric and surface conditions 


\section{Ts vs. RH}

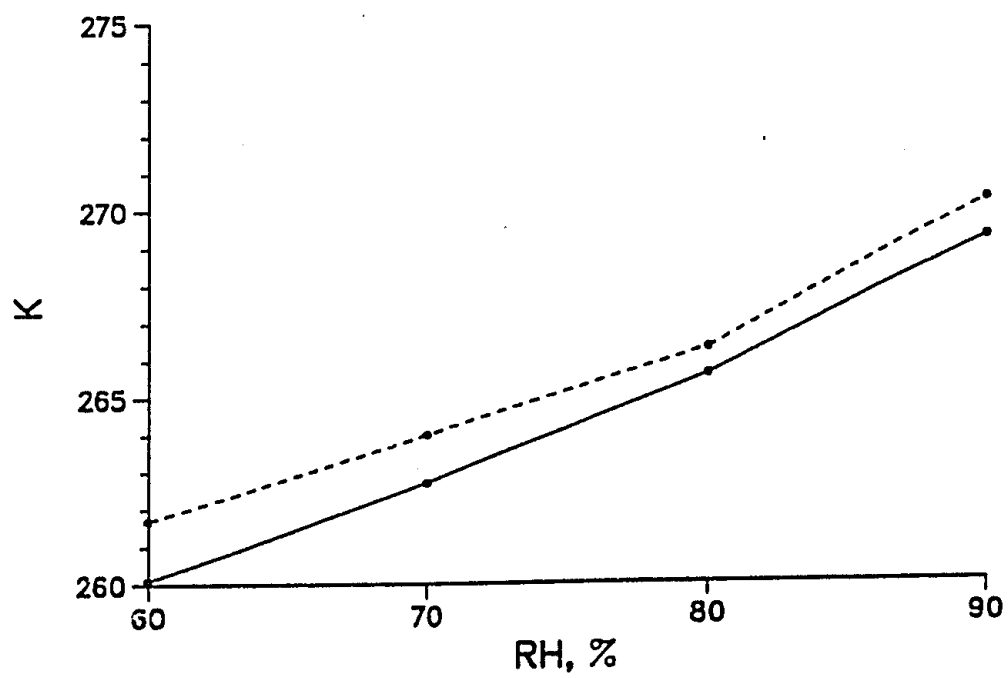

Figure 5-19: Clear (solid) and haze (dashed) daily-averaged equilibrium surface temperature (K) as a function of relative humidity.

remain fairly constant in a stable regime, sensible heat may not change significantly over a wide range of $T_{0}$. Hence in this case, $Q_{B}$ can primarily be considered, in a cautious sense, temperature-independent.

Figure 5-19 shows the daily averaged clear equilibrium $T$, as a function of RH (solid line). Surface temperature under clear conditions shows a fairly linear increase with humidity. In Fig. 5-20 solar absorption by the surface $Q_{S}$ (solid) under clear skies decreases very slightly from 60 to $90 \% \mathrm{RH}$ because as humidity increases, the atmosphere can absorb more solar energy. This is also evident in Fig. 5-21, which shows clear-sky planetary albedo $A_{p}$ as a function of RH (solid line). As the water vapor content increases, both upward and downward soiar streams are increasingly attenuated, reducing the planetary albedo by about $1 \%$. Downward longwave radiation absorbed by the surface $Q \frac{1}{I}$ (not shown) increases as $\mathrm{RH}$ is raised. The net IR at the surface $Q_{I}$ (Fig. 5-20, dashed line) suggests IR emitted by the surface $Q_{I}^{\dagger}$ dominates over IR absorption; $Q_{I}$ is reduced with higher $\mathrm{RH}$ due to the higher surface temperature.

Latent heat released by the surface $Q_{L}$ (Fig. 5-22, dashed line) decreases while sensible 


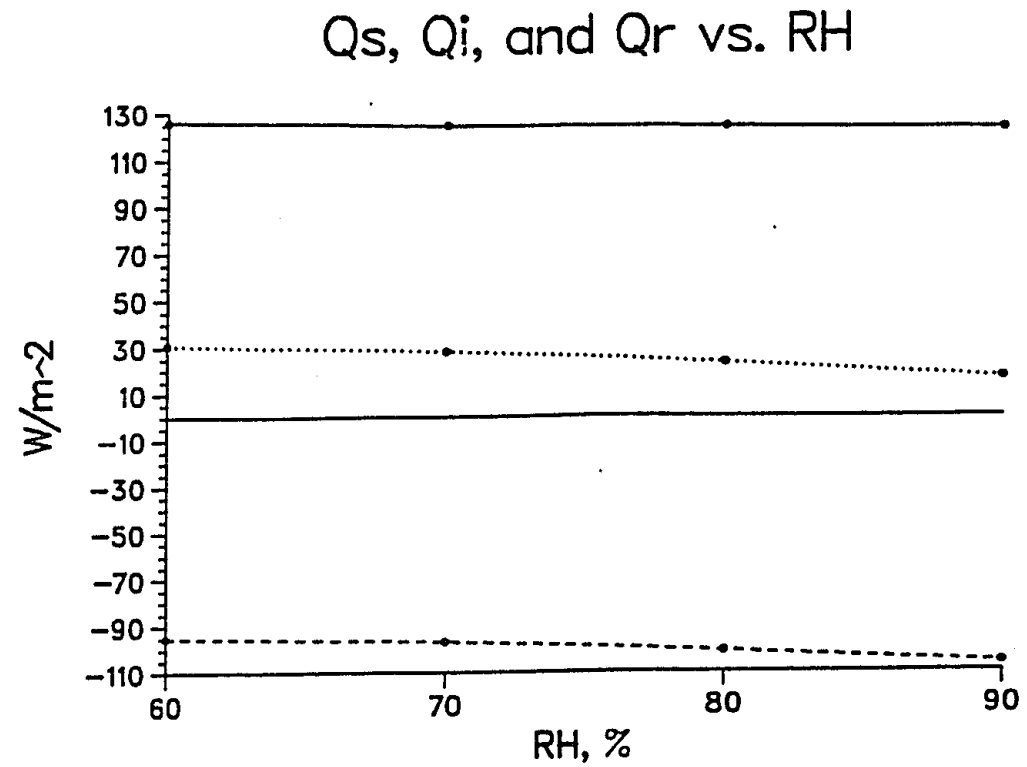

Figure 5-20: Clear equilibrium surface fluxes $\left(\mathrm{W} \mathrm{m}^{-2}\right)$ of net solar (solid), net IR (dashed) and net radiation (dotted) as a function of relative humidity. Positive indicates surface absorption.

Planetary albedo vs. RH

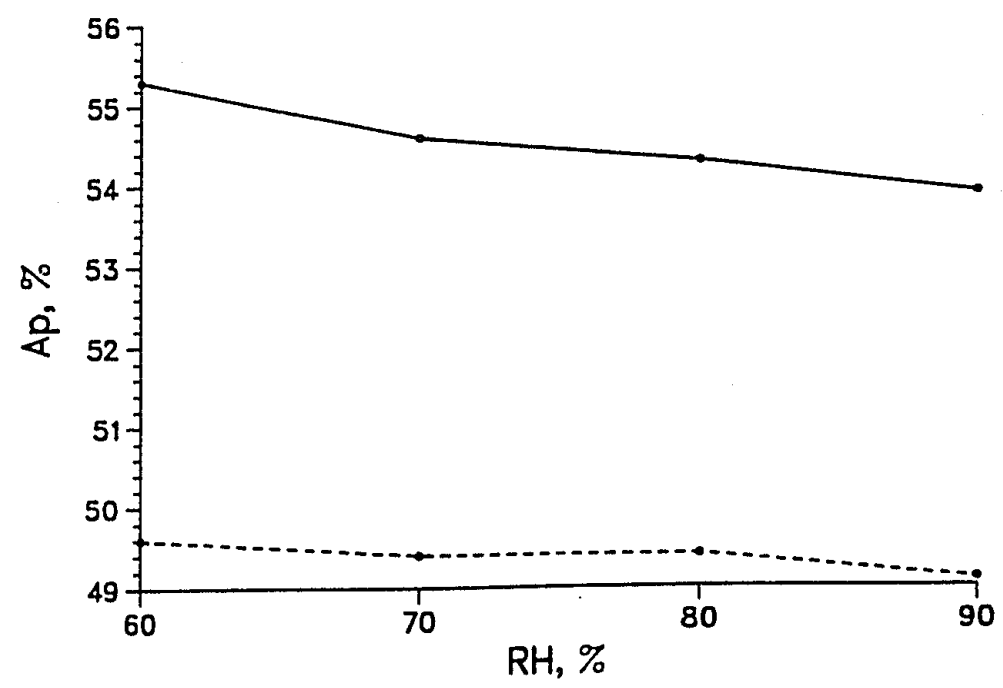

Figure 5-21: Same as Fig. 5-19, but for planetary albedo as a function of relative humidity. 


\section{Qh, Ql, and Qc vs. RH}

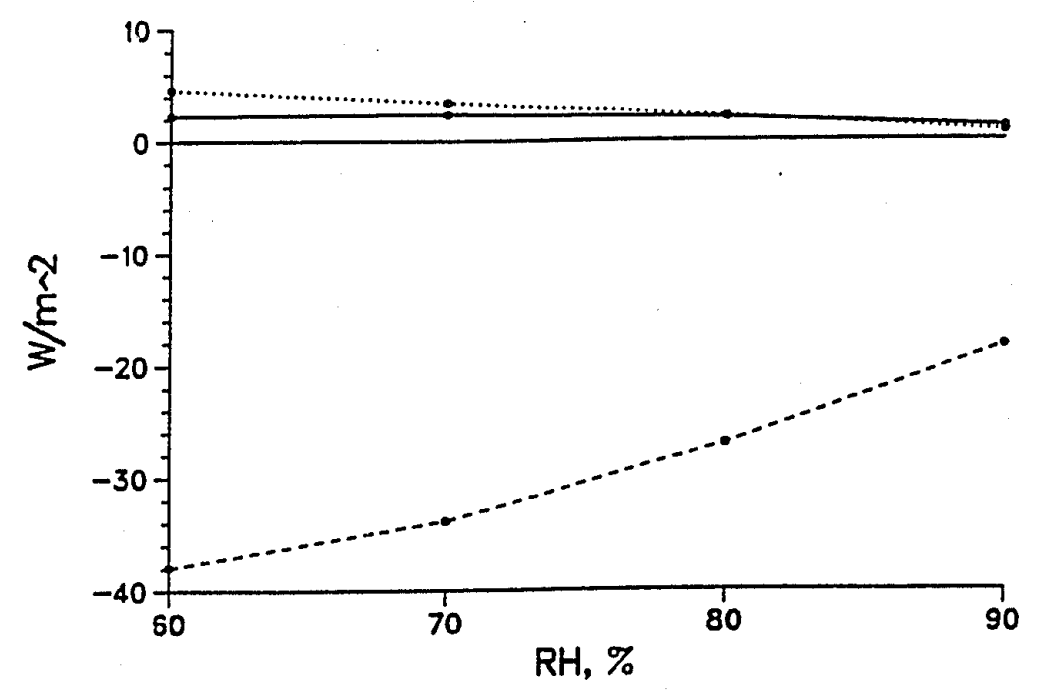

Figure 5-22: Same as Fig. 5-20, but for non-radiative surface fluxes of sensible (solid), latent (dashed), and conducted (dotted) heat.

heat into the surface $Q_{A}$ (solid line) slightly increases. Conductive flux $Q_{C}$ remains positive, meaning heat flows from the bottom of the ice for the entire range of RH; however, it is reduced as humidity is increased. The daily averaged conductive heat flux is proportional to the quantity $T_{0}-T_{B}$ since the non-linear temperature dependency term averages to zero at equilibrium; at high $\mathrm{RH}, T_{0}$ approaches $T_{B}$, so $Q_{C}$ is reduced. The fluxes responsible for forcing the surface to heat under clear skies as $\mathrm{RH}$ is raised are, in descending order, the downward IR flux from the atmosphere, latent heat, and sensible heat fluxes.

In the second part of the analysis, the haze-induced change in $T$, as a function of RH is discussed in terms of the change in surface fluxes. When haze is introduced, the surface warms for all values of humidity (Fig. 5-19, dashed line). The difference between haze and clear $T_{0}$ is large for low $\mathrm{RH}$, and a minimum difference exista at $80 \% \mathrm{RH}$. The planetary albedo exhibits about a 5\% decrease, with less of a difference between clear and haze at high RH (Fig. 5-21, dashed line). The changes to surface and atmospheric heat fluxes are given in Fig. 5-23 to Fig. 5-25, where positive changes indicate more absorption (or less emission) by the surface or the atmosphere, and negative changes denote the opposite. 


\section{Change in Qh, Ql, and Qc}

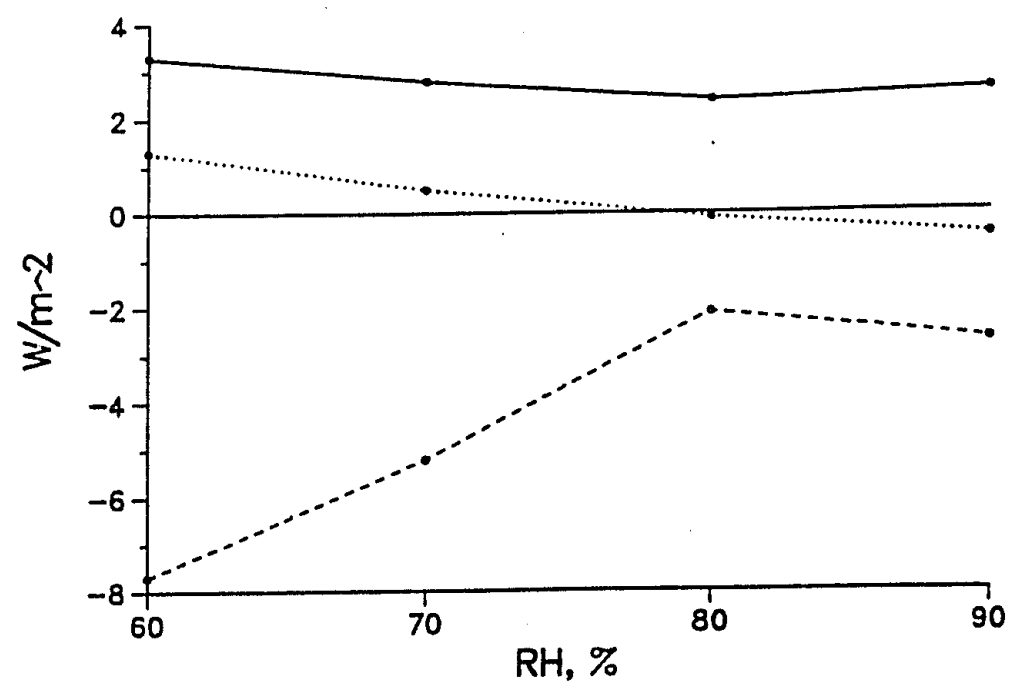

Figure 5-23: The haze-induced change to the non-radiative surface fluxes $\left(\mathrm{W} \mathrm{m}^{-2}\right)$ as a function of relative humidity. Positive changes indicate more absorption (or less emission).

The change in non-radiative fluxes are given in Fig. 5-23. The change in sensible heat flux (solid line) is positive and nearly constant with humidity. Since for the clear case $Q_{H}$ is a positive flux, this positive change indicates more heat is turbulently transported to the surface. Similar to the process discussed for the control case, haze strongly warms the lower atmosphere, increases static stability, which in turn increases the flux of heat from the atmosphere to the surface mainly through mechanical turbulence. The change in latent heat flux (dashed line) is negative at all RH, but less 80 at high humidity. For the clear case $Q_{L}$ is negative, so the negative change means more latent heat is released from the surface. The change to conducted flux through the ice (dotted line) is mostly positive, meaning more heat flows toward the surface, yet the change shows an almost linear decrease as RH is raised. These positive changes are puzzling, since an increase in surface temperature, on a daily average, should cause a negative change in $Q_{C}$. An upward flux to the surface apparently dominates, suggesting the non-linear term of $Q_{C}$ has an effect.

Figure 5-24 shows the change in the radiative fluxes at the surface. The major characteristic of these plots is the nearly constant change in the radiative fluxes over the range 


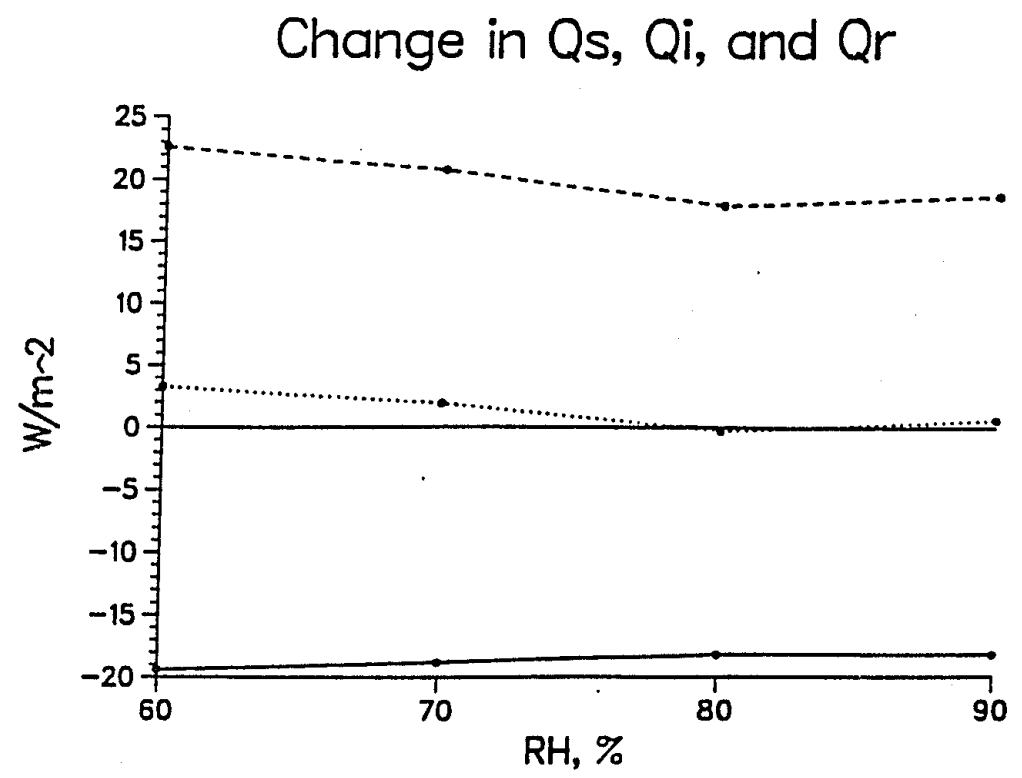

Figure 5-24: Same as Fig. 5-23, but for the surface fluxes of net solar (solid), net IR (dashed), and net radition (dotted).

of humidity. Absorbed solar (solid line) is reduced at a nearly constant $18 \mathrm{~W} \mathrm{~m}^{-2}$, with a slight dependency on RH. Net longwave radiation (dashed line) shows a positive change, meaning the surface is absorbing more IR from the atmosphere. Since the positive change in surface temperature induced by the haze increases the IR emitted from the surface (a negative change), the positive change in IR can only be attributed from increased surface IR absorption. For the most part, the positive change in net IR dominates over the reduction of solar, shown by the positive change in net radiative flux (dotted line).

For the changes in radiative fluxes in the atmosphere as a whole (Fig. 5-25), similar patterns exist, only reversed and amplified from the surface tendencies. For example, the change to atmospheric solar absorption $S^{N}$ (solid line) is positive and shows a slight reduction as RH increases. More longwave radiation $I^{N}$ (dashed line) is emitted by the atmosphere, with a minimum change for $80 \% \mathrm{RH}$ (the control case). Increased IR emission from the atmosphere supports the conclusions drawn from the discussion above that the surface gains more IR from the warmer atmosphere. The net effect of increased solar absorption and IR emission is a slight increase in atmospheric radiative absorption over all 


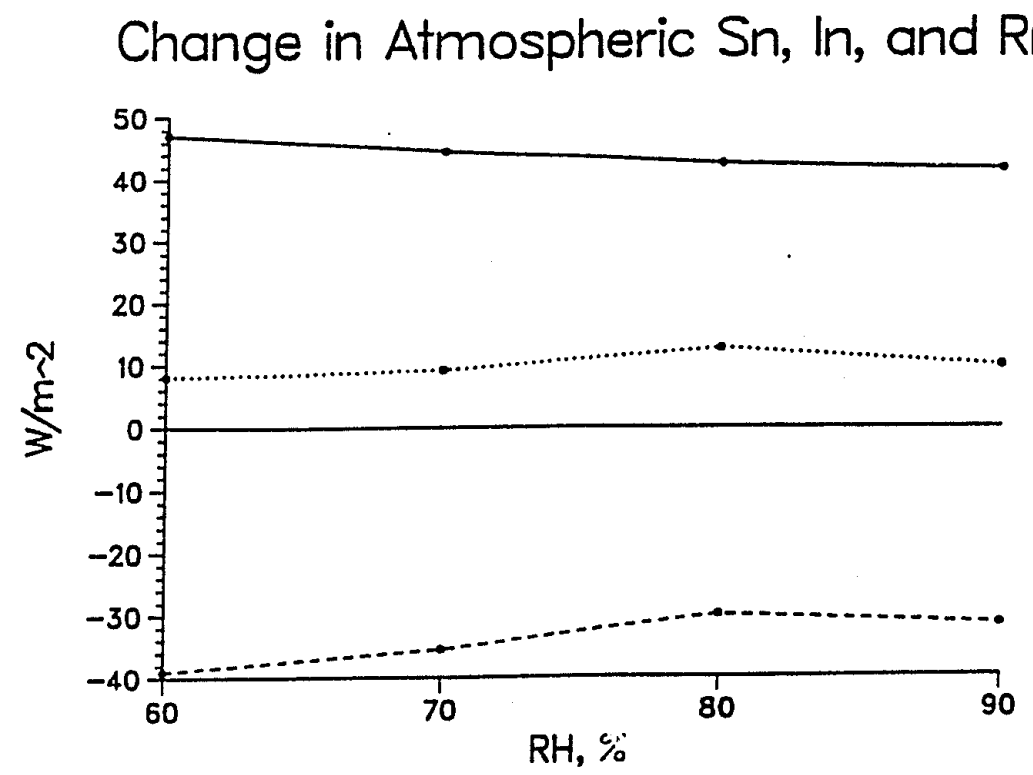

Figure 5-25: Same as Fig. 5-24, but for the atmosphere as a whole.

humidities (dotted line).

It is clear the atmosphere gains energy through haze-induced absorption of upward and downward solar fluxes, while the surface gains energy primarily through the IR feedback and an increase in sensible heat flux. Apparently, if surface IR absorption can just about balance the reduction of absorbed solar, the increase in turbulent flux of heat to the surface is the sole component responsible for surface warming.

A puzzling facet to these results is the minimum IR perturbation induced by the haze for the control run ( $80 \% \mathrm{RH})$. This minimum change in the atmospheric IR emission affects the change in the surface absorption of IR and hence causes a minimum change to the surface temperature. This critical relative humidity seems to be near a cross-over point between two competing parameters that account for the magnitude of longwave flux: the temperature-dependence $\left[T(z)^{4}\right]$, and the water vapor-dependence $(\epsilon)$. It therefore appears the two components of the longwave feedback are differentially important over a range of relative humidity, and that surface temperature is sensitive to perturbations in longwave fluxes. 


\section{Ts vs. As}

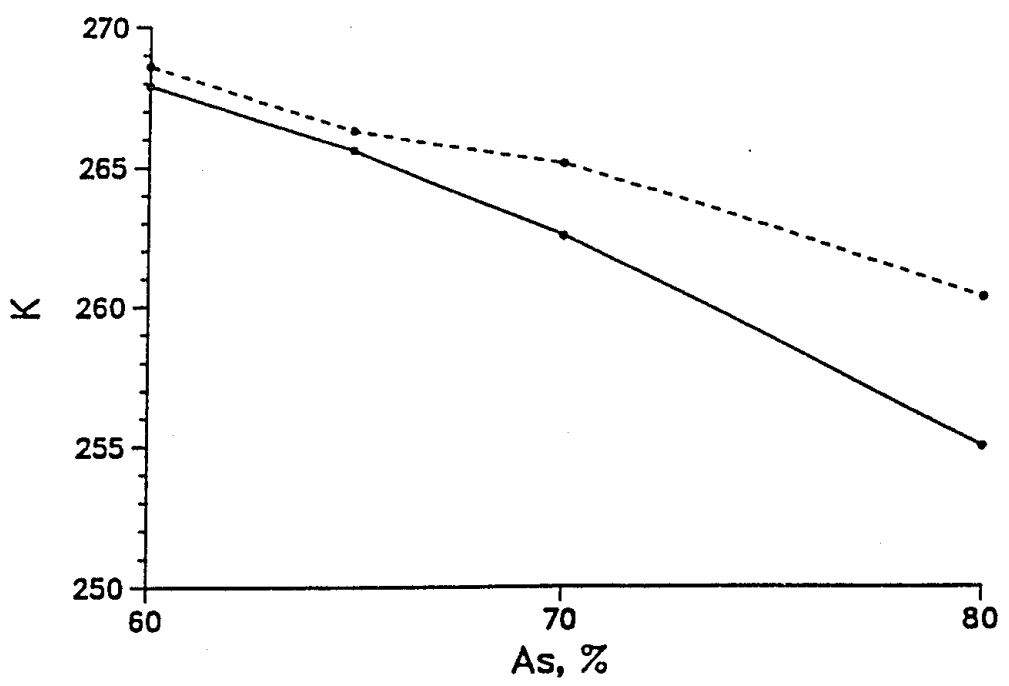

Figure 5-26: Clear (solid) and haze (dashed) daily-averaged equilibrium surface temperature (K) as a function of surface albedo.

\subsubsection{Effect of Surface Albedo}

A similar sensitivity analysis for surface albedo was performed for the range $A_{s}=0.6$ to 0.8. To reiterate, this range was selected so surface temperature would stay below $273 \mathrm{~K}$, at which point a drastic reduction in albedo and increase in snow density usually occur. Again, the heat flux figures that follow have the same sign convention as the previous section.

The clear-sky daily averaged surface temperature (solid line) decreases as $A_{0}$ increases (Fig. 5-26). The higher albedo reflects more solar energy back through the atmosphere so less is available to heat the surface; note the range of $T_{0}$ is much more substantial when compared to the RH cases. The planetary albedo increases with surface albedo by about $15 \%$ because surface albedo dominates planetary reflection (Fig. 5-27). Figure 5-28 shows the very linear decrease of solar absorption by the surface as $A_{\text {a }}$ increases to 0.8 (solid). Both downward absorbed IR and upward emitted IR are reduced as albedo is raised (not shown), but the latter effect dominates such that a smaller loss of IR at the surface (dashed line) occurs at high albedo. As shown by net radiation (dotted line), reduction of solar 
Planetary albedo vs. As

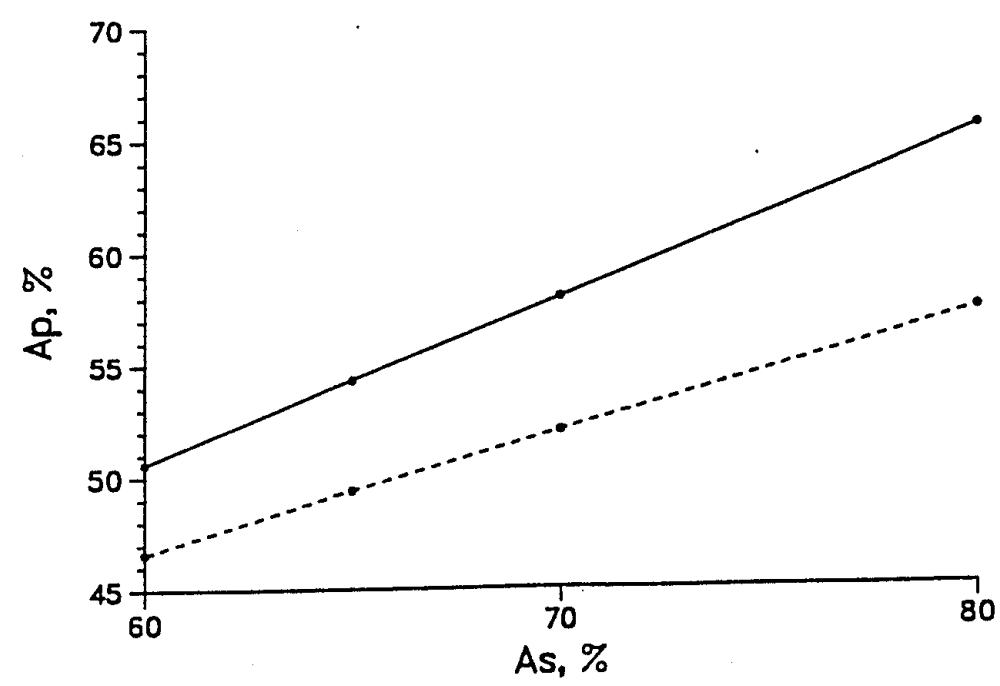

Figure 5-27: Same as Fig. 5-26, but for planetary albedo as a function of surface albedo.

Qs, Qi, and Qr vs. As

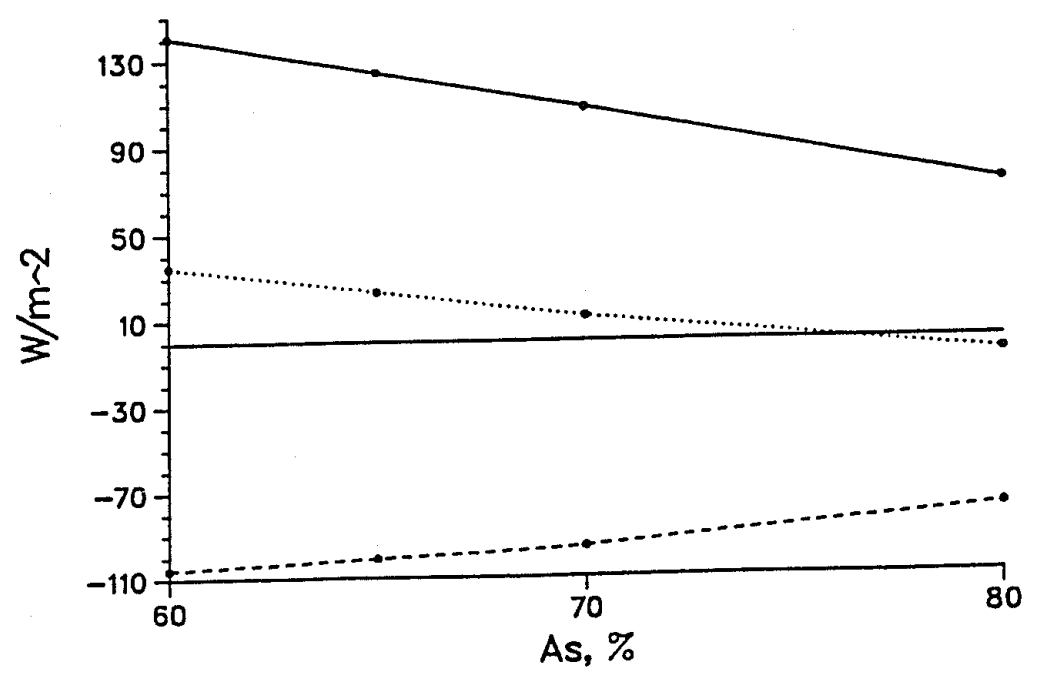

Figure 5-28: Clear equilibrium surface fluxes $\left(\mathrm{W} \mathrm{m}^{-2}\right)$ of net solar (solid), neל IR (dashed) and net radiation (dotted) as a function of surface albedo. Positive indicates surface absorption. 


\section{Qh, Ql, and Qc vs. As}

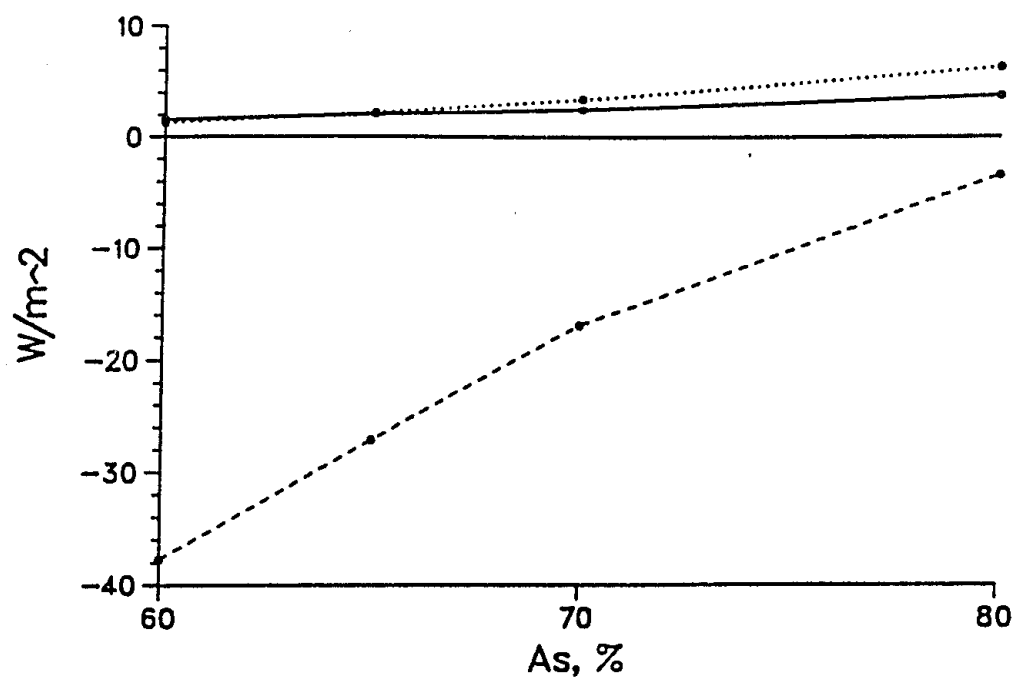

Figure 5-29: Same as Fig. 5-28, but for non-radiative surface fluxes of sensible (solid), latent (dashed), and conducted (dotted) heat.

energy into the surface dominates. For $A_{B}>0.76$ a net radiative gain exists, while below that albedo, there is a net radiative loss. The gain (loss) is balanced by the non-radiative fluxes, which also change sign at $A_{\mathbb{a}} \approx 0.76$. This is not the case for the RH experiments, which always showed a net radiative gain and a net non-radiative loss.

The non-radiative fluxes are shown in Fig. 5-29. Again, sensible heat flux (solid) is positive over the range of albedo, suggesting only a very slight increase toward higher albedo. Latent heat flux is continuously released from the surface, although less so at high albedo. At high albedo, the difference between the water content of the atmosphere and the surface is very small, leading to small fluxes of water vapor from the surface. Conductive flux represents an increasing amount of heat transferred to the surface as $A_{\text {o }}$ increases, due to lower surface temperature. Unlike the relative humidity cases, the surface temperature is strongly forced by the albedo-induced change in solar radiation. The increase in absorbed sensible heat and the decrease in released latent fluxes minimally offset surface cooling as $A_{8}$ increases.

When haze is introduced and the model is run to haze equilibrium, surface temperature 


\section{Change in Qh, Ql, and Qc}

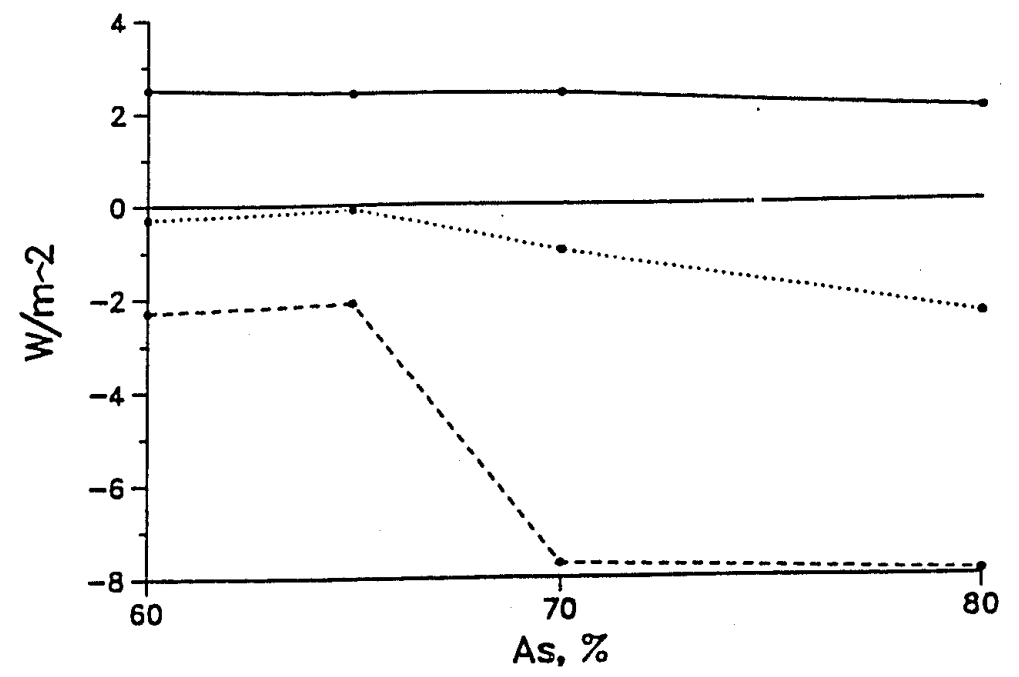

Figure 5-30: The haze-induced change to the non-radiative surface fluxes $\left(\mathrm{W} \mathrm{m}^{-2}\right)$ as a function of surface albedo. Positive changes indicate more absorption (or less emission).

is again increased as a function of $A_{8}$, only more strongly than the relative humidity runs (Fig. 5-26, dashed line). At $A_{s}=0.6$ the haze-induced change is less than $+1 \mathrm{~K}$, but at $A_{\theta}=0.8$, the change to surface temperature is over $+5 \mathrm{~K}$. This clearly suggests a stronger forcing than the humidity study. MacCracken et al. (1986) also calculated a positive surface temperature change proportional to albedo, but their surface temperature increased 6 to 9 $\mathrm{K}$ over the same $A$, range. The two models are clearly predicting similar surface forcing, yet the differences could be related to differing haze optical depths (our 0.25 vs. their 0.10 ), and zenith angles (our daily average $71^{\circ}$ vs. their constant $60^{\circ}$ ).

Planetary albedo is lowered 0.04 to 0.08 (Fig. 5-27, dashed line). This result agrees with Valero and Ackerman (1985) who also found haze decreases $A_{p}$ for $A_{g}$ values over snow/ice, but increases $A_{p}$ at $A_{\text {a }}$ values over open water. Our results indicate the two $A_{p}$ curves eventually cross at about $40 \%$ so at albedos typical for open ocean $\left(A_{8} \sim 10 \%\right)$ the planetary albedo for haze may be higher than that for a clear atmosphere.

Haze-induced change to the surface and atmospheric fluxes are shown in Fig. 5-30 to Fig. 5-32. At the surface, the change to sensible heat (Fig. 5-30, solid line) is always 


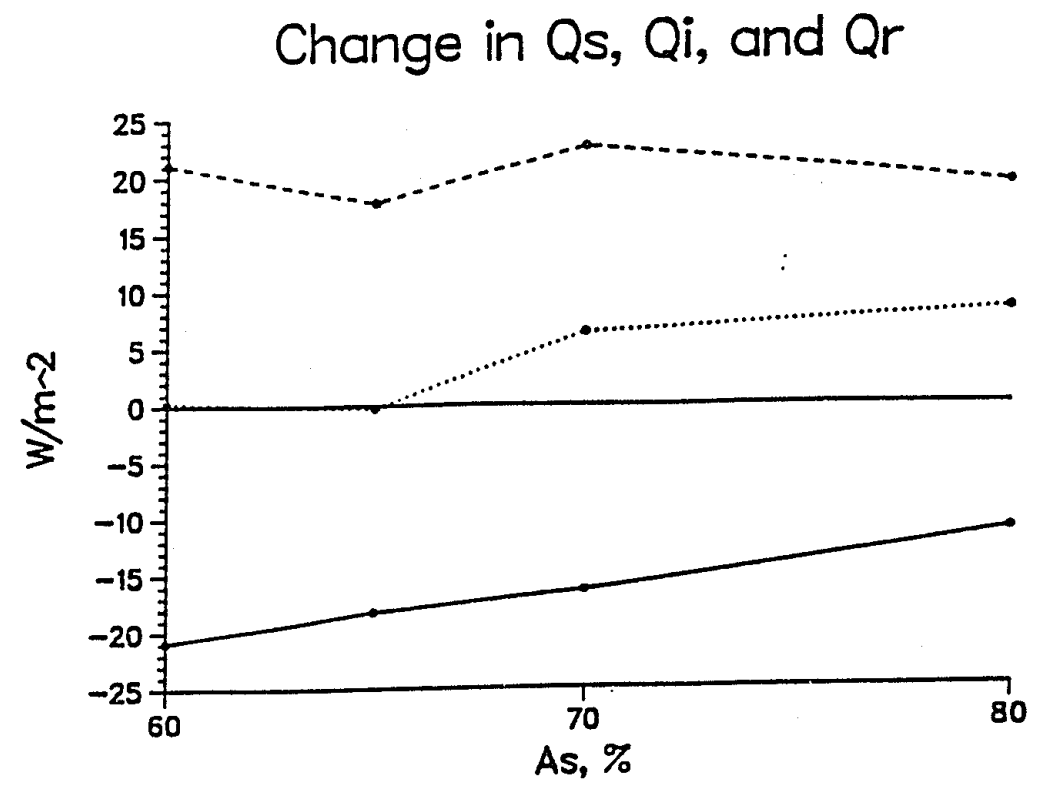

Figure 5-31: Same as Fig. 5-30, but for the surface fluxes of net solar (solid), net IR (dashed), and net radiation (dotted).

positive and about constant over the range of surface albedo, quite similarly in magnitude to the humidity cases. Note that this is the only positively changed non-radiative flux. The argument for the haze-induced change to sensible heat can again be made similar to the previous cases. The generally large increase in latent heat released from the surface (dashed line) can also be similarly explained as the change to $Q_{L}$ in the previous section: the change in $T_{0}$ is quite large at high albedo, so more latent heat escapes from the surface than at low albedo. The large positive change in $T_{0}$ at high albedo also causes the negative change in $Q_{C}$ (dotted line), meaning less heat is conducted to the surface at high albedo than at low albedo when haze is present.

For the radiative fluxes at the surface (Fig. 5-31) the change to solar absorption (solid line) is strongly influenced by $A_{0}$. The amount of solar flux absorbed by the surface is again reduced by the haze, but less so for high surface albedo since much less solar energy is absorbed at high $A_{\text {a }}$ anyway. The change to the net IR (dashed line) shows variation with albedo, but is increased by $20-25 \mathrm{~W} \mathrm{~m}^{-2}$ over the entire range. Both components of the change in net IR exhibit much smoother tendencies over the range of albedo (not shown). 


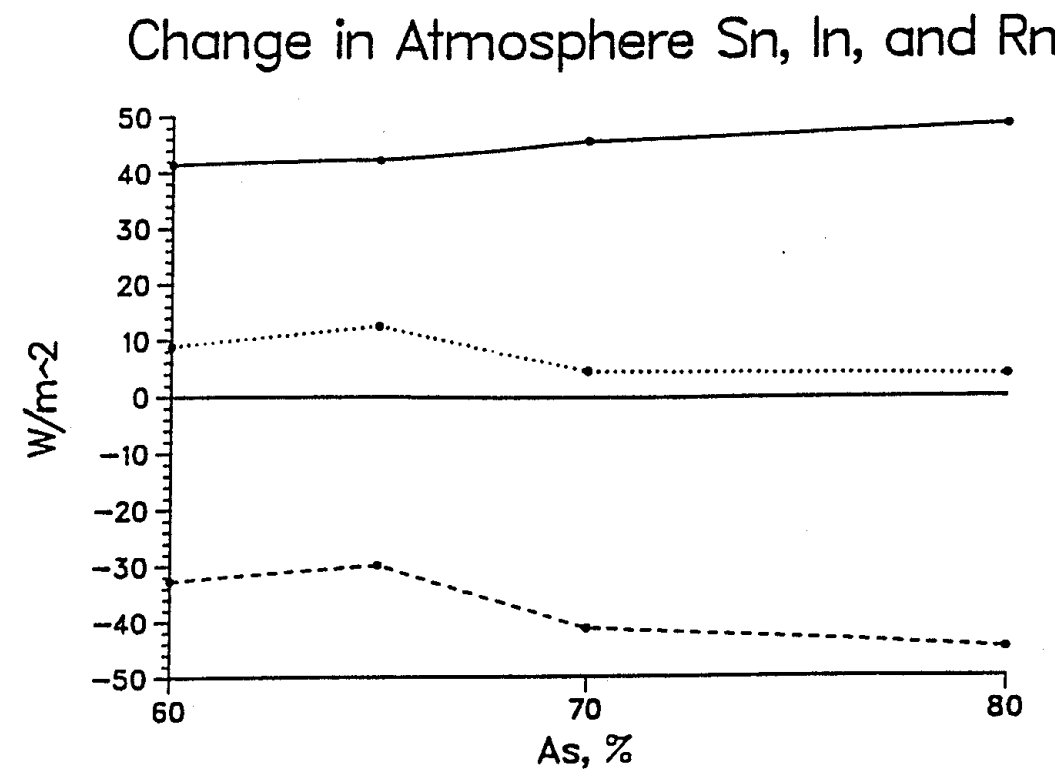

Figure 5-32: Same as Fig. 5-31, but for the atmosphere as a whole.

In general, however, the increased IR absorption by the surface again surpasses IR emission and the reduction in solar absorption. Hence the change in net radiation at the surface (dotted line) is positive and $\sim 100 \%$ higher than the humidity cases by about $4 \mathrm{~W} \mathrm{~m}^{-2}$.

In the atmosphere, net solar absorption (Fig. 5-32, solid line) is increased for all $A_{s}$, and, as expected, is larger for high surface albedo. This is consistent with conclusions of Valero and Ackerman (1985) that a high surface albedo leads to significant absorption of the strong upward solar stream. The change to the net IR (dashed) is negative, and generally decreasing with $A_{a}$; increased solar absorption is therefore offeet by increased atmospheric emission. The solar absorption slightly dominates over the entire range of $A_{\mathrm{a}}$ such that the net radiation (dotted) is positive. The atmosphere gains energy mainly through aerosol solar absorption, but at equilibrium, this gain is smaller than the humidity study, especially at high surface albedo. 


\section{Conclusion}

\subsection{Summary}

A number of numerical studies over the past decade have investigated the microphysics of Arctic haze aerosols and their ability to force radiative perturbations in the lower Arctic atmosphere when they are concentrated in the amount measured in situ during the spring season. Such work has included a wide range of solar radiation and aerosol models, from simple single-component particles to full multi-component hygroscopic urban aersols. Most results were similar in that optically thick, highly absorbing aerosols produced atmospheric warming. It was unclear, however, how this would affect the surface system and potentially alter the Arctic climate. Later studies investigated soot deposition onto the snowpack and aerosol influences on Arctic stratus separate from atmospheric perturbations. Only the few recent surveys with GCMs and $\mathrm{RCMs}$, run with coarse spatial and temporal resolution, have considered the diabatic consequences of Arctic haze on the total heat transfer process.

In the current study, an idealized one-dimensional three-component numerical model is developed that combines routines for radiative transfer through the tropopause, planetary boundary layer dynamics, and conduction of heat through a snow/packice slab. It successfully manages to reproduce the smaller scale vertical heat transport processes that are believed to be important to the Arctic environment. A Mie scattering model is used to calculate particle optical properties based on the physical properties reviewed. By linking these models we have a system similar to a radiative-convective model, but in much more resolved detail, which is used to understand the force-response processes brought about by a haze-laden atmosphere.

This study simply differentiates between two equilibrium springtime Arctic environments; one with a clear atmosphere, and one with a haze-laden atmosphere. Since the effects of introducing an optically thick haze to a solar stream of long atmospheric path length has been extensively discussed, this study primarily focuses on how the haze impacts the surface heat balance. The earlier studies suggest surface albedo and humidity, both of which are quite temporally and spatially variable, are important factors to consider when examining radiative perturbations due to Arctic haze. Therefore, two parametric studies 
are performed to determine how sensitive our model system is to these variables.

In order remove one very complicated facet to these analyses, we simplify the aerosol problem. Since this is not a study to investigate the sensitivity of the model to various haze parameters, we model only one representative set of aerosol properties and keep them constant in time and height. We assume the aerosol is simply composed of only two components: an absorber $(\mathrm{Cg})$ occupying the core of each particle, and a scatter (water) surrounding the core. The size distribution and core-to-shell volume ratio are selected to obtain representative wavelength-dependent optical properties. The extinction coefficient profile with height is specified by a log-normal distribution. This gives a very simple yet representative $\mathrm{Cg}$ mass concentration profile when we assume a value for the absorption cross section for a $\mathrm{Cg}$-water mixture. In this way we examine how cne haze type, concentrated within a constant vertical distribution, impacts the model system.

Results from the control experiment show haze actively absorbs solar energy. Consequently, the atmosphere heats, while the surface initially cools; this is a direct and instantaneous effect enhanced by 24 hours of incident solar radiation. Since most of the haze exists in an elevated concentration maximum as is commonly observed, maximum haze-induced heating of $\sim 15 \mathrm{~K}$ exists between 1 and $2 \mathrm{~km}$ above the surface. The entire troposphere is about $5 \mathrm{~K}$ warmer on average. As the model approaches equilibrium, the warmer wetter atmosphere begins to radiate (and absorb) more IR, which slows atmospheric heating and begins to warm the surface; this is a negative feedback effect. Surface IR absorption increases only to the point where it just about balances the reduction of solar absorption during the daytime. During the night, the constant increase of net IR at the surface prohibits the temperature from decreasing as it normally would under drier, cooler skies. At haze equilibrium, therefore, the surface is only slightly warmer than for clear equilibrium, which increases stabilization in the lower PBL.

The surface also warms due to the increase in downward turbulent heat flux throughout the day. An increase in $Q_{H}$ under increased stabilization may seem counter-intuitive, but the surface exchange coefficent $C_{H}$ does not significantly change between clear and haze cases. In both experiments, the PBL is forced primarily by mechanical mixing over the entire day, rather than convection from the surface. Therefore, sensible heat flux is based 
on $T_{a}-T_{b}$. For the haze case this quantity remains strongly positive for a much longer period. Although amplification of this daily averaged flux is only a few percent of the total surface heat budget, its actual magnitude is larger than the difference $\left(R^{N}\right)$ between the large net solar and IR fluxes. Apparently, if increased IR can just about balance reduced solar at the surface, the surface will warm solely by the increased turbulent heat flux.

The model is found to be sensitive to the humidity specification. When a constant representative relative humidity profile is used, the surface warms by almost $1 \mathrm{~K}$. Increased surface absorption of $I^{\downarrow}$ and $Q_{H}$ dominates reduction of reduced solar absorption. On the other hand, when a constant specific humidity is introduced, the surface slightly cools, mainly because IR emission from the drier atmosphere to the surface cannot compensate for the reduced solar absorption. Regardless, heat components such as $Q_{C}, Q_{I}^{\dagger}$, and $Q_{L}$ adjust in both cases to maintain the balance, causing only a small change in surface temperature.

The surface warms, however, for all runs within the relative humidity parametric study, but the model as a whole seems rather insensitive. The component most sensitive to RH is the IR feedback. Two possible competing IR processes are identified. In the first process, the IR feedback is simply dependent on the change in the temperature profile, which tends to dominate at low humidity. In the second process, very high humidity increases atmospheric emissivity and causes further warming via IR absorption. The relative humidity specification is also important for the latent heat component of the surface heat budget. Since the amount of water vapor sublimed from the surface is based on the difference between moisture content at the surface (assumed saturated) and at $1 \mathrm{~m}$, latent heat flux is drasticly reduced at high humidity, which makes this cooling term less effective.

The solar streams are shown to be most sensitive to the range of surface albedo. The strongest radiative forcing on the surface-atmosphere system exists at high albedo because the surface reflects most incident solar energy back through the atmosphere. Hence, at such albedo, intense atmospheric warming forces a strong IR feedback, which increases net radiative surface absorption by almost $10 \mathrm{~W} \mathrm{~m}^{-2}$; a much larger effect than in the humidity cases. The surface warms over the entire range of albedo when haze is introduced; but about 1-5 times more than for the range of RH. At low albedo, however, the surface warms a minimal $\sim 1 \mathrm{~K}$. This result suggests that once the snow surface is contaminated (its albedo 
lowered), airborne haze has less effect on surface temperature.

Although haze reduces planetary albedo, as shown by a net surface-atmosphere warming, haze actually appears to increase planetary albedo at $A_{0}<0.4$ (this is not demonstrated here). This trend is complicated by the fact that equilibrium suriace temperature at low albedo approaches the melting point, so changes in temperature may be manifested into changes in melt rates. These results also suggest the maximum effect that haze might have on the springtime Arctic climate should occur for high relative humidity and high surface albedo. At high albedo, solar absorption by the atmosphere is strongest, which would enhance the IR feedback, particularly at high humidty. Such conditions are the most representative of the Arctic at this season. However, surface temperature at high albedo is quite low $(\sim 250 \mathrm{~K})$, so the large increase in surface temperature predicted by this model system $(+5 \mathrm{~K})$ suggests surface temperature would remain subfreezing. Although this would not immediately cause surface melting, it could alter the time at which melting begins. At high albedo the immediate effect could quite possibly reduce conductive heat from the bottom of the ice because of the smaller difference between surface temperature and ice bottom temperature. This could increase the amount of ice ablated from the bottom if the flux from the oceanic mixed layer remained moderately constant.

Results in general indicate the model predicts a stable, robust, self-correcting system in which the IR and turbulent feedback processes are key components of the surface energy budget. Early radiative studies (Porch and MacCracken, 1982; Cess, 1983) first suggested haze would significantly force springtime atmospheric heating. In later experiments, MacCracken et al. (1986) suggested IR feedback resulting from atmospheric warming would warm the surface by almost $10 \mathrm{~K}$ at high albedo. This model does predict significant atmospheric warming, in agreement with all previous work, yet large increases in surface temperature are not neccessarily the case. From this work it is concluded that this model Arctic surface is a rather insensitive system. This seems to supported by data presented by Lindzen (1990), who reported that since about 1940, 5-year Atlantic Arctic seasonal surface-air temperatures have been cooling by several degrees - the most pronounced cooling occurs during winter and spring. 


\subsection{Uncertainties and Recommendations}

This highly interactive model captures the major forms of heat transfer in an Arctic surfaceatmosphere system, but it still represents a gross simplification of a very complex environment. A number of uncertainties exist for processes included within, and ignored by, our model. It should also be kept in mind that the model is used to calculate steady-state conditions for constant orbital parameters (i.e. a perpetual late-spring season) to simplify the analyses. Unfortunately, the Arctic springtime is a highly transitional period; steady state conditions are not realized until mid- to late-summer. Thus, these results cannot apply to the real Arctic, but should only be viewed as an account of how haze perturbs this model Arctic system.

The uncertainties within the model include its weaknesses. The weakest link in the model is the ice conduction model, since it was developed primarily for use in GCM applications. Neeman et al. (1988) state forcing on the diurnal scale leads to nonlinear temperature tendencies that make the assumptions allowing vertical integration of the conduction equations invalid. This appears to be related to the problem that the diurnal range of conducted heat is too large, which damps the diurnal range of surface temperature to about half of what is observed for the given latitude and season. Since most of our study concentrates on daily averaged quantities, which points to the linear formulation $Q_{C}=-K_{i a}\left(T_{a}-T_{B}\right)$ as the important component of the conductive flux, there does not seem to be a problem with the analyses. But an overdamped temperature wave could affect PBL mechanics during the day, which could overstabilize the PBL and damp turbulent fluxes.

Work extending from the current project should address the ice model problem more thoroughly; either a full grid-type conduction model similar to that of Maykut and Untersteiner (1971) should be developed, or the VIF currently used should be divided into a set of $10 \mathrm{~cm}$ layers. Also, some investigators (Overland, 1988; Burke and Thompson, 1989) have successfully applied the simple force-restore method to a homogeneous ice-slab. The latter suggestion would certainly be simplest, since the model already contains this routine for soil.

Another uncertainty concerns the magnitude of the turbulent heat fluxes, particularly for $Q_{H}$. The sensible heat flux is a function of surface roughness, the mean wind (and 
its resulting shear), and local stability; the first two are not varied at all, while the third is change only by haze-induced warming aloft. Surface roughness has been shown to vary considerably with season, ice form, and possibly even wind speed (Munn, 1966). Windspeed impacts near-surface stability and surface stress - the magnitude and sign of $Q_{H}$ is quite sensitive to both of these. Since this appears to be such a significant component of the surface heat budget, as opposed to results from MacCracken et al. (1986) who all but ignored its contribution at high albedo (low surface temperature), its sensitivity to varying atmospheric states could be important. As for further experiments, sensitivity analyses of the turbulent fluxes on a range of surface roughness, windspeeds, and temperature profiles appear warrented.

In a related problem, the PBL model demonstrates some rather peculiar, albeit minor, characteristics, particularly at handling sudden shifts from stable to mixed stability regimes. Periodic "bursts" of TKE are common at vertical levels or timesteps that divide two such regimes, but they appear to have a relatively small impact on momentum and heat trangport. This problem appears to be related to the theory upon which the Level 2.5 model is based; that the simple TKE equation does not fully realize rapidly growing turbulence. The fact that these bursts are suppressed during haze-induced stabilization suggests this is the problem. This type of turbulence closure was adopted for this study because of its ability to maintian turbulence within stable conditions while retaining rather simple turbulence equations. However, it is difficult to estimate whether this model may inherently calculate turbulent fluxes any different from higher order schemes.

The final model-related uncertainty concerns the humidity specification. Opposite surface forcing results between the relative humidity and specific humidity experiments. Yet it is difficult to argue the representativeness of either approach. During the fall, winter, and spring seasons, the atmosphere is cold and dry. Water is primarily transported by large scale horizontal advection; but because large scale subsidence is so prevalent, air at low elevations contains moisture from the dry upper troposphere, and the surface acts as a sink. This would tend to validate the specific humidity approach. In the late-spring and summer, however, the Arctic supplies its own source of moisture forced on a daily cycle of melting, evaporation, and sublimation, which is evident by the ubiquitous stratus that covers as 
much as $80-90 \%$ of the Arctic during this season. This would support a relative humidity approach. The real answer may lie somewhere in between such that there is no large net change in the surface heat budget. The problem would best be simulated by a complete hydrological cycle, but such a task is difficult to apply to a one-dimensional analysis.

Uncertainties about processes the model does not take into account include the complex and highly non-linear contributions from open water (leads) and cloud formation. Open areas of water are strong sources of buoyancy because of the huge magnitudes of sensible and latent heat that they give up to the atmosphere. Under stong winds, heat and moisture can be advected for long distances, which could affect PBL processes in more remote homogeneous regions (Badgley, 1966; Overland, 1985). Also, open leads create inhomogeneities in surface albedo, while clouds are important for local radiative transfer and tend to washout the haze aerosol. Overland (1988) includes a very simple analytic formulation in his 1-D model that accounts for open leads as a function of their surface area percentage. Both open water and clouds would require a more active role for moisture transport. The PBL model does include a moisture diffusion equation similar to the temperature equation, but it is incomplete; it considers moisture to be a passive gas, so no parameterizations are included for saturation conditions, and no term is included to parameterize the removal of vapor from the model by condensation or larger-scale horizontal processes.

Finally, and possibly most important, uncertainties related to our simple aerosol model exist. Early experiments have focused on the sensitivity of radiative transfer on aersol optical properties and found results were sensitive primarily to composition and concentration. The impact the environment has on Arctic haze optical properties are not well known even though many aersol scattering models predict significant changes with height and humidity. As a consequence, it is difficult to allow the environment to have an impact on aerosol parameters, such as humidity effects on optical properties, and just as difficult to justify the approach. 


\section{References}

Ackerman, T.P., and O.B. Toon, 1981: Absorption of visible radiation in an atmosphere containing mixtures of absorbing and nonabsorbing particles. Appl. Opt., 21, 36613668.

Andreas, E.L., 1988: Turbulent surface heat fluxes over polar, marine surfaces. Proceedings from Conference on Polar Meteorology and Oceanography, March 1988, 65-68.

Atmospheric Environment, 1981: Vol. 15, No. 8.

Badgley, F.I., 1966: Heat balance at the surface of the Arctic ocean. Proceedings of the Symposium on Arctic Heat Budget and Atmospheric Circulation, J.O. Fletcher, Ed., Rand Corp., Santa Monica, Ca., 215-246.

Bhumralkar, C.M., 1975: Numerical experiments on the compution of ground surface temperature in an atmospheric general circulation model. J. Appl. Meteorol., 14, 12461258.

Blackadar, A.K., 1976: Modeling the nocturnal boundary layer. Proceedings of the Third Symposium on Atmospheric Turbulence, Diffusion and Air Quality, AMS, Boston, Mass., 46-49.

Blackadar, A.K., 1978: High resolution models of the planetary boundary layer. Advances in Environmental Science and Engineering, J.R. Pfafflin and E.N. Ziegler, Eds., Gordon and Breach Science Publishers, New York, N.Y., 50-85.

Blanchet, J.P., 1987: The effects of Arctic aerosols on a CCC GCM simulation: A sensitivity study. Canadian Climate Center, AES, North York, Ontario, M3H 5T4, 10 pp.

Bodhaine, B.A., E.G. Dutton, and H. DeLuisi, 1984: Surface aerosol measurements at Barrow during AGASP. Geophys. Res. Lett., 11, 377-380.

Brodzinsky, R.S., G. Chang, S.S. Markowitz, and T. Novakov, 1980: Kinetics and mechanics for the catalytic oxidation of sulfer dioxide on carbon in aqueous suspensions. $J$. 
Phys. Chem., 84, 3354-3359.

Cahill, T.A., and R.A. Eldred, 1984: Elemental composition of Arctic particulate matter. Geophys. Res. Lett., 11, 413-416.

Carey, J., 1988: Scientific sleuths solve the mystery of Arctic haze. Weatherwise, April 1988, 97-99.

Cess, R.D., 1983: Arctic aerosols: model estimates of interactive influences upon the surfaceatmosphere clear sky radiation budget. Atmos. Environ., 17, 2555-2564.

Cess, R.D., G.L. Potter, S.J. Ghan, and W.L. Gates, 1985: The climatic effects of large injections of atmospheric smoke and dust: A study of climate feedback mechanisms with one- and three-dimensional climate models. J. Geophys. Res., 90, 12937-12950.

Clarke, A.D., R.J. Charlson, and L.F. Radke, 1984: Airborne observations of Arctic aerosols IV: Optical properties of Arctic haze. Geophys. Res. Lett., 11, 405-408.

Clarke, A.D., and K.J. Noone, 1985: Soot in the Arctic snowpack: A cause for perturbations in radiative transfer. Atmos. Environ., 19, 2045-2053.

Coakley, J.A., Jr., R.D. Cess, and F.B. Yurevich, 1983: The effect of tropospheric aerosols on the earth's radiation budget: a parameterization for climate models. J. Atmos. Sci., $40,116-138$.

Deardorff, J.W., 1978: Efficient prediction of ground surface temperature and moisture with inclusion of a layer of vegetation. J. Geophys. Res., 83, 1889-1903.

Dutton, E.G., J.J. DeLuisi, and B.A. Bodhaine, 1984: Features of aerosol optical depth at Barrow, March 10-20, 1983. Geophys. Res. Lett., 11, 385-388.

Eicken, H., and M.A. Lange, 1989: Sea ice thickness data: the many vs. the few. Geophys. Res. Lett., 16, 495-498.

Fletcher, J.O., 1965: The Heat Budget of the Arctic Basin and Its Relation to Climate. The Rand Corp., Santa Monica, Ca., RM-5793-NSF, 108 pp.

Forkel, R., and P. Wendling, 1986: A numerical study of the formation of Arctic stratus 
clouds with consideration of absorbing aerosol particles. Meteorol. $R$ Rdsch., 39, 74-79.

Francis, J.A., 1988: A summer radiation budget for the Fram Straight Marginal Ice Zone. Senior Research Thesis, San Jose State University, San Jose, Ca., 28 pp.

Geophysical Research Letters, 1984: Vol. 11., No. 5

Hale, G.M., and M.R. Querry, 1973: Optical constants of water in the 200-nm to 200- $\mu \mathrm{m}$ wavelength region. Applied Optics, 12, 555-563.

Hansen, A.D.A., and H. Rosen, 1984: Vertical distribution of particulate Carbon, Sulfur, Bromine in the Arctic haze and comparison with ground-level measurements at Barrow, Alaska. Geophys. Res. Lett., 11, 381-384.

Hansen, A.D.A., and H. Rosen, 1985: Horizontal inhomogeneities in the particulate carbon component of the Arctic haze. Atmos. Evniron., 19, 2175-2180.

Hansen, A.D.A., and T. Novakov, 1988b: Aerosol black carbon measurements in the Arctic haze during AGASP II. J. Atmos. Chem., , in press.

Harris, J.M., 1984: Trajectories during AGASP. Geophys. Res. Lett., 11, 453-456.

Helfand, H.M., and J.C. LaBraga, 1988: Design of a nonsingular Level 2.5 second-order closure model for the prediction of atmospheric turbulence. J. Atmos. Sci., 45, 113-132.

Hoff, R.M., and N.B.A. Trivett, 1984: Ground-based measurements of Arctic haze made at Alert, N.W.T., Canada, during the AGASP. Geophys. Res. Lett., 11, 389-392.

Holt, T., and S. Raman, 1988: A review and comparative evaluation of multilevel boundary layer parameterizations for first-order and turbulent kinetic energy closure schemes. Rev. Geophys., 26, 761-780.

Iversen, T., 1984: On the atmospheric transport of pollution to the Arctic. Geophys. Res. Lett., 11, 457-460.

Joranger, E., and B. Ottar, 1984: Air pollution studies in the Norweigian Arctic. Geophys. Res. Lett., 11, 365-368. 
Katz, D.I., 1980: Air stress measurements from an aircraft. Sea Ice Processes and Models, P.S. Pritchard, Ed., University of Washington Press, Seattle, 452-463.

Kellner, G., C. Wamser, and R.A. Brown, 1987: An observation of the PBL in the MIZ. J. Geophys. Res., 92, 6955-6965.

Kellogg, W.W., 1975: Climate feedback mechanisms involving the Polar regions. Climate of the Arctic, G. Weller and S.A. Bowling, Eds., Geophysical Institute, University of Alaska, Fairbanks, 111-116.

Kolmogoroff, A.N., 1942: The equations of turbulent motion in an incompressible fluid. Izv. Akad. Nauk SSSR, Ser. Fiz., 6, 56-58.

Li, S., and J.W. Winchester, 1990: Haze and other aerosol components in late winter Arctic Alaska, 1986. J. Geophys. Res., 95, 1797-1810.

Lindzen, R.S., 1990: Some coolness concerning global warming. Bull. Amer. Met. Soc., 71, 288-299.

Liou, K.N., 1974: Analytic two-stream and four-stream solutions for radiative transfer. $J$. Atmos. Sci, 31, 1473-1475.

MacCracken, M.C., R.D. Cess, and G.L. Potter, 1986: The climatic effects of Arctic aerosols: An illustration of climate feedback mechanisms with one- and two-dimensional climate models. J. Geophys. Res., 91, 14445-14450.

Maykut, G.A., 1978: Energy exchange over young sea ice in the central Arctic. J. Geophys. Res., 83, 3646-3658.

Maykut, G.A., 1982: Large-scale heat exchange and ice production in the central Arctic. J. Geophys. Res., 87, 7971-7984.

Maykut, G.A., and N. Untersteiner, 1971: Some results from a time dependent thermodynamic model of sea ice. J. Geophys. Res., 6, 1550-1575.

Mellor, G.L., and T. Yamada, 1974: A heirarchy of turbulence closure models for planetary boundary layers. J. Atmos. Sci., 31, 1791-1806. 
Mellor, G.L., and T. Yamada, 1982: Development of a turbulence closure model for geophysical fluid problems. Rev. Geophys. Space Phys., 20, 851-875.

Meteorological Office, 1964: Weather in Home Fleet Waters, Volume 1 - The Northern Seas. Her Majesty's Stationery Office, London, $9-25$

Mitchell, J.M., Jr., 1957: Visual range in the polar regions with particular reference to the Alaskan Arctic. J. Atmos. Terr. Phys., Spec. Suppl., Part 1, 195-211.

Morison, J.H., M.G. McPhee, and G.A. Maykut, 1987: Boundary layer, upper ocean, and ice observations in Greenland Sea Marginal Ice Zone. J. Geophys. Res., 92, 6987-7011.

Munn, R.E., 1966: Descriptive Micrometeorology. Academic Press, Inc., Orlando, Fla., 245 pp.

Neeman, B.U., J.H. Joseph, and G. Ohring, 1988: A vertically integrated snow/ice model over land/sea for climate models. 1. Development. J. Geophys. Res., 93, 3663-3675.

Oort, A.H., 1983: Global Atmospheric Circulation Statistic8, 1958-1979. National Oceanic and Atmospheric Administration, NOAA Professional Paper 14, U.S. Government Printing Office, Washington D.C.

Orvig, S., Ed., 1970: Climates of polar regions. World Survey of Climatology Volume 14, Elseveir Publishing Co., New York, 129-239

Overland, J.E., 1985: Atmospheric boundary layer structure and drag coefficients over sea ice. J. Geophys. Re8., 90, 9029-9049.

Overland, J.E., 1988: A model of the Atmospheric boundary layer over sea ice during winter. Proceedings from Conference on Polar Meteorology and Oceanography, March 1988, $65-68$.

Patterson, E.M., B.T. Marshal, and K.A. Rahn, 1982: Radiative properties of the Arctic aerosol. Atmos. Environ., 16, 2967-2977.

Porch, W.M., and M.C. MacCracken, 1982: Parametric study of the effects of Arctic soot on solar radiation. Atmos. Environ., 16, 1365-1371. 
Raatz, W.E., 1984: Tropospheric circulation patterns during AGASP, March/April 1983. Geophys. Res. Lett, 11, 449-452.

Raatz, W.E., and R.C. Schnell, 1984: Aerosol distributions and an Arctic aeosol front during AGASP: Norweigian Arctic. Geophys. Res. Lett., 11, 373-376.

Radke, L.F., P.V. Hobbs, and I.H. Bailey, 1984: Airborne observations of Arctic Aerosols III: Origins and effects of airmasses. Geophys. Res. Lett., 11, 401-404.

Radke, L.F., J.H. Lyons, D.A. Hegg, P.V. Hobbs, and I.H. Bailey, 1984: Airborne observations of Arctic aerosols I: Characteristics of Arctic haze. Geophys. Res. Lett., 11, 393-396.

Ramanatham, V., M.S. Lian, and R.D. Cess, 1979: Increased atmospheric $\mathrm{CO}_{2}$ : zonal and seasonal estimates of the effect on the radiation energy balance and surface temperarture. J. Geophys. Res., 84, 4949-4958.

Robock, A., 1980: The seasonal cycle of snow cover, sea ice and surface albedo. Mon. Weath. Rev., 108, 267-285.

Roessler, D.M., and F.R. Faxvog, 1980: Photoacoustic determination of optical absorption to extinction ratio in aerosols. Appl. Opt., 19, 578-581.

Rodgers, C.D., and C.D. Walshaw, 1966: The computation of infrared cooling rate in planetary atmospheres. Quart. J. Roy. Meteorol. Soc., 93, 43-54.

Rosen, H., and A.D.A. Hansen, 1984: Role of combustion-generated Carbon particles in the absorption of solar radiation in the Arctic haze. Geophys. Res. Lett., 11, 461-464.

Rotta, J.C., 1951: Statistische Theorie nichthomogener Turbulenz. Z. Phys., 129, 547-572.

Schnell, R.C., 1984: Arctic Haze and the Arctic Gas and Aerosol Sampling Program (AGASP). Geophys. Res. Lett., 11, 361-364.

Schnell, R.C., and W.E. Raatz, 1984: Vertical and horizontal characteristics of Arctic haze during AGASP: Alaskan Arctic. Geophys.Res. Lett., 11, 369-372.

Shaw, G.E., 1984: Micropartical size spectrum of Arctic haze. Geophys. Res. Lett., 11, 
409-412.

Shaw, G.E., and K. Stamnes, 1980: Arctic haze: perturbations of the polar radiation budget. Ann. N.Y. Acad. Sci., 338, 533-539.

Shettle, E.P., and R.W. Fenn, 1979: Models for the aerosols of the lower atmosphere and the effects of humidity variations on their optical properties. Air Force Geophysics Laboratory, Report No. AFGL-TR-0214.

Szkarlat, A.C., and S.M. Japar, 1981: Light absorption by airborne aerosols: comparison of integrating plate and spectrophone techniques. Appl. Opt., 20, 1151-1155.

Tsay, S., K. Stamnes, and K. Jayaweera, 1989: Radiative energy budget in the cloudy and hazy Arctic. J. Atmos. Sci., 46, 1002-1018.

Untersteiner, N., 1964: Calculations of temperature regime and heat budget of sea ice in the central Arctic. J. Geophys. Res., 69, 4755-4766.

Velero, F.P.J., T.P. Ackerman, and W.J.Y. Gore, 1983: Radiative effects of Arctic haze. Geophys. Res. Lett., 10, 1184-1187.

Valero, F.P.J., and T.P. Ackerman, 1985: Arctic haze and the radiation balance. Symposium Volume: Arctic Air Pollution, B. Stonehouse, Ed., Cambridge University Press, Cambridge, 121-134.

Valero, F.P.J., T.P. Ackerman, and W.J.Y. Gore, 1987: The effects of Arctic haze as determined from airborne radiometric measurements during AGASP II. NASA Ames Research Center, Space Science Div., Moffett Field, Ca., 15 pp. 


\section{Appendix A: List of Symbols}

PBL model

\begin{tabular}{|c|c|}
\hline$A_{1}, A_{2}$ & Turbulence constants \\
\hline$a_{1}-a_{3}$ & Vertical coordinate transformation constants \\
\hline$B_{1}, B_{2}$ & Turbulence constants \\
\hline$C_{1}$ & Turbulence constants \\
\hline$E_{1}, E_{2}$ & Turbulence constants \\
\hline$f$ & Coriolis parameter, $\mathrm{s}^{-1}$ \\
\hline$G$ & Stability function \\
\hline$g$ & Gravitational acceleration, $\mathrm{ms}^{-2}$ \\
\hline$K$ & Diffusion coefficient, $\mathrm{m}^{2} \mathrm{~s}^{-1}$ \\
\hline$k$ & Von Karman's constant \\
\hline$L$ & Monin-Obukhov length, $m$ \\
\hline$l$ & Mixing length, $\mathrm{m}$ \\
\hline$N$ & Total number of layers \\
\hline$P$ & Generic variable in matrix equation \\
\hline$P_{\text {}}$ & Production of TKE by buoyancy, $\mathrm{m}^{2} \mathrm{~s}^{-3}$ \\
\hline$P_{s}$ & Production of TKE by shear, $\mathrm{m}^{2} \mathrm{~s}^{-3}$ \\
\hline$p$ & Pressure, $\mathrm{Nm}^{-2}$ \\
\hline$Q$ & Generic variable in matrix equation \\
\hline$\dot{Q}_{D}$ & Dynamic heating rate, $\mathrm{K}_{\text {day }}{ }^{-1}$ \\
\hline$\dot{Q}_{R}$ & Radiative heating rate, $\mathrm{K}_{\text {day }}{ }^{-1}$ \\
\hline$q^{2} / 2$ & Turbulent kinitic energy, $\mathrm{m}^{2} \mathrm{~s}^{-2}$ \\
\hline$R$ & Generic variable in matrix equation \\
\hline$R i$ & Richardson number \\
\hline$R i_{c}$ & Critical Richardson number \\
\hline$S$ & Stability function \\
\hline$t$ & Time, $\mathrm{s}$ \\
\hline$t_{0}$ & Initial time, $\mathbf{s}$ \\
\hline
\end{tabular}




\begin{tabular}{|c|c|}
\hline$U$ & Zonal mean wind, $\mathrm{ms}^{-1}$ \\
\hline$u$ & Turbulent perturbation of zonal wind, $\mathrm{m} \mathrm{s}^{-1}$ \\
\hline$u_{*}$ & Friction velocity, $\mathrm{m} \mathrm{s}^{-1}$ \\
\hline$V$ & Meridional mean wind, $\mathrm{ms}^{-1}$ \\
\hline $\boldsymbol{v}$ & Turbulent perturbation of meridional wind, $\mathrm{m} \mathrm{s}^{-1}$ \\
\hline$w$ & Turbulent perturbation of vertical wind, $\mathrm{ms}^{-1}$ \\
\hline$z$ & Height, $\mathrm{m}$ \\
\hline$z_{0}$ & Surface roughness height, $m$ \\
\hline$\alpha_{m}, \alpha_{h}$ & Monin-Obukhov constant \\
\hline$\beta$ & Coefficient of thermal expansion, $\mathbf{K}^{-1}$ \\
\hline$\beta_{m}, \beta_{h}$ & Monin-Obukhov constant \\
\hline$\delta$ & Solar declination, degrees \\
\hline$\Delta t$ & Timestep, s \\
\hline$\Delta \xi$ & Layer thickness, $\mathrm{m}$ \\
\hline$\epsilon$ & TKE dissipation, $\mathrm{m}^{2} \mathrm{~s}^{-3}$ \\
\hline$\theta$ & Mean potential temperature, $\mathrm{K}$ \\
\hline$\theta$ & Turbulent perturbation potential temperature, $\mathrm{K}$ \\
\hline$\theta_{*}$ & Friction potential temperature, $\mathrm{K}$ \\
\hline$\mu$ & Crank-Nicholson weighting factor \\
\hline$\nu_{m}$ & Vertical metric, $\mathrm{m}$ \\
\hline$\xi$ & Transformed vertical coordinate \\
\hline$\rho$ & Atmospheric density, $\mathrm{kg} \mathrm{m}^{-3}$ \\
\hline$\Phi$ & Generic scaled prognostic variable \\
\hline$\phi$ & Latitude, degrees \\
\hline$\psi_{m}, \psi_{h}$ & Monin-Obukhov stability parameter \\
\hline$O_{a}$ & Value at grid point nearest surface \\
\hline $0_{0}$ & Geostrophic value \\
\hline $\mathrm{O}_{H}$ & Value for heat \\
\hline()$_{k}$ & Vertical grid index \\
\hline$O_{l}$ & Value for mixing length \\
\hline
\end{tabular}


$0_{M}$

()

().

$0^{n}$

$0^{\prime}$

$\overline{0}$

Ice model

$b_{1}-b_{5}$

$C_{H}$

$c_{p}$

$c_{i, \varepsilon, w}$

d

$e_{8}$

F

$F_{B}$

$F_{I s, I i}$

$F_{M}$

$F_{\text {eca }}$

$F_{T}$

$H_{s}(i)$

$H_{\text {. }}(6)$

$h_{i, s}$

$K_{\text {is }}$

$k_{i, n, w}$

L

$L_{f}$

L。

$L_{v}$

po
Value for momentum

Value for TKE

Value at surface

timestep index

Scaled variable

Time averaged quantity

Difference equation coefficients

Bulk drag coefficient for heat, $\mathrm{m} \mathrm{s}^{-1}$

Speciñc heat of dry air at constant pressure, $\mathrm{J} \mathrm{K}^{-1} \mathrm{~kg}^{-1}$

Specific heat of ice, snow, or water, respectively, $\mathrm{J} \mathrm{K}^{-1} \mathrm{~kg}^{-1}$

Oceanic mixed layer depth, $m$

Saturation vapor pressure, $\mathrm{Nm}^{-2}$

Below-surface heat flux component, $\mathrm{W} \mathrm{m}^{-2}$

Ice bottom heat flux, $\mathrm{W} \mathrm{m}^{-2}$

Conductive heat fluxes at snow-ice interface, $\mathrm{W} \mathrm{m}^{-2}$

Oceanic mixed layer heat flux, $\mathrm{W} \mathrm{m}^{-2}$

Large-scale oceanic heat flux, $\mathrm{W} \mathrm{m}^{-2}$

Conductive flux to the surface from Neeman et al. (1988), $\mathrm{W} \mathrm{m}^{-2}$

Atmospheric heat fluxes from Neeman et al. (1988), $\mathrm{W} \mathrm{m}^{-2}$

Large-scale oceanic heat flux from Neemam et al. (1988), $\mathrm{W} \mathrm{m}^{-2}$

Depth of ice or snow, respectively, $m$

Bulk snow/ice conductivity, $\mathrm{Wm}^{-2} \mathrm{~K}^{-1}$

Conductivity for ice, snow, or water, respectively, $\mathrm{W} \mathrm{m}^{-1} \mathrm{~K}^{-1}$

Temperature weighted latent heat, $\mathrm{Jkg}^{-1}$

Latent heat of fusion, $\mathrm{Jkg}^{-1}$

Latent heat of sublimation, $\mathrm{Jkg}^{-1}$

Latent heat of vaporization, $\mathrm{Jkg}^{-1}$

Surface pressure, $\mathrm{Nm}^{-2}$ 


\begin{tabular}{|c|c|}
\hline 8 & Surface heat flux component, $\mathrm{W} \mathrm{m}^{-2}$ \\
\hline$Q c$ & Conductive fux to the surface, $\mathrm{W} \mathrm{m}^{-2}$ \\
\hline$Q_{H}$ & Sensible heat flux, $\mathrm{W} \mathrm{m}^{-2}$ \\
\hline$Q_{I}$ & Net surface IR flux, $\mathrm{W} \mathrm{m}^{-2}$ \\
\hline$Q_{I}^{\downarrow}$ & Downward surface IR flux, $\mathrm{W} \mathrm{m}^{-2}$ \\
\hline$Q_{I}^{\dagger}$ & upward surface IR flux, $\mathrm{W} \mathrm{m}^{-2}$ \\
\hline$Q L$ & Latent heat flux, $W \mathrm{~m}^{-2}$ \\
\hline$Q_{M}$ & Snow melt hest flux, $\mathrm{W} \mathrm{m}^{-2}$ \\
\hline$Q_{R}$ & Net radiative flux, $W \mathrm{~m}^{-2}$ \\
\hline $8 s$ & Net surface solar flux, $\mathrm{W} \mathrm{m}^{-2}$ \\
\hline$q$ & Specific humidity, $\mathrm{g} \mathrm{kg}^{-1}$ \\
\hline$q_{*}$ & PBL friction moisture, $\mathrm{g} \mathrm{kg}^{-1}$ \\
\hline$R_{v}$ & Water vapor gas constant, $\mathrm{J} \mathrm{K}^{-1} \mathrm{~kg}^{-1}$ \\
\hline$r_{i s}$ & Coefficient of integration, $\mathrm{Jm}^{-2} \mathrm{~K}^{-1}$ \\
\hline$T$ & Temperature, $\mathrm{K}$ \\
\hline$T_{0}$ & Oceanic mixed layer temperature, $\mathrm{K}$ \\
\hline$T_{T}$ & Surface temperature of Neeman et al. (1988), K \\
\hline $\boldsymbol{t}$ & Time, 8 \\
\hline$u_{*}$ & PBL friction velocity, $\mathrm{ms}^{-1}$ \\
\hline$z$ & Depth, $m$ \\
\hline$\epsilon_{0}$ & Surface infrared emissivity \\
\hline$\varepsilon$ & Ratio of molecular weights \\
\hline$\theta_{*}$ & PBL friction temperature, $K$ \\
\hline$\mu$, & Surface Crank-Nicholson weighting factor \\
\hline$\rho_{i, e, w}$ & Density of ice, snow, or water, respectively, $\mathrm{kg} \mathrm{m}^{-3}$ \\
\hline$\sigma$ & Stefan-Boltzmann constant, $\mathrm{Wm}^{-2} \mathrm{~K}^{-1}$ \\
\hline()$_{a}$ & Value at gridpoint nearest surface \\
\hline (). & Value at surface \\
\hline
\end{tabular}




\section{Radiation and Mie scattering models}

\begin{tabular}{|c|c|}
\hline$A_{p}$ & Planetary albedo \\
\hline$A_{0}$ & Surface albedo \\
\hline$a$ & absorption cross section, $\mathrm{m}^{2} \mathrm{~g}^{-1}$ \\
\hline $\mathrm{Cg}$ & Graphitic carbon \\
\hline$c_{p}$ & Specific heat of dry air at constant pressure, $\mathrm{J} \mathrm{K}^{-1} \mathrm{~kg}^{-1}$ \\
\hline$g$ & Aerosol assymetry factor \\
\hline$I$ & Infrared flux, $\mathrm{W} \mathrm{m}^{-2}$ \\
\hline$k$ & Layer index \\
\hline$m$ & Mass concentration, $\mathrm{ng} \mathrm{m}^{-3}$ \\
\hline$N$ & Normalized number of particles \\
\hline$n$ & Aerosol complex index of refraction \\
\hline$n_{i}$ & Imaginary part of $n$ \\
\hline$p$ & Atmospheric pressure, $\mathrm{Nm}^{-2}$ \\
\hline$Q D$ & Estimated large-scale meridional heat flux, $\mathrm{W} \mathrm{m}^{-2}$ \\
\hline$R$ & Net solar + net IR radiative flux, $\mathrm{W} \mathrm{m}^{-2}$ \\
\hline$R_{V}$ & Aerosol volume ratio of core to shell \\
\hline$r$ & Aerosol radius, $\mu \mathrm{m}$ \\
\hline$r_{c}$ & Aerosol core radius, $\mu \mathrm{m}$ \\
\hline$r_{\text {on }}$ & Aerosol number mean geometric radius, $\mu \mathrm{m}$ \\
\hline$r_{g v}$ & Aerosol volume mean geometric radius, $\mu \mathrm{m}$ \\
\hline$S$ & Solar flux, $\mathrm{W} \mathrm{m}^{-2}$ \\
\hline$z$ & Height, $\mathrm{m}$ \\
\hline$z_{\max }$ & Height at $\left(\sigma_{e}\right)_{\max }, \mathrm{m}$ \\
\hline$\lambda$ & Wavelength, $\mu \mathrm{m}$ \\
\hline$\lambda_{r}$ & Reference wavelength, $\mu \mathrm{m}$ \\
\hline$\varpi_{0}$ & Aerosol single scattering albedo \\
\hline$\sigma$ & Aerosol optical coefficient \\
\hline$\sigma_{g}$ & Size distribution standard deviation \\
\hline$\sigma_{z}$ & Height distribution standard deviation \\
\hline
\end{tabular}




$\begin{array}{ll}\tau & \text { Aerosol optical depth } \\ ()_{a} & \text { Value for absorption } \\ ()_{e} & \text { Value for extinction } \\ ()_{o} & \text { Value for scattering } \\ ()_{s f c} & \text { Flux at surface } \\ ()_{t o p} & \text { Flux at top of model } \\ ()^{N} & \text { Net radiative flux } \\ ()^{\dagger} & \text { Upward radiative flux } \\ ()^{\downarrow} & \text { Downward radiative flux }\end{array}$




\section{Appendix B: PBL Finite Difference Equations}

Equation (1-11) in Section 4.1 is solved generally by specifying the appropriate coefficients $P, Q$, and $R$ given in the table following (1-11). The discrete differencing method employs a fully implicit scheme, which requires solving a set of tri-diagonal matrix equations. Time and spatial derivatives are approximated by

$$
\begin{aligned}
& \frac{\partial()}{\partial t}=\frac{()_{k}^{n+1}-()_{k}^{n}}{\Delta t} \\
& \frac{\partial()}{\partial \xi}=\frac{()_{k+1}^{n+1 / 2}-()_{k-1}^{n+1 / 2}}{\Delta \xi_{k}}
\end{aligned}
$$

where

$$
()^{n+1 / 2}=\mu()^{n+1}+(1-\mu)()^{n}
$$

Here, $k$ represents the vertical level index and varies from 1 to $2 N+1$, where $N$ is the total number of layers. Therefore, odd values of $k$ represent layer interfaces (i.e. the levels where vertical gradients, diffusivities, TKE, and mixing length are calculated), and even values of $k$ represent layer midpoints (i.e. the levels carrying the prognostic hydrodynamic variables $U, V$, and $\Theta$ ). The time step index is represented by $n, \Delta t$ is the time step (constant), $\Delta \xi_{k}$ is the layer thickness, and $\mu$ is the Crank-Nicholson weighting factor. Our study employs $\mu=1$, a fully implicit scheme, while $\delta=0$ is a fully explicit, conditionally stable scheme, and $\mu=1 / 2$ is the semi-implicit Crank-Nicholson scheme.

Equation (1-11) now becomes

$$
\begin{aligned}
\frac{\Phi_{k}^{n+1}-\Phi_{k}^{n}}{\Delta t}= & \left\{\rho_{k+1}^{\prime} P_{k+1}\left[\left(\frac{\Phi_{k+2}^{n+1 / 2}}{\rho_{k+2}^{\prime}}\right)-\left(\frac{\Phi_{k}^{n+1 / 2}}{\rho_{k}^{\prime}}\right)\right] \frac{1}{\Delta \xi_{k+1}}\right. \\
& \left.-\rho_{k-1}^{\prime} P_{k-1}\left[\left(\frac{\Phi_{k}^{n+1 / 2}}{\rho_{k}^{\prime}}\right)-\left(\frac{\Phi_{k-2}^{n+1 / 2}}{\rho_{k-2}^{\prime}}\right)\right] \frac{1}{\Delta \xi_{k-1}}\right\} \frac{1}{\Delta \xi_{k}} \\
& +Q_{k} \Phi_{k}^{n+1 / 2}+R_{k} .
\end{aligned}
$$

After evaluating terms with ()$^{n+1 / 2}$ using (B-3), the finite difference equation can be rearranged into the form

$$
A_{k} \Phi_{k-2}^{n+1}+B_{k} \Phi_{k}^{n+1}+C_{k} \Phi_{k+2}^{n+1}=D_{k}
$$


where, after extensive manipulation,

$$
\begin{aligned}
A_{k}= & -\mu \Delta t\left(\frac{\rho_{k-1}^{\prime}}{\rho_{k-2}^{\prime}}\right) P_{k-1}\left(\Delta \xi_{k} \Delta \xi_{k-1}\right)^{-1} \\
C_{k}= & -\mu \Delta t\left(\frac{\rho_{k+1}^{\prime}}{\rho_{k+2}^{\prime}}\right) P_{k+1}\left(\Delta \xi_{k} \Delta \xi_{k+1}\right)^{-1} \\
B_{k}= & 1-\left(\frac{\rho_{k-2}^{\prime}}{\rho_{k}^{\prime}}\right) A_{k}-\left(\frac{\rho_{k+2}^{\prime}}{\rho_{k}^{\prime}}\right) C_{k}-\mu Q_{k} \Delta t \\
D_{k}= & -\frac{(1-\mu)}{\mu} A_{k} \Phi_{k-2}^{n}+\left[1+\frac{(1-\mu)}{\mu}\left(1-B_{k}\right)\right] \Phi_{k}^{n} \\
& -\frac{(1-\mu)}{\mu} C_{k} \Phi_{k+2}^{n}+R_{k} \Delta t .
\end{aligned}
$$

Equations (B-6)-(B-9) hold within the range $4 \leq k \leq 2 N$ for $U, V$, and $\theta$, and within the range $3 \leq k \leq 2 N-1$ for $q^{2}$ and $q^{2} l$. At the boundaries, the coefficients $A_{k}-D_{k}$ take on slightly different forms, depending on the flux boundary conditions incorporated and whether the coefficients represent terms from the hydrodynamic or turbulence equations.

At the model top, all fluxes are zero. This allows some terms in (B-4) to vanish. Upon arranging terms in the form of (B-5) we find that for the hydrodynamic equations $(k=2)$

$$
\begin{aligned}
& A_{2}=0 \\
& C_{2}=-\mu \Delta t\left(\frac{\rho_{3}^{\prime}}{\rho_{4}^{\prime}}\right) P_{3}\left(\Delta \xi_{2} \Delta \xi_{3}\right)^{-1} \\
& B_{2}=1-\left(\frac{\rho_{4}^{\prime}}{\rho_{2}^{\prime}}\right) C_{2}-\mu Q_{2} \Delta t \\
& D_{2}=\left[1+\frac{(1-\mu)}{\mu}\left(1-B_{2}\right)\right] \Phi_{2}^{n}-\frac{(1-\mu)}{\mu} C_{2} \Phi_{4}^{n}+R_{2} \Delta t .
\end{aligned}
$$

and for the turbulence equations $(k=1)$

$$
\begin{aligned}
& A_{1}=0 \\
& C_{1}=-\mu \Delta t\left(\frac{\rho_{2}^{\prime}}{\rho_{3}^{\prime}}\right) P_{2}\left(\Delta \xi_{1} \Delta \xi_{2}\right)^{-1}
\end{aligned}
$$




$$
\begin{aligned}
& B_{1}=1-\left(\frac{\rho_{3}^{\prime}}{\rho_{1}^{\prime}}\right) C_{1}-\mu Q_{1} \Delta t \\
& D_{1}=\left[1+\frac{(1-\mu)}{\mu}\left(1-B_{1}\right)\right] \Phi_{1}^{n}-\frac{(1-\mu)}{\mu} C_{1} \Phi_{3}^{n}+R_{1} \Delta t .
\end{aligned}
$$

At $k=2 N$, we must consider the fluxes into or out of the surface for the equations that govern velocity and temperature. First, the boundary conditions given by (1-6)-(1-8) in Section 4.1 can be written in a scaled general form:

$$
\left(F_{2 N+1}\right)_{\Phi}=-\frac{u_{*}}{\left(\nu_{m}\right)_{2 N}}\left(\frac{k}{\ln _{\Phi}}\right)\left(\Phi_{2 N}-\Phi_{s}\right)
$$

where

$$
\ln \Phi= \begin{cases}\ln \frac{z_{2 N}}{z_{0}}-\psi_{m}, & \text { for } \Phi=U^{\prime} \text { or } V^{\prime} \\ \ln \frac{z_{2 N}}{z_{0}}-\psi_{h}, & \text { for } \Phi=\theta^{\prime}\end{cases}
$$

Now Eq. (1-11) is rewritten as

$$
\begin{aligned}
\frac{\Phi_{2 N}^{n+1}-\Phi_{2 N}^{n}}{\Delta t}= & -\frac{F_{2 N+1}-F_{2 N-1}}{\Delta \xi_{2 N}} \\
= & -\frac{1}{\Delta \xi_{2 N}}\left\{\left[-\frac{u_{*}}{\left(\nu_{m}\right)_{2 N}}\left(\frac{k}{\ln _{\Phi}}\right)\left(\Phi_{2 N}^{n+1 / 2}-\Phi_{s}\right)\right]\right. \\
& \left.+\frac{\rho_{2 N-1}^{\prime} P_{2 N-1}}{\Delta \xi_{2 N-1}}\left[\left(\frac{\Phi_{2 N}^{n+1 / 2}}{\rho_{2 N}^{\prime}}\right)-\left(\frac{\Phi_{2 N-2}^{n+1 / 2}}{\rho_{2 N-2}^{\prime}}\right)\right]\right\} \\
& +Q_{2 N} \Phi_{2 N}^{n+1 / 2}+R_{2 N} .
\end{aligned}
$$

Finally, expanding the equation again via (B-3) and rearranging into the form of (B-5) we find that

$$
\begin{aligned}
& A_{2 N}=-\mu \Delta t\left(\frac{\rho_{2 N-1}^{\prime}}{\rho_{2 N-2}^{\prime}}\right) P_{2 N-1}\left(\Delta \xi_{2 N} \Delta \xi_{2 N-1}\right)^{-1} \\
& C_{2 N}=0 \\
& B_{2 N}=1-\left(\frac{\rho_{2 N-2}^{\prime}}{\rho_{2 N}^{\prime}}\right) A_{2 N}-\frac{u_{*}}{\left(\nu_{m}\right)_{2 N}}\left(\frac{k}{\ln _{\Phi}}\right)\left(\frac{\mu \Delta t}{\Delta \xi_{2 N}}\right)-\mu Q_{2 N} \Delta t
\end{aligned}
$$




$$
\begin{aligned}
D_{2 N}= & -\frac{(1-\mu)}{\mu} A_{2 N} \Phi_{2 N-2}^{n}+\left[1+\frac{(1-\mu)}{\mu}\left(1-B_{2 N}\right)\right] \Phi_{2 N}^{n} \\
& -\frac{u_{*}}{\left(\nu_{m}\right)_{2 N}}\left(\frac{k}{\ln \Phi}\right)\left(\frac{\Delta t}{\Delta \xi_{2 N}}\right) \Phi_{s}+R_{2 N} \Delta t .
\end{aligned}
$$

The boundary conditions for the TKE and mixing length equations are given by Eqs. (1-9) and (1-10) in Section 4.1. Accordingly, the coefficients at $k=2 N+1$ for the TKE equation are

$$
\begin{aligned}
& A_{2 N+1}=0 \\
& B_{2 N+1}=1 \\
& C_{2 N+1}=0 \\
& D_{2 N+1}=\rho_{2 N+1}^{\prime} B^{2 / 3} u_{*}^{2},
\end{aligned}
$$

and for the mixing length equation are

$$
\begin{aligned}
& A_{2 N+1}=0 \\
& B_{2 N+1}=1 \\
& C_{2 N+1}=0 \\
& D_{2 N+1}=0 .
\end{aligned}
$$




\section{Appendix C: The VIF and Surface Heat Balance}

The basic form of the surface heat balance is given in Section 4.2 as Eq. (2-1), while the oceanic mixed layer temperature tendency is given in Eq. (2-3). These equations are transformed into two independent linear finite differenced equations for $T_{s}^{n+1}$ and $T_{o}^{n+1}$, respectively. Using their algebraic solutions, the change in ice and snow thicknesses are found by discretizing Eq. (2-2) and (2-4).

By expanding all flux terms of Eq. (2-1) into their equivalent expressions, we obtain

$$
\begin{aligned}
Q_{M}= & Q_{s}+Q_{I}^{\downarrow}-\epsilon_{s} \sigma T_{s}^{4} \\
& +\rho_{2 N} c_{p} C_{H}\left(\Theta_{2 N}-T_{s}\right)+\rho_{2 N} L C_{H}\left(q_{2 N}-q_{s}\right) \\
& -K_{i s}\left(T_{s}-T_{B}\right)-\frac{r_{i s}}{2} \frac{\partial T_{s}}{\partial t}
\end{aligned}
$$

where $\sigma$ is the Stefan-Boltzman constant, $T_{b}=\theta_{0}$ since $p_{s}=1000 \mathrm{mb}, Q_{M}=0$ if $T_{s}<273$ $K$, and where

$$
C_{H}=\frac{u_{n} k}{\ln \frac{z_{2 N}}{z_{0}}-\psi_{h}}
$$

We solve Eq. (C-1) similarly to the PBL equations using a semi-implicit finite difference technique. To begin, the surface longwave emission, sensible heat and latent heat terms must be linearized as they depend on $T_{s}$ nonlinearly. We can linearize them via a Taylor series expansion by letting

$$
\begin{aligned}
\left(T_{a}^{n+1}\right)^{4} & =\left(T_{\bullet}^{n}\right)^{4}+4\left(T_{s}^{n}\right)^{3}\left(T_{s}^{n+1}-T_{s}^{n}\right) \\
q_{s}^{n+1} & =q_{a}^{n}+\left(\frac{\partial q_{b}}{\partial T}\right)_{T_{b}^{n}}\left(T_{\bullet}^{n+1}-T_{\bullet}^{n}\right) .
\end{aligned}
$$

These terms are now treated implicitly in time, while $\partial q_{s} / \partial T$ is determined from the Clausius-Clapeyron equation. Also, $T_{0}^{n} \Rightarrow T_{a}^{n+1 / 2}$ in the sensible heat and conductive flux terms, so a Crank-Nicholson weighting factor $\mu_{s}$ for the surface equations must be introduced. Substituting these into Eq. (C-1) and rearranging, we obtain 


$$
\begin{aligned}
T_{s}^{n+1}= & T_{s}^{n}\left\{\frac{1+b_{1}\left[3 b_{2}-\left(1-\mu_{s}\right) b_{3} c_{p}+b_{3} L\left(\frac{\partial q_{e}}{\partial T}\right)_{T_{s}^{n}}-\left(1-\mu_{s}\right) K_{i s}\right]}{1+b_{1}\left[4 b_{2}+\mu_{s} b_{3} c_{p}+b_{3} L\left(\frac{\partial q_{e}}{\partial T}\right)_{T_{s}^{n}}+\mu_{s} K_{i s}\right]}\right\} \\
& +\left\{\frac{b_{1}\left[b_{3} c_{p} \theta_{2 N}^{n}+b_{3} L\left(q_{2 N}^{n}-q_{s}^{n}\right)+Q_{S}+Q_{I}^{\downarrow}+K_{i s} T_{B}-Q_{M}\right]}{1+b_{1}\left[4 b_{2}+\mu_{s} b_{3} c_{p}+b_{3} L\left(\frac{\partial q_{s}}{\partial T}\right)_{T_{s}^{n}}+\mu_{s} K_{i s}\right]}\right\},
\end{aligned}
$$

where

$$
\begin{aligned}
\left(\frac{\partial q_{s}}{\partial T}\right)_{T^{n}} & =\frac{e_{s} \varepsilon L}{p_{s} R_{v}\left(T_{s}^{n}\right)^{2}} \\
b_{1} & =\frac{2 \Delta t}{r_{i s}} \\
b_{2} & =\epsilon_{s} \sigma\left(T_{s}^{n}\right)^{3} \\
b_{3} & =\rho_{2 N} C_{H} .
\end{aligned}
$$

By combining the disgnostic equation for the oceanic mixed layer heat flux $F_{M}$ with the tendency equation for $T_{O}$ (Eq. 2-3), we may now calculate $T_{O}$ at the new timestep:

$$
T_{o}^{n+1}=\frac{T_{O}^{n}\left[1-b_{4} b_{5}\left(1-\mu_{s}\right)\right]+b_{5}\left(b_{4} T_{B}+F_{s e a}\right)}{1+b_{4} b_{5} \mu \mathrm{m}_{s}}
$$

where $b_{4}=2 k_{w} / d$ and $b_{5}=\Delta t / \rho_{w} c_{w} d$.

From new calculations of $T_{s}^{n+1}$, we may obtain $h_{i}^{n+1}$ from Eq. (2-4):

$$
h_{i}^{n+1}=h_{i}^{n}+b_{6}\left[b_{5}\left(T_{B}-T_{O}\right)-K_{i o}\left(T_{s}^{n+1}-T_{B}\right)+b_{1}^{-1}\left(T_{a}^{n+1}-T_{s}^{n}\right)\right],
$$

where $b_{6}=\Delta t / \rho_{i} L_{f}$. To compute any change in snow depth, the surface heat balance is updated via Eq. (C-1) to obtain $Q_{M}$, and then the finite differenced form of Eq. (2-2) is used:

$$
h_{s}^{n+1}=h_{g}^{n}+\frac{\Delta t}{\rho_{g}}\left(-\frac{Q_{M}}{L_{f}}-\frac{Q_{L}}{L}\right)
$$

